\title{
ROLE OF A NOVEL FIMBRIAL ADHESIN IN ACID-INDUCED HOST ADHESION OF ESCHERICHIA COLI O157:H7
}

by

\author{
Frances B. Chingcuanco \\ Bachelors of Science Biology \\ University of Maryland Baltimore County, MD, USA 2007
}

A thesis presented to Ryerson University

in partial fulfillment of the requirements for the degree of

Master of Science in the Program of

Molecular Science

Toronto, Ontario, Canada, 2009

(C) Frances B. Chingcuanco 2009 


\section{Author's Declaration}

I hereby declare that I am the sole author of this thesis.

I authorize Ryerson University to lend this thesis to other institutions or individuals for the purpose of scholarly research.

I further authorize Ryerson University to reproduce this thesis by photocopying or by other means, in total or in part, at the request of other institutions or individuals for the purpose of scholarly research. 


\section{Abstract \\ Role of a Novel Fimbrial Adhesin in Acid-Induced Host Adhesion of Escherichia coli 0157:H7}

Frances B. Chingcuanco, Ryerson University, 2009, Master of Science in Molecular Science

Enterohemorrhagic Escherichia coli (EHEC) O157:H7 must be able to survive the acid stress of gastric passage. Previous studies show that adhesion of EHEC O157:H7 to human epithelial cells is increased if EHEC was pre-exposed to acid. Whole genome array analysis of EHEC reveals that the putative fimbrial gene $y a d K$ is significantly upregulated after EHEC exposure to acid treatments. In this study, a YadK deficient mutant $(\Delta y a d K)$ in EHEC O157:H7 wild-type (WT) strain 85-170 was constructed and phenotyped. The results of this study demonstrate that $\Delta y a d K$ exposed to acid stress showed no acid-induced increase in bacteria-host cell adhesion observed in similarly acid-induced wild type cells. This study concludes that YadK plays a role in acidinduced host adhesion of EHEC O157:H7. It also indicates that acid stress, which is a part of the host's natural assault to resist invasion, may regulate factors responsible for enhanced bacteriahost attachment, resulting in increased EHEC virulence. 


\section{Table of Contents}

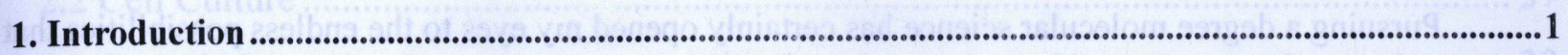

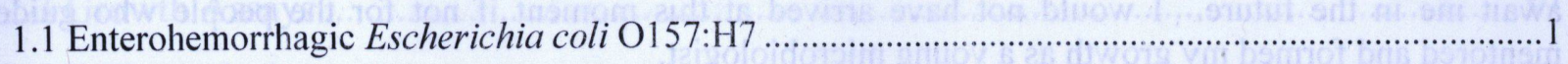

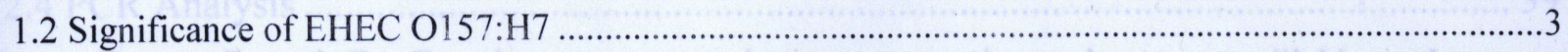

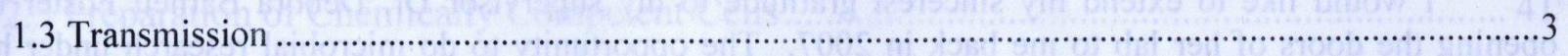

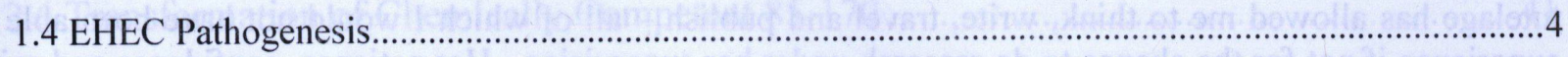

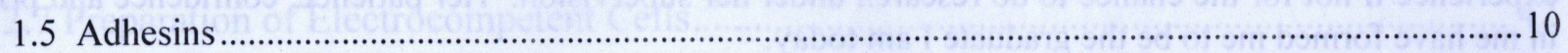

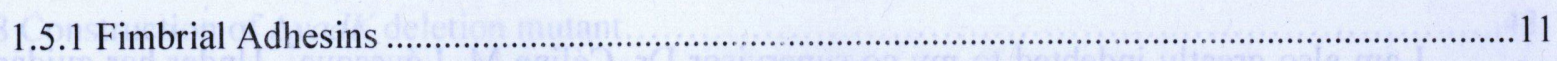

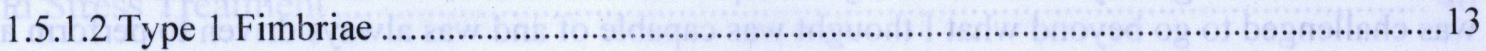

1.5.1.2 Curli

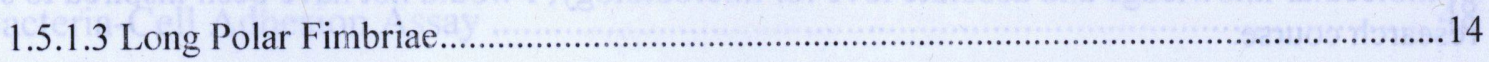

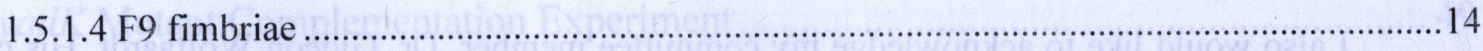

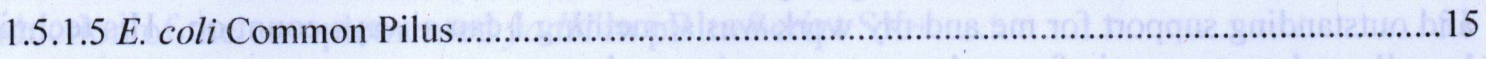

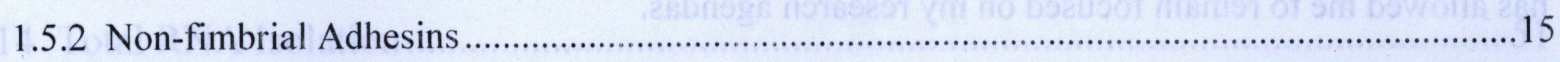

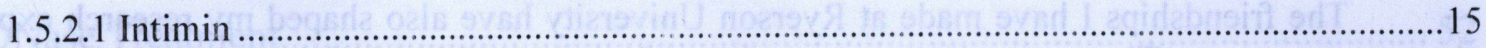

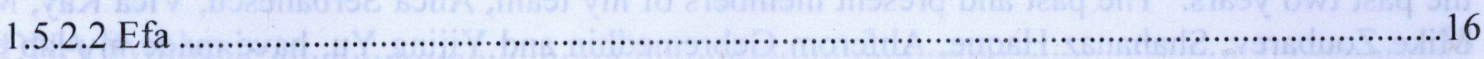

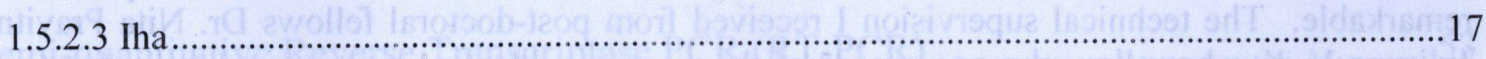

1.6 Regulation of Fimbrial Adhesin Genes ............................................................................................17

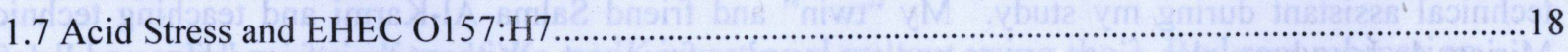

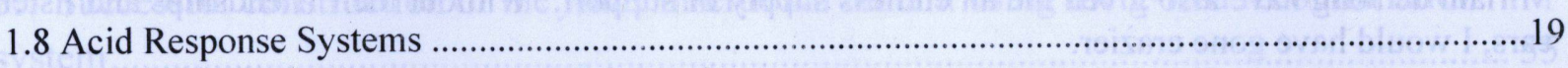

1.8.1 Oxidative Repressed Acid Resistance (AR1) …………......................................................... 19

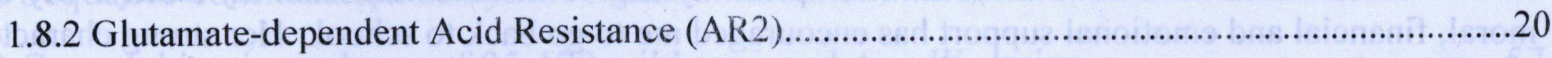

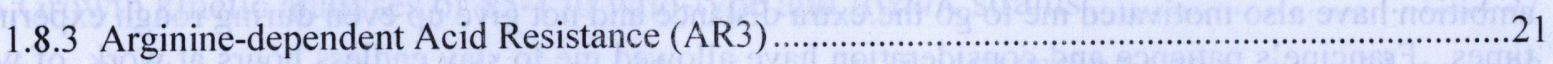

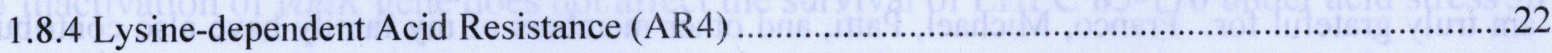

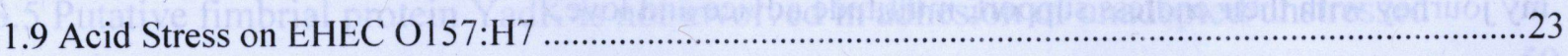

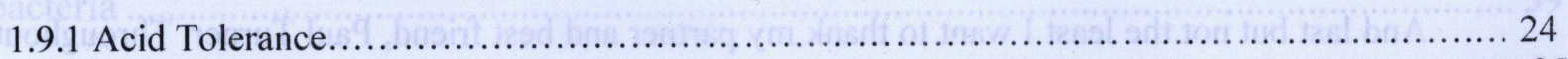

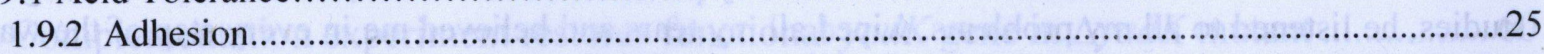

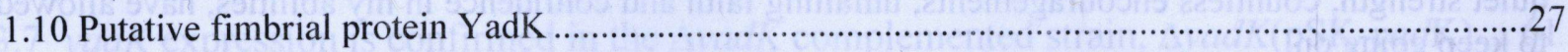

1.11 Chaperone-Usher Mediated Biochemical Synthesis of the locus 2 Operon...................................... 31

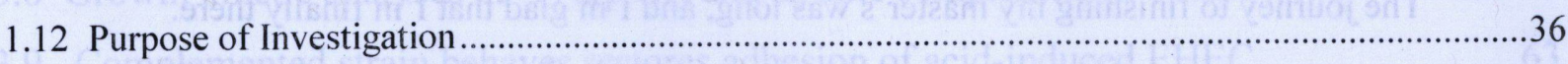

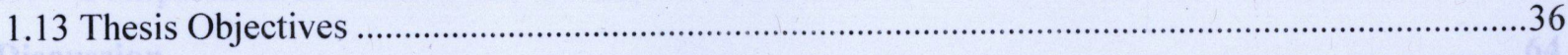

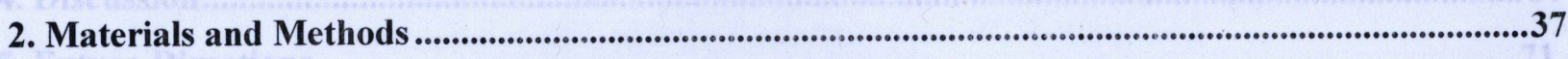

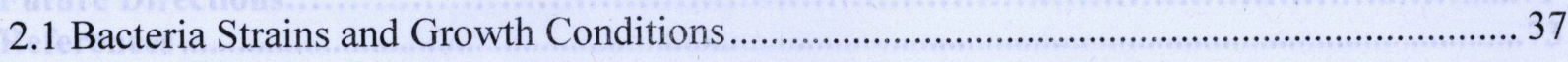




\section{Acknowledgement}

Pursuing a degree molecular science has certainly opened my eyes to the endless possibilities that await me in the future. I would not have arrived at this moment if not for the people who guided, mentored and formed my growth as a young microbiologist.

I would like to extend my sincerest gratitude to my supervisor Dr. Debora Barnett Foster for opening the doors of her lab to me back in 2007 . The opportunity to do microbial research under her tutelage has allowed me to think, write, travel and publish - all of which I would not have been able to experience if not for the chance to do research under her supervision. Her patience, confidence and pride in me have formed me to be the graduate I am today.

I am also greatly indebted to my co-supervisor Dr. Céline M. Lévesque. Under her guidance, I was challenged to go beyond what I thought was capable of and was always driven to perform at my best. Her mentorship and friendship have thoroughly shaped my views of research science. Without her wealth of molecular knowledge and absolute love for microbiology, I would not have been inspired to stay on the research course.

I also would like to acknowledge my committee member, Dr. Gideon Wolfaardt. His continuous and outstanding support for me and my work was something I can always count on. His technical advice has allowed me to remain focused on my research agendas.

The friendships I have made at Ryerson University have also shaped my research experience in the past two years. The past and present members of my team, Anca Serbanescu, Vica Kay, Mark Lino, Mike Zoubarev, Shahanaz Haque, Ahferom Gebremedhin and Yijing Yu, have made my lab experience remarkable. The technical supervision I received from post-doctoral fellows Dr. Nita Prayitno and Dr. Julianne V. Kus has allowed me to overcome the many roadblocks I encountered throughout my study. I also wish to extend my gratitude to the members of the Cvitkovitch, Lévesque and Wolfarrdt labs for their technical assistant during my study. My "twin" and friend Salma Al-Karmi and teaching technician Miriam de Jong have also given me an endless supply of support. Without their friendships and listening ears, I would have gone crazier.

I also would have not been able to complete my degree without help from my family. My mom's moral, financial and emotional support has encouraged me to go back to school. Her strong character and ambition have also motivated me to go the extra distance and not give up even during rough experimental times. Francine's patience and consideration have ailowed me to stay endless hours at work, of which I am truly grateful for. Franco, Michael, Patti, and other members of my family have also contributed to my journey with their endless support, multitude advice and love.

And last but not the least I want to thank my partner and best friend, Paul Turner. Throughout my studies, he listened to all my problems, wiped all my tears and believed me in every step of the way. His quiet strength, countless encouragements, unfailing faith and confidence in my abilities, have allowed me to keep going on.

The journey to finishing my master's was long, and I'm glad that I'm finally there. 


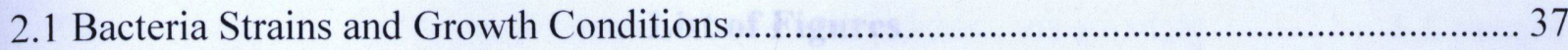

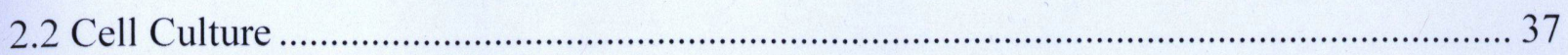

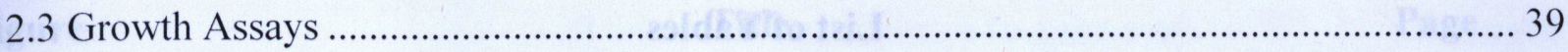

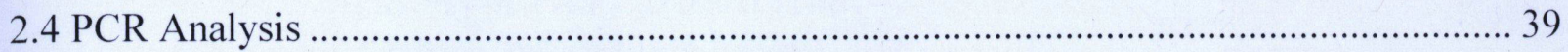

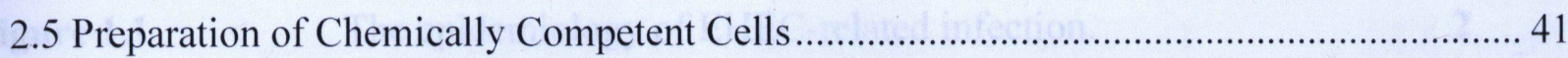

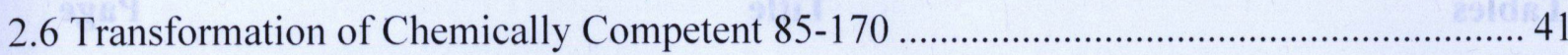

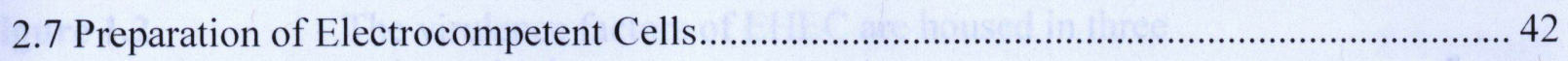

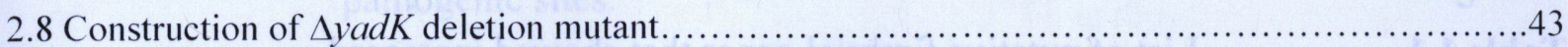

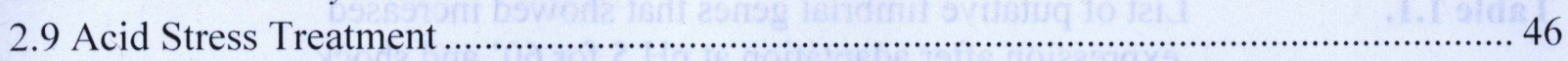

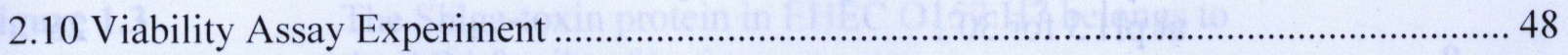

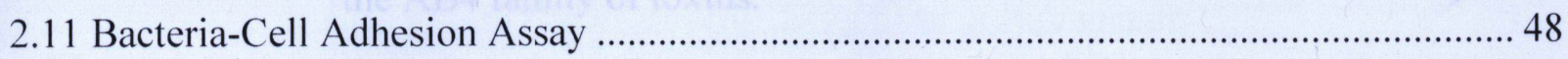

2.12 syadK Mutant Complementation Experiment …………………………........................ 49

2.13 Induction of the complemented $y a d K$ in pBlueScript SK $+\ldots \ldots \ldots \ldots \ldots \ldots \ldots \ldots \ldots \ldots \ldots \ldots \ldots \ldots \ldots \ldots . . .51$

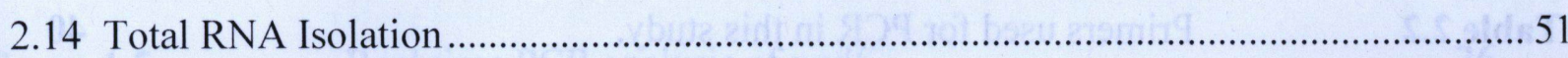

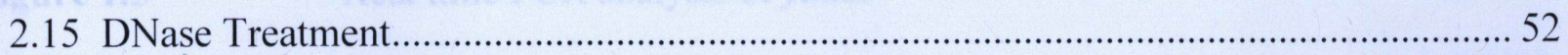

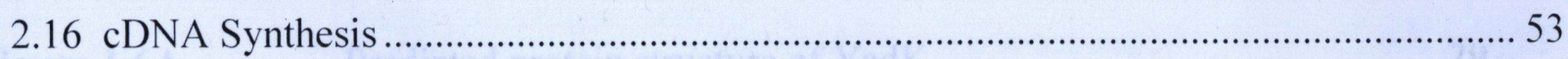

2.17 Semi-quantitative Reverse Transcriptase PCR (RT-PCR) .............................................. 53

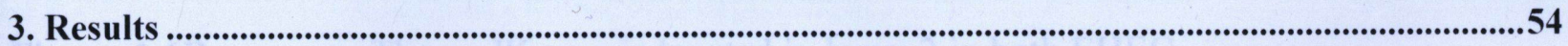

3.1 Successful construction of the $y a d K$ insertional mutant using the $\lambda$-Red recombination

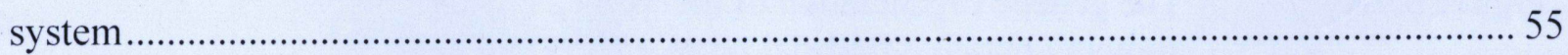

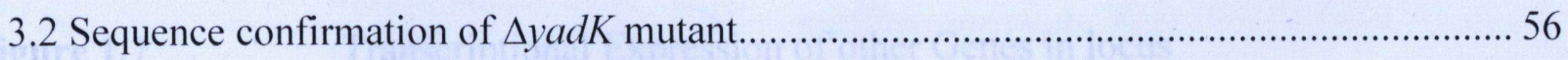

3.3 Growth kinetic analyses of 85-170 wild-type and $\Delta y a d K$ strains ....................................... 57

3.4 Inactivation of $y a d K$ gene does not affect the survival of EHEC 85-170 under acid stress 58

3.5 Putative fimbrial protein YadK is not involved in adhesion of unadapted/unstressed

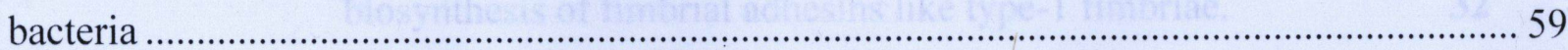

3.6 Complementation experiment restores functional $y a d K$ gene in $\Delta y a d K$ mutant ................ 60

$3.7 y a d K$ expression is confirmed in the $\Delta y a d K$ complemented strain, $\Delta y a d K(\mathrm{pSK}-y a d \mathrm{~K}) \ldots 61$

3.8 Growth kinetic analyses 85-170(pSK) and $\Delta y a d K$ complemented strains ..........................6. 62

3.9 Complemented strain behaves restores adhesion of acid-induced EHEC...........................63 63

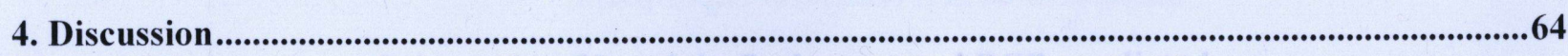

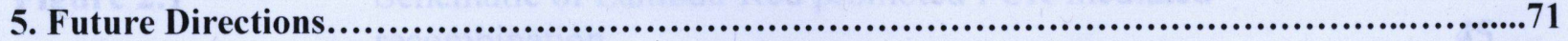

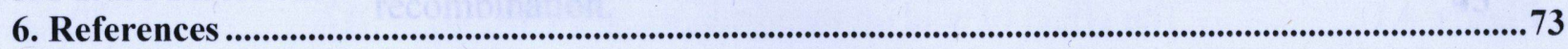




\section{List of Tables}

Tables

Title

Page

Table 1.1. List of putative fimbrial genes that showed increased expression after adaptation at $\mathrm{pH} 5$ for $60^{\prime}$ and shock at $\mathrm{pH} 3$ for 30 '.

Table 2.1

List of strains used in this study.

Table 2.2

Primers used for PCR in this study.

40 


\section{List of Figures}

Figure

Title

Page

Figure 1.1 The epidemiology of EHEC-related infection.

2

Figure 1.2 The virulence factors of EHEC are housed in three pathogenic sites.

Figure 1.3

The Shiga-toxin protein in EHEC O157:H7 belongs to the $\mathrm{AB} 4$ family of toxins.

Figure 1.4 Known fimbrial operons in E. coli O157:H7 str. Sakai.

Figure 1.5 Real time PCR analysis of yadK.

Figure 1.6A Predicted protein structure of YadK.

Figure 1.6B

The $y a d K$ gene is located in locus 2 in both EHEC O157:H7 strains EDL933 and Sakai.

Figure 1.7 Transcriptional Expression of other Genes in locus 2 after Acid Adaptation and Acid Stress.

Figure 1.8

The chaperone-usher mechanism illustrates the biosynthesis of fimbrial adhesins like type-1 fimbriae.

Figure 1.9

The genetic organization of $y a d K$ in locus 2 is similar to the genetic organization of other fimbrial loci that follow the chaperone-usher biosynthetic pathway.

Figure 2.1

Schematic of Lambda-Red promoted PCR-mediated recombination. 
Figure 2.2

Figure 3.1

Figure 3.2

Figure 3.3

Figure 3.4

Figure 3.5

Figure 3.6

Figure 3.7A

Figure 3.7B

Figure 3.8

Figure 3.9

Growth kinetics of EHEC 85-170 and $\triangle y a d K$ in LB broth at $37^{\circ} \mathrm{C}$.

The viability of 85-170 wild-type and its $\triangle y a d K$ mutant during unadapted, unstressed and during acid adapted, acid stressed conditions.

Adhesion was assessed and compared during a bacteria-host cell adhesion experiment.

Sequence alignment between the wild-type $y a d K$ gene in EDL933 strain and the $y a d K$ gene cloned into the pBlueScript SK+ inducible expression vector.

The genetic organization of the locus 2 cluster showing putative fimbrial protein encoding gene yadC downstream from yadK.

RT-PCR gene expression profiles of $y a d K$ and yadC genes.

Growth kinetics of EHEC 85-170(pSK), $\Delta y a d K(\mathrm{pSK})$ and $\Delta y a d K(\mathrm{pSK}-y a d K)$ in LB broth at $37^{\circ} \mathrm{C}$.

Adhesion was assessed and compared during a bacteria-host cell adhesion experiment.

Figure 4.1 The effect of acid on the virulence of EHEC O157:H7. 


\section{List of Abbreviations Used}

\begin{tabular}{|c|c|}
\hline AA & Acid adapted/acid stressed cells \\
\hline $\mathrm{A} / \mathrm{E}$ & Attaching and effacing lesions \\
\hline AR & Acid response \\
\hline ATCC & American Type Culture Collection \\
\hline ATR & Acid tolerance response \\
\hline $\mathrm{CaCo}-2$ & Colonic adenocarcinoma cells \\
\hline $\mathrm{Da}$ & Daltons \\
\hline DMEM & Dulbecco's MEM \\
\hline EDTA & Ethylenediaminetetraacetic acid \\
\hline Efa-1 & EHEC factor for adherence \\
\hline EHEC & Enterohemorrhagic Escherichia coli \\
\hline EPEC & Enteropathogenic Escherichia coli \\
\hline Esp & E. coli secreted protein \\
\hline FBS & Fetal bovine serum \\
\hline GABA & glutamate $/ \gamma$ aminobutyric acid \\
\hline Gb-3 & Glycolipid globotriaosylceramide- 3 recepto1 \\
\hline GI & Gastrointestinal tract \\
\hline $\mathrm{HC}$ & Hemorrhagic colitis \\
\hline HUS & Hemolytic-uremic syndrome \\
\hline Iha & IrgA homologue adhesin \\
\hline LB & Luria-Bertani \\
\hline LEE & Locus of enterocytes effacement LEE \\
\hline Ler & LEE-encoded regulator \\
\hline MEM & Minimal essential media \\
\hline ORF & Open reading frame \\
\hline PBS & Phosphate buffered saline \\
\hline pSK & pBlueScriptSK + plasmid \\
\hline RT - PCR & Real Time PCR \\
\hline STEC & Shiga toxin producing E. coli \\
\hline Stx & Shiga toxin \\
\hline Tir & Translocated intimin receptor \\
\hline TTP & Thrombocytopenic purpura \\
\hline TTSS & Type III secretion system \\
\hline UA & Unadapted/acid stressed cells \\
\hline UPEC & Uropathogenic Escherichia coli \\
\hline UU & Unadapted/unstressed cells \\
\hline & Verotoxin \\
\hline
\end{tabular}


ingerse 5

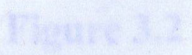

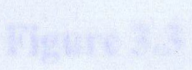

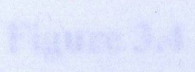

wixtire 3.5

Ficure 3.6

Higare 3,7 A

ingere $3.2 x$

Iriman $=0$

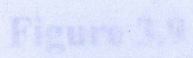

Bigure 4.15

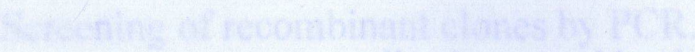

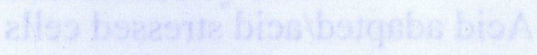

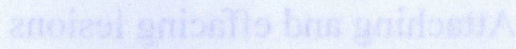

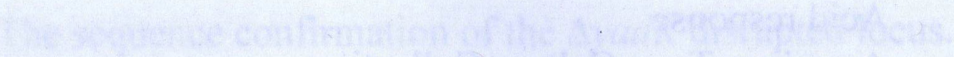

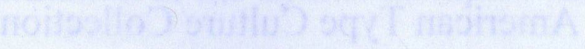

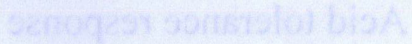

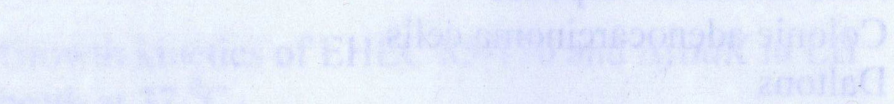

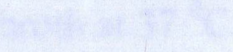

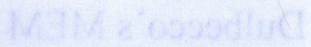

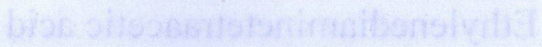

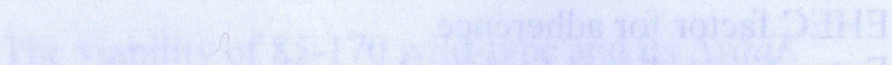

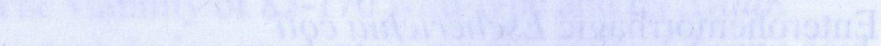

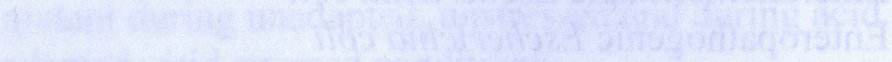

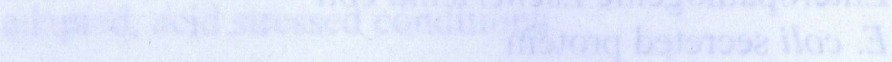

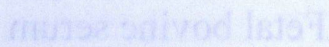

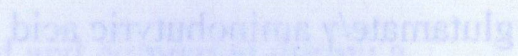

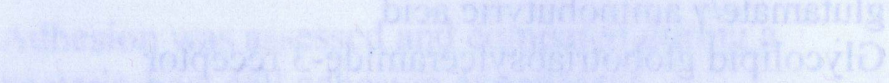

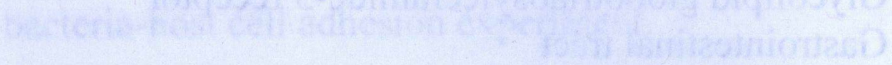

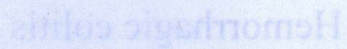

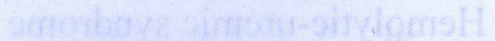

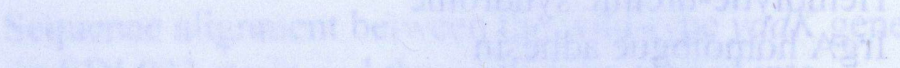

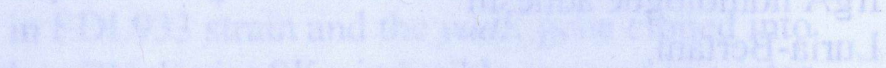

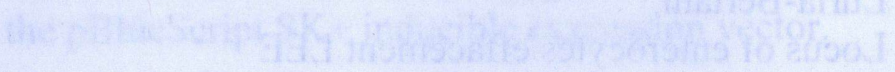

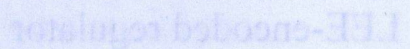

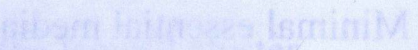

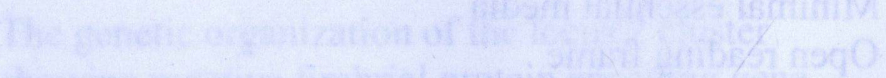

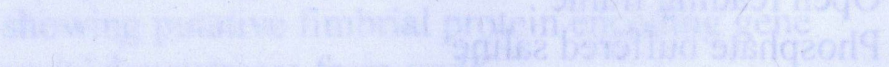

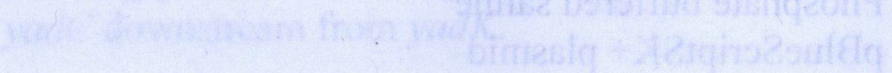

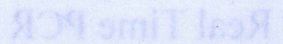

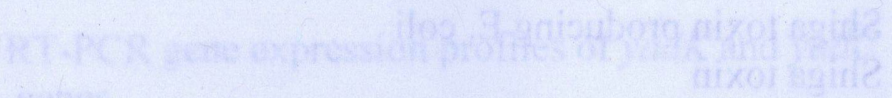

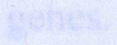

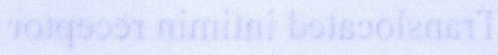

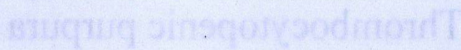
misteve noils wez 111 om: I 45. 918 $2011 \mathrm{~A}$ MTA $(-0) 6$ ?

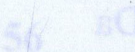
WhatidC A TOPI:

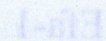
39114 397967 c 42 287 x 84a9 $(2-6)$

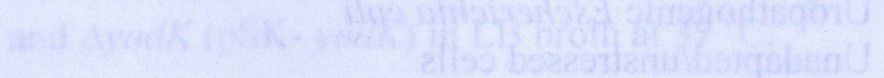
$\sqrt{34}+5$ anconoly

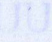
YY

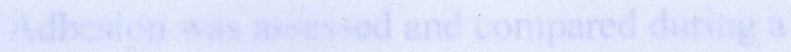

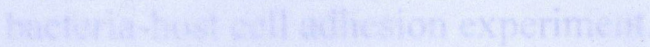




\section{Introduction}

\subsection{Enterohemorrhagic Escherichia coli 0157:H7}

Enterohemorrhagic Escherichia coli (EHEC) 0157:H7 is one of six pathotypes of pathogenic $E$. coli that expresses the $157^{\text {th }}$ somatic $(O)$ and $7^{\text {th }}$ flagellar $(H)$ antigen (1). Like commensal E. coli, EHEC is a facultative anaerobe that has adapted the ability to inhabit the human gastrointestinal tract (GI); however, it perturbs the resident flora that live in the GI tract and cause a variety of diseases including acute gastroenteritis, diarrhea, fever, nausea, vomiting and abdominal cramps $(2,3)$. During infection, EHEC colonizes the human bowel within 1-3 days of ingestion and can persists for a few days to a few weeks $(3,4)$. EHEC infections can lead to further life threatening diseases including thrombocytopenic purpura (TTP), acute renal failure, hemorrhagic colitis (HC) and haemolytic uremic syndrome (HUS) (2). In fact, EHEC is responsible for $90 \%$ of HUS infections worldwide (4) (Figure 1.1).

Morphologically, EHEC exists as a Gram-negative, rod shaped bacteria that ranges from 1-5 $\mu \mathrm{m}$ in size and 0.3-0.4 $\mu \mathrm{m}$ in thickness (5). Genomic comparison between EHEC and K12 strains reveals that almost half of EHEC-specific DNA is made of prophage DNA (6). Like other pathogenic bacteria, EHEC possesses several virulence factors including those encoded on pathogenicity islands: the locus of enterocyte effacement (LEE), the 0157 plasmid, as well as the phage encoded Shiga-toxin (stx) genes (2). Most of these pathogenic regions are believed to have been horizontally acquired and have allowed EHEC to evolve into a deadly intestinal pathogen. 


\section{Ingestion of EHEC 0157:H7}

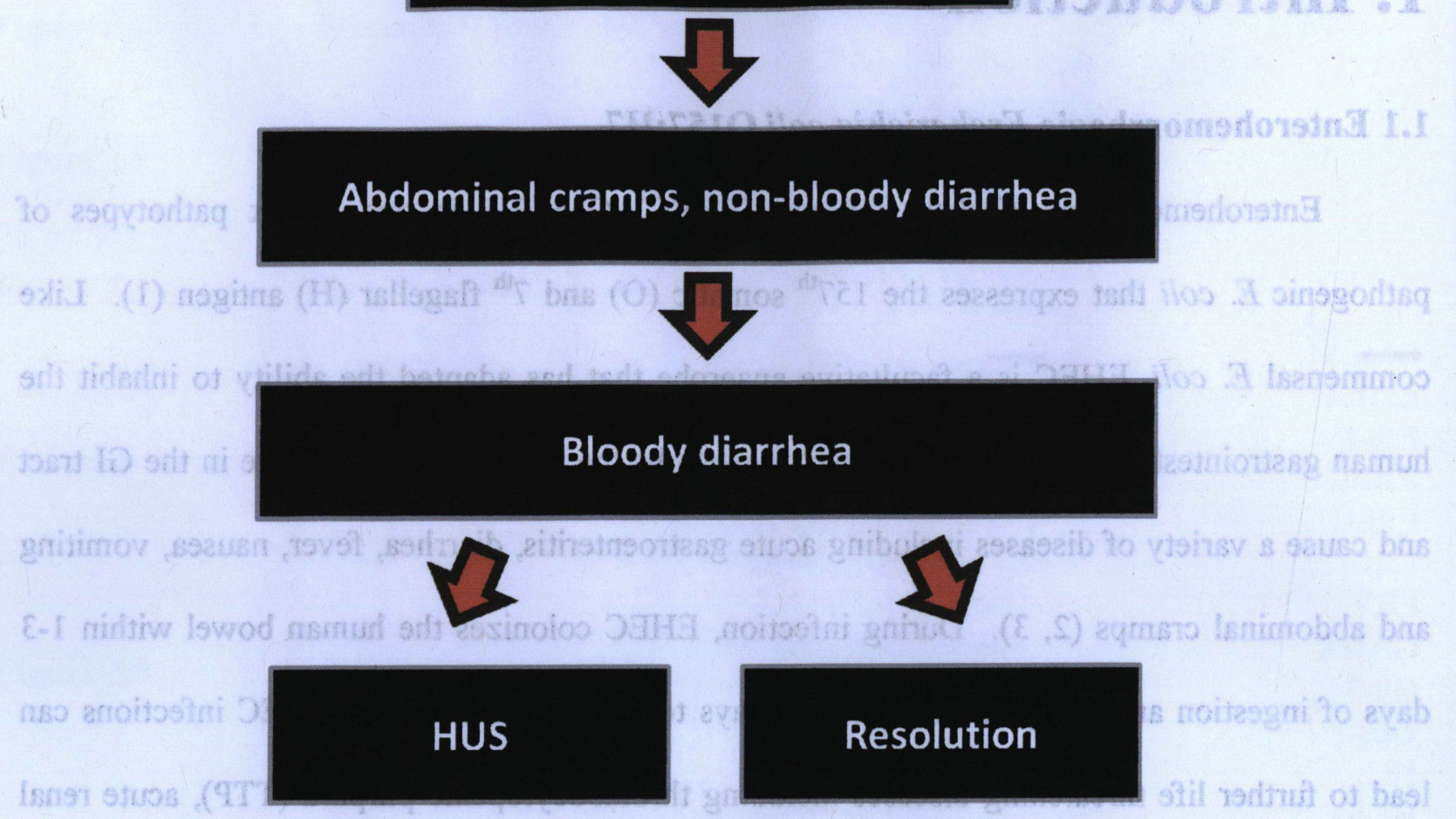

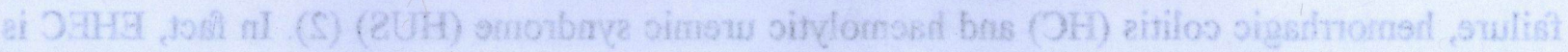

Figure 1.1 The epidemiology of EHEC-related infection. EHEC is responsible for over $90 \%$ of all HUS disease worldwide. Adapted from (1)

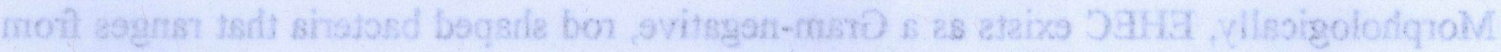

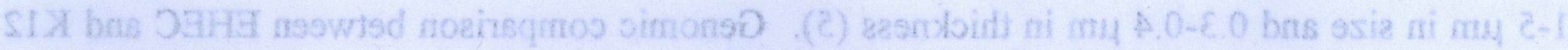

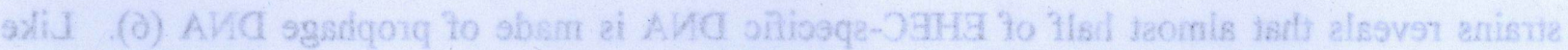

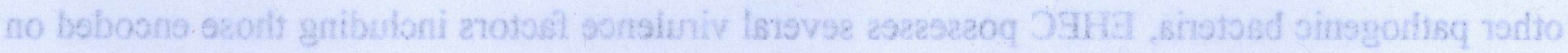

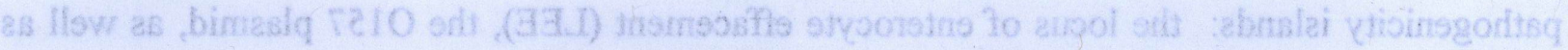

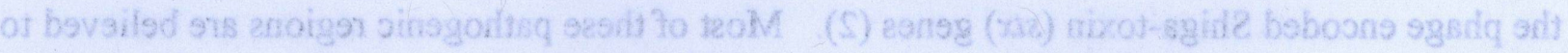

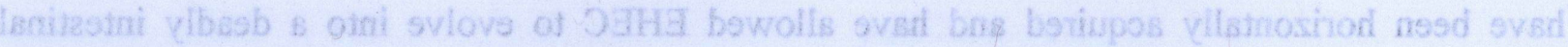




\subsection{Significance of EHEC O157:H7}

EHEC infections have been reported in at least 30 countries worldwide (7). Because healthy adults are naturally able to recover from these infections, cases of EHEC infections remain grossly underreported. Thus, EHEC O157:H7 infections only account for approximately 75,000 human related gastrointestinal infections across USA (8). Interestingly, the incidence of EHEC related disease is lower in third world countries that have no access to drinking water. This observation is often attributed to the high prevalence of enteropathogenic E. coli (EPEC) infections in developing countries that seems to provide cross-protection from EHEC among its victims (8).

Complications from EHEC disease can lead to a high mortality rate among very young children, immunocompromised individuals and the elderly. EHEC infections can cause hemorrhagic colitis, often described as "all blood, no stool" diarrhea, and can progress to HUS and death. While hemolytic uremic syndrome occurs in only $2-7 \%$ of infected victims, the lifelong complications that range from long-term renal failure to severe brain damage, cause high morbidity among EHEC infection survivors (2).

\subsection{Transmission}

EHEC can be transmitted through ingestion of contaminated food and water sources, through direct contact from one infected person to the other, and occasionally through occupational exposure (1). As little as $10^{2}$ EHEC cells are needed to cause disease among its victims (9). Healthy cattle ruminant remains the number one reservoir of this deadly bacteria. As many as $30 \%$ of all cattle in the United States are asymptomatic carriers of the EHEC (10). In spite of the severe diseases EHEC is responsible for in humans, it is not able to cause illness in cattle and therefore causes major problems for the transmission of these bacteria. Approximately 
$75 \%$ of $\mathrm{O} 157: \mathrm{H} 7$ outbreaks, including EHEC, are linked to contaminated bovine-derived products including consumption of contaminated ground beef and raw milk (5). Manure contaminated runoff is also another source of EHEC contamination in crop irrigation systems as colonized cattle can shed EHEC bacteria yearlong, contaminating drinking water (10). Other food and waterborne outbreaks can be traced to contaminated fruits and vegetables, unpasteurized apple juice, unchlorinated drinking water. EHEC can also be transmitted through direct contact; outbreaks have been observed in day-care centers, among incarcerated individuals in prisons, visits to petting zoos and dairy farms (reviewed in 11). Occupational exposures to the bacteria among nurses, farmers, microbiologists can also lead to EHEC infections.

\subsection{EHEC Pathogenesis}

EHEC pathogenesis is a multi-step process that involves different interactions between bacteria effectors and host cell receptors. As mentioned above, EHEC virulence factors are contained within pathogenicity islands within the bacteria's genome. These virulence factors include the pO157 plasmid, the locus of enterocyte effacement and phage-encoded Shiga-toxin genes (Figure 1.2) 


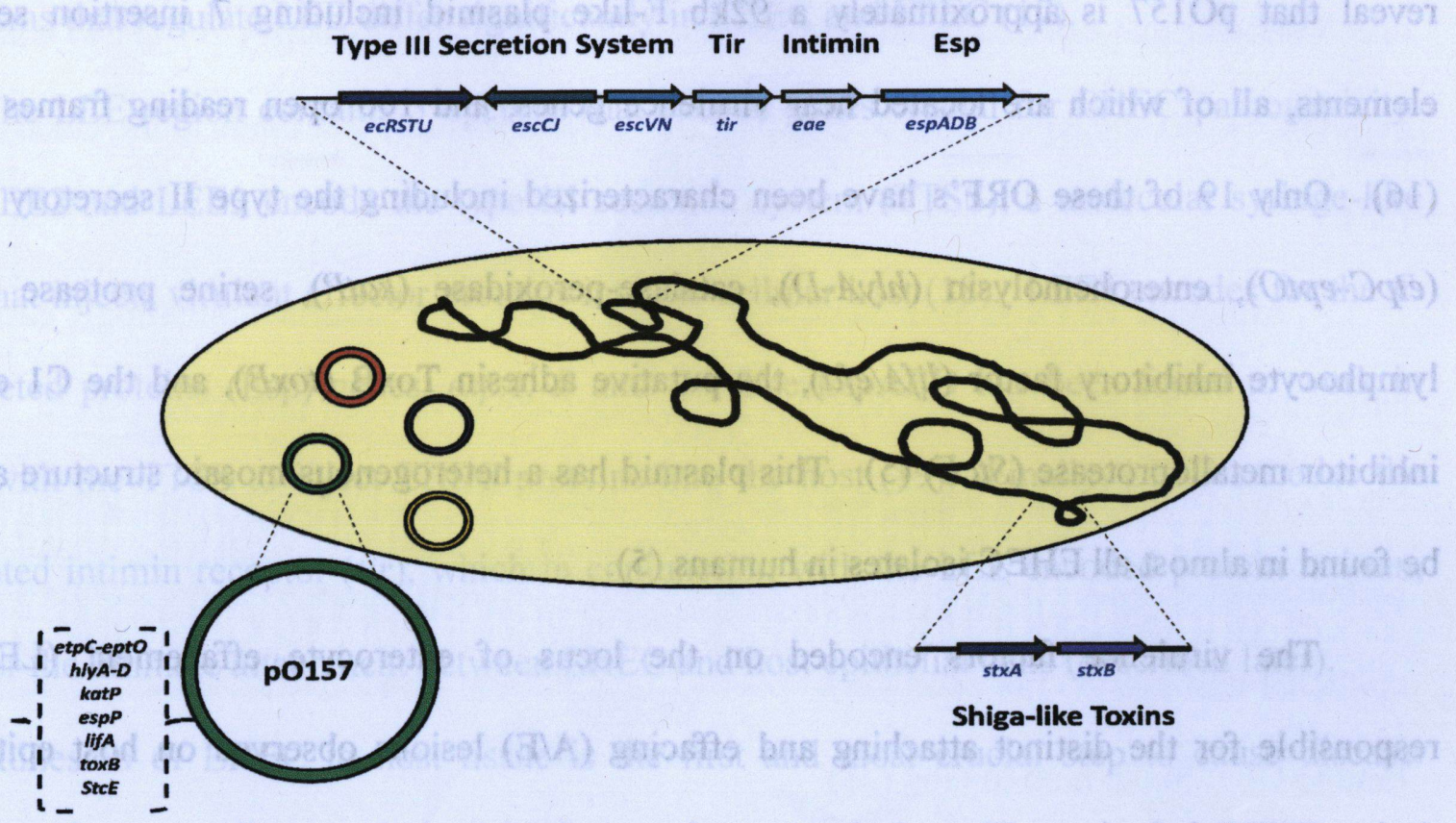

Figure 1.2 The virulence factors of EHEC are housed in three pathogenic sites: the LEE pathogenicity island, the Shiga-toxin pathogenicity island and the plasmid pO157. These virulence factors contribute to EHEC's virulent epidemiology. Adapted from (2). 
Despite extensive research on the pO157 plasmid, its role in EHEC pathogenicity has yet to be fully elucidated. It is believed that pO157 encodes a hemolysin that allows EHEC to use blood released in the intestinal tract as a source of iron (12). Several studies have indicated the importance of p0157 in the expression of fimbrial adhesins in EHEC (16). Molecular studies reveal that pO157 is approximately a $92 \mathrm{~kb}$ F-like plasmid including 7 insertion sequence elements, all of which are located near virulence genes, and 100 open reading frames (ORF) (16). Only 19 of these ORF's have been characterized including the type II secretory system $(\operatorname{etp} C$-ept $O)$, enterohemolysin $(h l y A-D)$, catalase-peroxidase $(k a t P)$, serine protease $(\operatorname{esp} P)$, lymphocyte inhibitory factor (lifA/efa), the putative adhesin ToxB (toxB), and the $\mathrm{C} 1$ esterase inhibitor metalloprotease (StcE) (5). This plasmid has a heterogenous mosaic structure and can be found in almost all EHEC isolates in humans (5).

The virulence factors encoded on the locus of enterocyte effacement (LEE) are responsible for the distinct attaching and effacing (A/E) lesions observed on host epithelium during EHEC infection. These lesions are characterized by intimate adherence of bacteria to enterocytes, thinning and shortening of microvilli, degeneration of brush borders, and formation of cuplike pedestals due to actin polymerization on infected host cells (13). A/E lesions result from the intimate attachment of the bacteria to host epithelial that causes cytoskeletal restructuring, leading to the extensive histological damage of the brush border cells at the site of bacteria attachment (14). During in vivo experiments, investigators have found that the $\mathrm{A} / \mathrm{E}$ lesions were mostly localized around the follicle-associated epithelium in bovine animal models (15).

Genomic sequence of the LEE locus reveals that approximately $7.5 \mathrm{~kb}$ of this locus encodes putative prophage genes (16). The LEE pathogenicity island is represented in a variety 
of intestinal pathogens including EHEC, related gastrointestinal pathogen enteropathogenic $E$. coli (EPEC) and Citrobacter rodentium. Transformation of K12 strains with the EHEC LEE island does not induce $\mathrm{A} / \mathrm{E}$ lesions in in vitro experiments; in contrast, transformation of $\mathrm{K} 12$ MG1655 with EPEC LEE induces A/E phenotypes in vitro. This suggests that the molecular mechanisms that regulate LEE differ significantly in EHEC and EPEC (17).

The LEE region contains 5 operons that encode genes crucial for EHEC pathogenicity. LEE1, LEE2 and LEE3 encode the type III secretion system (TTSS), a molecular syringe-like system that injects virulent effector proteins into the cellular host (18). LEE4 encodes for the $E$. coli secreted proteins (Esp) genes, espA, $B$ and $D$. The EspABD has been found to work in concert with the TTSS to inject EHEC proteins into the host (19). Finally, LEE5 encodes the translocated intimin receptor (tir), which in conjunction with the LEE encoded protein intimin, allows for the intimate attachment between EHEC and host epithelial cells (described later).

Adhesion of EHEC to host tissue is the first and most crucial step to cause disease. Adhesins encoded in the bacteria's genome mediate the crucial bacteria-host cell attachment that allow the bacteria to evade host immune response and proliferate while in the infected host. It is during attachment when EHEC causes characteristic attaching and effacing (A/E) lesions phenotype as a result of bacteria-host cell adhesion.

EHEC and other related Shiga-toxin producing E. coli (STEC) strains produce one or more phage-encoded Shiga-toxins (Stx) that are essential for the bacteria's virulence (20). These toxins are largely responsible for the development of hemorrhagic colitis and hemolytic uremic syndrome, the major hallmarks for EHEC pathogenesis (21). EHEC Stx are classified under two major groups: Stx1 (similar to the toxins produced by Shigella dysenteria type 1) and Stx2 (20). Molecular studies suggest that bacteriophage were largely responsible for transferring the stx 
genes from Shigella to EPEC, and eventually to EHEC eventually acquired during the course of its evolution $(22,23)$.

The Stx proteins belong to the AB4 toxin family that bear one enzymatically active A subunit and identical pentamers of B subunits (24) (Figure 1.3). These toxins are composed of one A subunit that can be nicked and reduced to an enzymatically active A1 (27 kDa)and an A2 peptide $(4 \mathrm{kDa})$ and a pentamer of $\mathrm{B}$ subunits $(7 \mathrm{kDa} /$ monomer) that binds to the eukaryotic cells (25).

Although Stx1 and Stx2 share very strong amino acid sequence homology, each toxin is antigenically distinct (26). As many as $3 \mathrm{Stx} 2$ variants have been identified (Stx2c, Stx2d and Stx2e) that work in the same mechanism as Stx2 (27). Universally, Stx proteins bind to globotriaoslceramide (Gb3) or globotetra-osylceramide (Gb4) receptors expressed on a variety of epithelial and endothelial cells (28). Stx1 and all of Stx2 proteins with the exception of Stx2e bind to Gb3; Stx2e bind to Gb4 (28).

Welinder-Olsson et al., show that Stx possesses the mechanism to cross the intestinalepithelial barrier and induces neutrophil-rich inflammatory response in the gut (7). To actually cause disease, Stx must be able to reach the blood stream from the gut, though the underlying mechanism behind this phenomenon is poorly understood (5). During infection, EHEC Stx enter intestinal cells through a clathrin-dependent mechanism mediated by the binding of the B subunit to $\mathrm{Gb} 3 / \mathrm{Gb} 4$ receptors (29); once the toxins are in the cytoplasm, the A subunit is cleaved by a calcium-sensitive serine protease called furin, resulting in a $27 \mathrm{kDa} \mathrm{N}$-terminal fragment (A1) and a $4 \mathrm{kDa}$ C-terminal peptide (A2) (30). The catalytically active A1 acts like a hydrolase and interacts with $60 \mathrm{~S}$ ribosomal subunit and inhibits intracellular protein synthesis. The resulting 


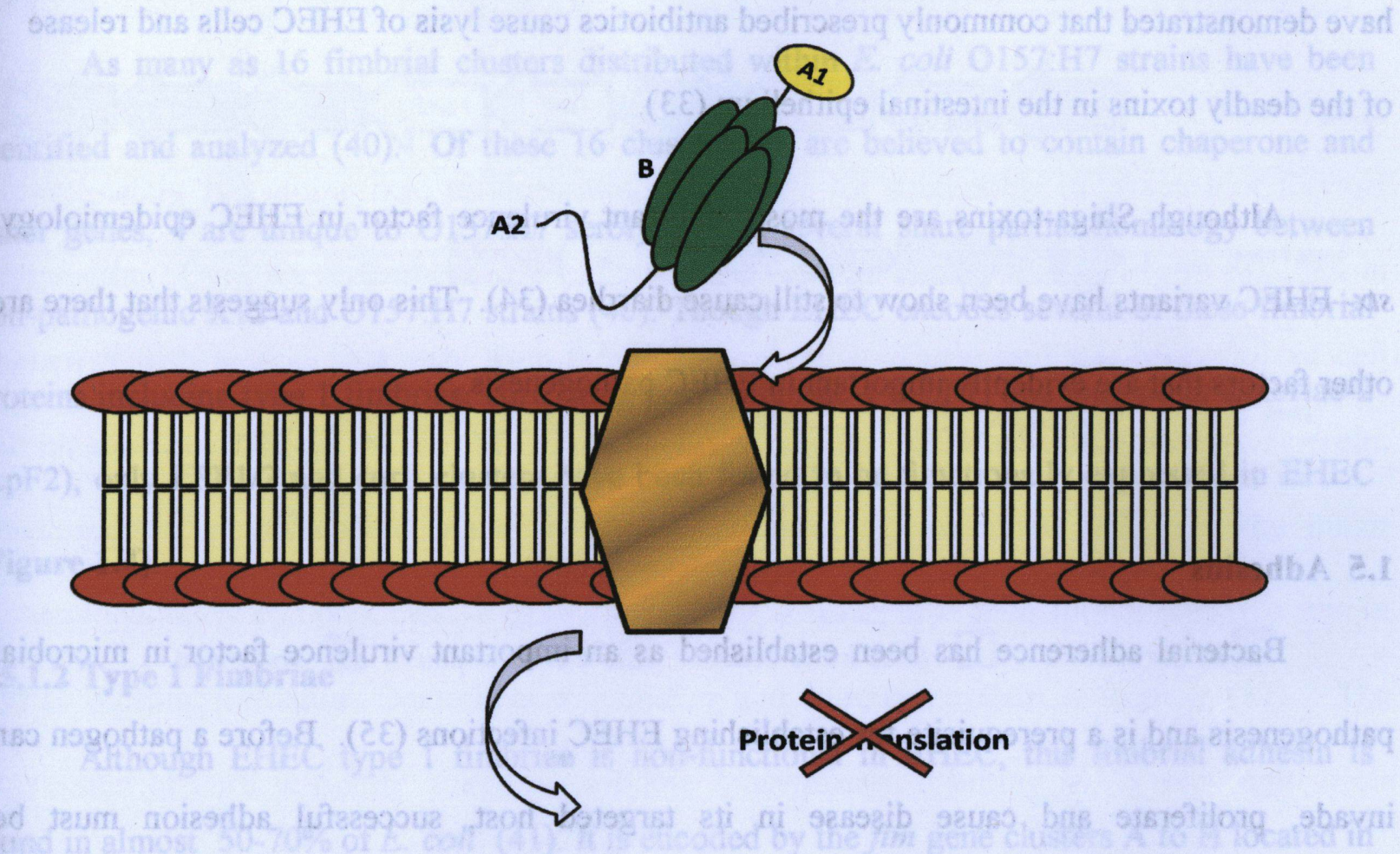

Figure 1.3 The Shiga-toxin protein in EHEC 0157:H7 belongs to the AB4 family of toxins; the B subunit interacts with cellular receptor found on host cell membrane while the enzymatically active $A$ subunit is responsible for the toxin's cytotoxic activity. Adapted from (3). 
inhibition to protein synthesis leads to cell death. In addition, Stx proteins can also stimulate cell apoptosis through activation of a caspase cascade (31). Stx have been shown to induce the upregulation of proapoptotic bax gene, which activates caspase signaling events (32).

Ironically, antibiotic treatments do more harm than help in EHEC infections. Studies have demonstrated that commonly prescribed antibiotics cause lysis of EHEC cells and release of the deadly toxins in the intestinal epithelium (33).

Although Shiga-toxins are the most important virulence factor in EHEC epidemiology, stx- EHEC variants have been show to still cause diarrhea (34). This only suggests that there are other factors that are evidently important in EHEC pathogenesis.

\subsection{Adhesins}

Bacterial adherence has been established as an important virulence factor in microbial pathogenesis and is a prerequisite for establishing EHEC infections (35). Before a pathogen can invade, proliferate and cause disease in its targeted host, successful adhesion must be accomplished (36). Bacterial adhesins promote the initial attachment of the bacteria to host cells, allowing pathogen colonization (37). The specificity of adhesion to target tissue allows bacteria to determine and even differentiate sites for attachment and even invasion (38). For some pathogens, adhesins are also responsible for bacteria-cell contact and some are even important for toxin delivery (39). EHEC employs a number of both fimbrial and non-fimbrial factors for host-cell adhesion. These adhesins can be either filamentous or amorphous (39). Filamentous adhesins or fimbriae/pili are non-flagellar appendages that are projected throughout bacteria surface. The term fimbriae is used to designate this type adhesin, reserving the term pili isfor 
sexual appendages (39). Amorphous adhesins are non-fimbrial or afimbriael adhesive structures. Both filamentous and amorphous adhesins require specific cell receptors for successful attachment.

\subsubsection{Fimbrial Adhesins}

As many as 16 fimbrial clusters distributed within E. coli 0157:H7 strains have been identified and analyzed (40). Of these 16 clusters, 13 are believed to contain chaperone and usher genes, 4 are unique to 0157:H7 serotypes and several share partial homology between non-pathogenic K12 and 0157:H7 strains (40). Though EHEC encodes several of these fimbrial proteins including type 1 fimbriae, curli, long polar fimbriae-1 (LpF1) and long polar fimbriae-2 (LpF2), only LPF1/2 and curli clusters have been found to be functionally expressed in EHEC (Figure 1.4).

\subsubsection{Type 1 Fimbriae}

Although EHEC type 1 fimbriae is non-functional in EHEC, this fimbrial adhesin is found in almost $50-70 \%$ of $E$. coli (41). It is encoded by the fim gene clusters A to $\mathrm{H}$ located in the bacteria genome. Type 1 fimbriae is composed $500-3000$ copies of the main structural subunit FimA, which forms the structural base that is around $7 \mathrm{~nm}$ thick and 0.1 and $2 \mu \mathrm{m}$ long. Multiple subunits of structure of FimF make up the filamentous part of the fimbriae rod and a 3 $\mathrm{nm}$ wide fibrillum at the end of the FimF structure contains FimG and the type 1 fimbriae adhesin tip FimH (42).

Type 1 fimbriae recognize specific mannose-containing oligosaccharides found on target tissue cells receptors (43). Receptors that highly express mannose sugars have very high affinity for the adhesin tip, FimH, as evident with the adhesin's selective binding with highly mannose 


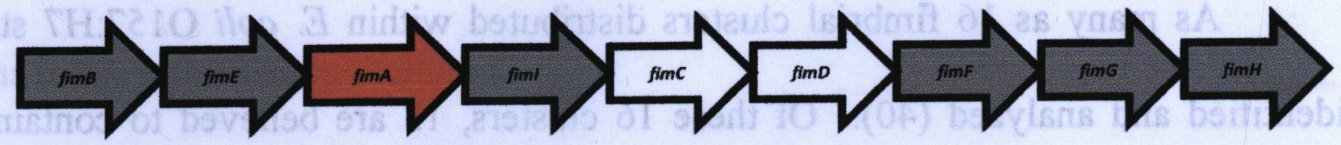

Long Polar

Fimbriae

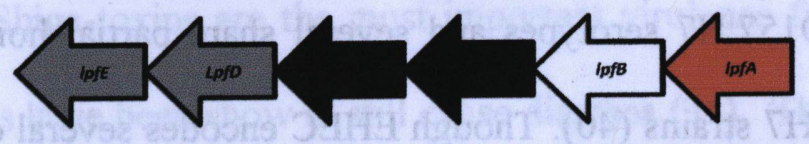

Curli

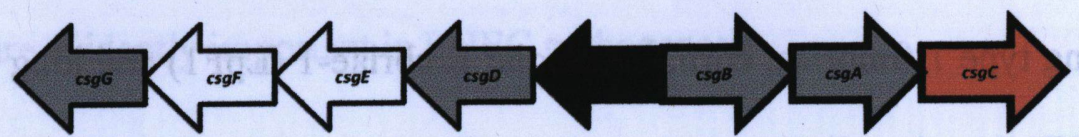

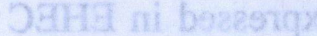

$\square$ Major Subunit $\square$ Chaperone-Usher $\square$ Minor Subunit $\square$ Undefined

Figure 1.4 Known fimbrial operons in $E$ coli 0157:H7 str. Sakai. Red filled arrows indicate major subunit within operon. Black filled arrows indicate unknown sequences. Schematic of long polar fimbria operon is based on Lpf-1 in EHEC Sakai. Arrow sizes not drawn to scale. Adapted from (40).

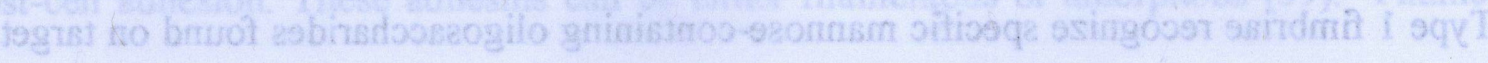

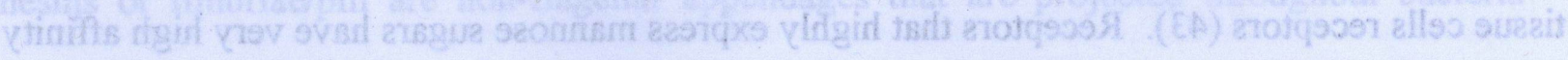


glycosylated uroplakin UPIa over the structurally related but not as glycosylated uroplakin UPIb (44).

\subsubsection{Curli}

EHEC also produces long, proteinaceous, coiled, curli protein fibers. These curli proteins consists of repeating subunits $\mathrm{CsgC}$ that form non-branching $\beta$-sheet rich fibers that are approximately 100 amino acid residues long, which are not susceptible to protease or thermal degradation. Curli are assembled in the surface of most enteric microbes and form 6-12 nm in diameters with lengths that vary from 0.5 to $1.0 \mu \mathrm{m}$ (45). Curli mediates bacteria-host cell colonization by binding to the extracellular matrix protein, as well as fibronectin, laminin, plasminogen, human contact phase proteins located in the intestinal wall and the major histocompatibility complex class 1 molecules (46). Curli has also been shown to play a role in EPEC biofilm formation, bacteria-host invasion and immune system activation (47). The expression of curli is tightly linked to cellulose biosynthesis, resulting in the very tight hostbacteria cell and cell-surface interaction during pathogenesis (48).

\subsubsection{Long Polar Fimbriae}

Torres et al., identified two loci in EHEC that showed strong homology to the long polar fimbriae in Salmonella enterica serovar Typhimurium (49). The six ORFs that were characterized in the first $l p f$ operon (49) showed considerable similarity to $S$. enterica lpf gene cluster. The nomenclature of EHEC $\operatorname{lpf}-1, \operatorname{lpf} \mathrm{ABCC}$ 'DE is also similar to $S$. enterica.

Protein prediction analysis of the Lpf proteins suggests structural homology to the Fim proteins of type 1 fimbriae. The first gene in the operon, LpfA, shows high homology to FimA, 
while proteins $\mathrm{LpfB}$ and $\mathrm{LpfC} / \mathrm{LpfC}^{\prime}$ are structurally similar to FimC and FimD, the usherchaperone subunits of type 1 fimbriae (49).

Investigators examined the role of Lpf proteins in EHEC bacteria-host adhesion and found that the long polar fimbriae contributed significantly to the colonization of EHEC in in vivo studies (50). While they did not observe any changes in $\mathrm{A} / \mathrm{E}$ lesions formed in either their single lpfl or double lfpl lpf2 mutant strains during microscopic studies, they did note that adhesion to human epithelial cells was significantly decreased in $\operatorname{lpf} 2$ mutants after $3 \mathrm{~h}$ of infection during bacteria-host cell adhesion assay. To this, investigators concluded that the Lpf proteins may be required in initial bacteria adherence in vitro (50).

\subsubsection{F9 fimbriae}

F9 fimbriae is one of the 16 fimbrial clusters that is expressed in vitro (51). F9 fimbriae form short 1-2 $\mu \mathrm{M}$ long fimbrial stalks that can be removed at $60{ }^{\circ} \mathrm{C}$. The gene, chaperone and half of the usher of the F9 operon is deleted in E. coli K12 MG1655 strain; however, regions within this operon are 98\% identical among E. coli O157:H7 and CFT073 strains (51). Cloning the F9 operon into the K12 strains increases bacteria-host cell adhesion. Adhesion of transformed K12 was 3.5 fold higher than control during bacteria-host cell adhesion assays (51). In vivo experiments show that a deletion in the major subunit of the F9 operon reduces the ability of E. coli $\mathrm{O} 157: \mathrm{H7}$ strain EDL933 to colonize 1-2 week old calves $(52,53)$. This data strong supports the importance of $\mathrm{F} 9$ operon in the successful adhesion of pathogenic E. coli. 


\subsubsection{E. coli Common Pilus}

The E.coli Common Pilus (Ecp) found in a variety of E. coli O157:H7 serotypes, is composed of multiple subunits of the fimbriae's gene, ecpA (54). EcpA is revealed to be $60 \%$ hydrophobic and is assembled into a pili "MAT" (meningitis associated and temperatureregulated pili) $(55,56)$. Investigators demonstrate that ECP filaments are visible as early as $1.5 \mathrm{~h}$ after affection; ecpA (also know as yagZ) mutants also show deficiency in adherence onto human epithelial cells, indicating that it plays a role in EHEC bacteria-host cell adhesion (54).

\subsubsection{Non-fimbrial Adhesins}

In addition to fimbrial adhesins, non-fimbrial adhesins have also been implicated in EHEC O157:H7 bacteria-host cell adhesions. Several non-fimbriated proteins include intimin, Iha, Efa-a have been identified to be crucial to the bacteria's pathogenicity.

\subsubsection{Intimin}

The eae gene which encodes the non-fimbrial adhesion intimin is responsible for the intimate attachment of EHEC to host cells. Intimin binds to the translocated intimin receptor (Tir) which is injected into host epithelia using the type III secretion system. Intimin was predicted to be a $94 \mathrm{kDa}$ membrane protein with several Ig-like domains (57). Its $\mathrm{N}$-terminus bears a $30 \%$ sequence resemblance to an invasin protein and its C-terminus forms a $\mathrm{C}$-type lectin domain that forms a rigid superdomain binding for Tir (58). Intimin receptor Tir is an effector molecule containing two transmembrane helices with an extracellular intimin-binding domain. Once injected into host cytoplasm, Tir is phosphorylated and becomes anchored in the membrane 
and exposed for intimin binding (57). This extracellular domain forms two antiparallel $\alpha$-helices joined by a $\beta$-hairpin. The intimin-Tir interaction mainly occurs around the residues that form the $\beta$-hairpin. Both of the Tir $\mathrm{N}$ and $\mathrm{C}$-termini face the cytoplasm of the host cell and are involved in the cytoskeletal rearrangement due to downstream signalling events (58).

Molecular typing has identified several intimin classes $(\alpha, \beta, \gamma, \delta$ and $\varepsilon)$ though only $\beta$ and $\gamma$ have been implicated in EHEC O157:H7 pathogenesis (58). Although the binding distance between intimin and Tir is only $1334 \AA$, it is enough to cause the damaged histological $\mathrm{A} / \mathrm{E}$ lesions distinctive of EHEC colonization $(57,59)$.

\subsubsection{Efa}

Another non-fimbriated factor that is important for EHEC colonization is the E. coli factor for adherence (Efa) (60). EHEC 0157:H7 contains a truncated efa-1 gene that when mutated, significantly impairs the bacteria's adhesion onto human epithelial cells (62). Efa-1 was originally identified in Shiga-toxin producing E. coli (STEC) $0111: \mathrm{H}^{-}$strains and conferred adherence onto Chinese hamster ovary cells (61). Genotypic analysis on Efa-1 in O111:Hstrains reveals that it shares very strong amino acid identity with EPEC lymphostatin LifA, a lymphotoxin that contributes to EPEC adherence (59). Live animal studies also show that cattle infected with $\Delta e f a-1$ in $0111: \mathrm{H}$ - strains showed decreased fecal shedding compared to their wild-type counterparts (61). 


\subsubsection{Iha}

The IrgA homolog adhesin (Iha) is a $67 \mathrm{kDa}$ protein identified in EHEC O157:H7. Transformation of non-pathogenic E. coli with iha confers an increased adhesion on human epithelial tissue in vitro, suggesting its role in adhesion. Molecular analyses show that the iha gene is present in $91 \%$ of all pathogenic EHEC strains, suggesting that Iha is a common adhesin used by a variety of virulent $E$. coli serotypes (63). Interestingly, iha expression is higher among E. coli strains found in bovine ruminant rather than humans. Iha was also shown to be important for bovine gut colonization of O157:H7 (64).

\subsection{Regulation of Fimbrial Adhesin Genes}

Over the last two decades, investigators have shown that pathogenic bacteria's microenvironment is crucial in the regulation and expression of fimbrial adhesin encoding genes and other virulence factors. Low et al., surmise that EHEC carries an arsenal of fimbrial adhesin proteins that expressed only under very specific conditions and may confer the virulent phenotypes observed from this pathogen (40). Several of these microenvironments include suboptimal temperature and $\mathrm{pH}$, osmolarity, bacteria cell density and ingestion stress.

Gene expression analyses have shown that expression of type 1 fimbrial protein gene fimA is temperature dependent. Expression of fimA transcripts appeared slightly higher at $30^{\circ} \mathrm{C}$ than at $37^{\circ} \mathrm{C}(65)$. It was determined that at $37^{\circ} \mathrm{C}$, the invertible switch that regulates fim operon expression is at a neutral position and neither turns "on" nor "off" fim genes. However, at $30^{\circ} \mathrm{C}$, the switch becomes biased to an "on" position, and thus results to slightly higher fim expression. This apparent environmental mode of regulation of fim suggests that the bacteria can easily adapt 
to the conditions of its environment, which is a crucial attribute for its survival and pathogenicity (65).

Environmental $\mathrm{pH}$ also affects the transcription of fim genes. Neutral $\mathrm{pH}$ of 7 shows maximal expression of fim, whereas low pH (pH 5.5 or lower) negatively regulates the gene (66). Transcriptional analyses of $\operatorname{fim} B$ and $\operatorname{fim} E$ results in to a 2-fold decrease in expression when clinical UPEC was grown in $\mathrm{pH}$ 5.5. The expression of the invertible switch that regulates the fim promoter is also seen to decrease 4-fold when bacteria is grown at this $\mathrm{pH}$, suggesting that the orientation of the switch is phased off (66).

Torres et al., report that $l p f 2$ expression is environmentally regulated as well. Molecular work on $\operatorname{lpf} 2$ reveal that its expression during lac fusion assays was observed highest when induced in media at $\mathrm{pH} 6.7$ than in slightly acidic media at $\mathrm{pH} 5.5$ (67). $\beta$-galactosidase assay also reveals that $\operatorname{lpf} 2$ expression was modulated in media supplemented with $\mathrm{NaCl}$. Expression of $\operatorname{lpf} 2$ was reduced in half in media with high salt molarity when compared to controls (67).

Expression of ecpA is believed to be regulated by temperature and growth media. EHEC is able to produce ECP at temperatures below $37^{\circ} \mathrm{C}$, indicating its role in the bacteria's adhesion outside its host environment (54). ECP is also produced only when EHEC is grown in DMEM and not LB.

\subsection{Acid Stress and EHEC 0157:H7}

The microenvironment that EHEC is exposed to during ingestion include a variety of stresses from gastric acid shock found in the stomach, bile-salt stress from the small intestine and short-chain fatty acid stress in the large intestine (68). To establish successful infection, EHEC must be able to survive in these ingestion stresses, especially the acute acid conditions of 
stomach that can range between $\mathrm{pH} 1.4$ to $\mathrm{pH} 2.0$ among healthy individuals $(69,70)$. In addition, EHEC must also survive the acidic conditions commonly used for bacteria growth control in the food industry (71). Acid challenge such as organic acid spray washes are routinely used to destroy pathogens and other contaminants from beef carcasses in meat processing plants (71).

\subsection{Acid Response Systems}

In response to these acute acidic challenges, EHEC has developed a sophisticated acid tolerance response (ATR) mechanism. In the last decade, as many as four acid response (AR) systems have been identified (described below). These systems each illustrate a unique and independent acid stress mechanism, allowing EHEC to develop specific mechanisms for protection against acid challenged situations (72). These mechanisms of acid resistance contribute to the survival of even a few EHEC cells during gastric passage.

\subsubsection{Oxidative Repressed Acid Resistance (AR1)}

The oxidative repressed acid resistance (AR1) is the first acid response system identified and is also the one that is least understood. Stationary phase EHEC cells grown in LB media buffered at $\mathrm{pH} 5.5$ exhibited significant resistance and protection against acute acid above $\mathrm{pH} 3.0$ compared to the same cells grown at $\mathrm{pH} 8.0$ (73). However, this acid tolerance response is repressed when stationary phase bacteria is grown in LB supplemented with glucose. Molecular studies reveal that the stationary phase alternative sigma factor, $\sigma^{\mathrm{s}}$ or RpoS, is required for these cells to induce and develop acid tolerance. $\sigma^{\mathrm{s}}$ is a global regulatory protein that works in conjunction with cyclic AMP (cAMP) and cAMP receptor protein (CRP) (74). Experimental 
analyses have also shown that cells grown at $\mathrm{pH} 8.0$ produce an inhibitory response against AR1 that prevents this acid response mechanism. Inhibition of AR1 is not induced below pH 5.0, thereby allowing the bacteria to survive acute $\mathrm{pH}$ conditions. Interestingly, supplementation of glutamate in the media even at $\mathrm{pH} 8.0$ induces AR1 action, suggesting that environmental conditions play a role in EHEC acid tolerance response (75). While very little is known about AR1, investigators believe that it requires the putative glutamate/ $\gamma$ aminobutyric acid (GABA) antiporter, GadC, and its mode of action overlaps with the other acid response systems that have been identified (72).

\subsubsection{Glutamate-dependent Acid Resistance (AR2)}

The most well- characterized acid resistance mechanism is the glutamate-decarboxylase dependent system. AR2 employs two decarboxylase isozymes encoded by the gadA and gadB genes, AraC-family regulatory protein products of $\operatorname{gad} W, \operatorname{gad} Y$ and $\operatorname{gadX}$ and the GABA antiporter GadC (76). Investigators believe that AR2 provides EHEC the best protection against acid stress, as it functions in acid-challenged media of $\mathrm{pH} 2.0$ or less (73). The AR2 system maintains the internal cytoplasmic $\mathrm{pH}$ by converting glutamate into GABA and consumes a proton in the process $(72,74)$. When the external $\mathrm{pH}$ is at 2.0 or lower, the AR2 system maintains the cells' internal $\mathrm{pH}$ at $4.2 \pm 0.1$ (76). This mechanism of acid tolerance, however, is only induced if glutamate is supplemented in the acid challenged media.

Like AR1, AR2 induction occurs during stationary phase, although the gad genes are somewhat induced in log-phase cultures grown in minimal glucose media (72). Evidence show that AR2 partially depends on global regulator such as $\sigma^{\mathrm{s}}$ to function and to develop acid 
resistance. However, it can also operate in an RpoS-independent fashion (77). Molecular mapping illustrates that both $\operatorname{gadB}$ and $\operatorname{gad} C$ are co-transcribed in one operon, while gadA is transcribed under a separate promoter. In natural conditions, these gad genes are repressed by CRP; however, after acid induction, a repressor protein, GadY, (also known as YhiX) stabilizes gadX mRNA that in turn activates gadE. GadE functions as an activator and turns on the transcription of gadA and $\operatorname{gadBC}$, thereby allowing the AR2 system to function (75). Loss of function $\triangle \operatorname{gad} Y$ or $\triangle c r P$ mutants results to a constitutive gadA and gadBC expression independent of $\mathrm{pH}$. This suggests that AR2 is tightly regulated in nature, most likely to facilitate survival and pathogenesis of EHEC in response to a variety of environmental conditions (72).

Of the four AR systems, AR2 is believed to be most crucial for gastrointestinal survival of pathogenic E. coli (73). Interestingly, the GAD proteins are not active in log-phase cells, even if its gene transcripts are highly expressed. This strongly indicates that while the AR2 system is crucial for acid tolerance response, other systems are at work in the survival of acid-induced EHEC in vivo during logarithmic growth.

\subsubsection{Arginine-dependent Acid Resistance (AR3)}

The arginine decarboxylase-dependent system requires the addition of arginine in acid challenged minimal media for induction. AR3 functions in anaerobic conditions and only when cells are previously exposed to rich media (74). As with AR2, the mechanism of AR3 is simple; in the presence of acute acidity, arginine-inducible decarboxylase AdiA converts arginine to agmatine and in the process consumes a proton (78). The antiporter AdiC mediates the transfer of arginine across the membrane. Like AR2, AR3 increases cellular $\mathrm{pH}$ to $4.7 \pm 0.1$ allowing EHEC to survive low extracellular $\mathrm{pH}$ (76). 
Mutational experiments demonstrate that a regulator protein, $\mathrm{CysB}$, is involved in the control of AR3; cysB mutants fail to respond in an arginine-dependent fashion (71). Another AraC-family of protein regulators, AdiY, seem to activate the AR3 dependent adiA and adiC genes. Like AR2, $\sigma^{\mathrm{s}}$ seems to play a role in AR3 induction, but is not solely required for this acid tolerance response (74).

As with $\mathrm{AR} 2, \mathrm{AR} 3$ is crucial for the maintenance of internal $\mathrm{pH}$ in acid challenged media. Richard and Foster describe a sophisticated arginine-dependent acid resistance model, wherein excess protons that enter the cell are immediately consumed during decarboxylation (70). The consumption of a proton allows the conversion of arginine into agmatine and drives the internal $\mathrm{pH}$ to $4.0-5.0$. Richard and Foster argue that protons in the form of $\mathrm{HCl}$ easily diffuse into EHEC cells in low $\mathrm{pH}$ environments. $\mathrm{HCl}$ species dissociate in the cell as $\mathrm{H}+$ and Cl-. Antiporter, AriC, consumes a proton during decarboxylation. The negatively charged $\mathrm{Cl}^{-}$ ions are left in the cell and are ultimately discharged through chloride transport pumps to prevent hyperpolarization when cells are returned to neutral media $(76,79)$.

\subsubsection{Lysine-dependent Acid Resistance (AR4)}

The lysine-dependent decarboxylation system was first identified in non-pathogenic $E$. coli strains but its presence in $\mathrm{O} 157: \mathrm{H} 7$ pathotypes has been confirmed. AR4 protein products are encoded by the cadBA genes and like with AR2 and AR3, consumes a proton for every decarboxylation of lysine $(80,81)$. The lysine-dependent decarboxylation provides some degree of protection against mild acid shock, but is not sufficient to respond to $\mathrm{pH}$ lower than $3.0(80)$. The decarboxylase encoded by the gene, cadA, is fully induced in the presence of low $\mathrm{pH}$, anaerobic conditions and high concentrations of lysine in the media (80). Currently, it is not 
known whether or not $\sigma^{\mathrm{s}}$ partially regulates AR4 response as with the other decarboxylasedependent systems (80). Investigators also believe that the degree of acid protection provided by AR4 is not as strong as AR2 and AR3 (81)

\subsection{Acid Stress on EHEC O157:H7}

\subsubsection{Acid Tolerance}

In addition, acid stress challenge appears to play a crucial role in EHEC survival and virulence. Habituation or adaptation of EHEC cells in sublethal $\mathrm{pH}$ conditions seems to increase its survival in acute acidic environments. Leyer et al., report that acid adaptation of $E$. coli O157:H7 beef isolates can confer resistance to lactic acid (81). Tosun et al., also show that clinical isolate $\mathrm{O} 157: \mathrm{H} 7932$ tolerate acute acidic conditions as low as $\mathrm{pH} 3.0$ if previously exposed to $\mathrm{pH} 4.5$ (82).

Acid adapted EHEC cells are also able to retain their acid resistance even after prolonged periods in cold storage (83). In spite of the long interval between slaughter and human ingestion, EHEC pre-exposed to weak organic acids in the farming industry, still exhibit a strong degree of acid resistance and therefore are able to face subsequent exposure to gastric acid (84).

Acid-adapted EHEC are also able to tolerate other environmental stresses compared to their non-adapted counterparts. Cheng et al., demonstrate that acid-adapted cells show increased thermal and sodium chloride tolerance (85). Habituation in mild acid also provides EHEC a degree of freeze-thaw resistance. The cellular membranes of acid adapted cells seem to be more adaptable and therefore less susceptible to freeze-thaw rupture (86). 
Genome array analyses also reveal that acid shock promotes differential gene expression in EHEC O157:H7. As many as 21 genes, including periplasmic protein encoding gene, marB, are significantly upregulated when cells are shocked in acid for $15 \mathrm{~min}(87)$. While the function of $\operatorname{mar} B$ is yet to be elucidated, the mar operon confers multiple drug resistance in $E$. coli and when induced, increases the bacteria's survival in toxic environments (88).

Our lab has also showed that exposure of EHEC to a variety of acid adaptation and acid shock conditions results in the significant upregulation of virulence genes that encode flagella, adhesins and type III secretion proteins (69). These two studies indicate that acid stress induces gene expression of numerous virulence genes that can contribute and alter EHEC's pathogenic abilities.

\subsubsection{Adhesion}

Recent work in our lab has shown that exposure to acute acid stress can significantly enhance EHEC adhesion to human epithelial cells for up to $150-480 \%$ (89). Bacteria preexposed to acid treatments are able to adhere significantly better than unstressed controls. Previous studies on the related diarrhaegenic pathogen EPEC also showed enhanced host cell adhesion of the bacteria after acid stress (68). The acid-induced host cell adhesion enhancement for both EPEC and EHEC can be eliminated if the bacteria are treated with subinhibitory concentrations of erythromycin, an antibiotic known to inhibit bacterial protein synthesis (62). This indicates that the adhesion enhancement requires protein synthesis and likely involves either or both increased expression of known or new adhesins.

Transcriptomic experiments were performed in order to identify possible adhesin encoding genes that are upregulated after EHEC exposure to acid stress and/or adaptation. Our 
microarray data were also examined for changes in expression of fimbrial and non-fimbrial adhesins under three different acid treatment protocols, which had been used in the host adhesion assays (69). These three acid treatment protocols included exposure of the bacteria to: a) 60 min at $\mathrm{pH} 7.4$ and $30 \mathrm{~min}$ at $\mathrm{pH} 7.4$ (unadapted/ unstressed; UU); b) $60 \mathrm{~min}$ at $\mathrm{pH} 7.4$ and 30 min at $\mathrm{pH} 3.0$ (unadapted/ acid shocked; UA30); and c) $60 \mathrm{~min}$ at $\mathrm{pH} 5.0$ and $30 \mathrm{~min}$ at $\mathrm{pH} 3.0$ (acid adaptation/acid shock; AA30). The increased expression of several adhesin encoding genes were specifically observed after the bacteria were exposed to AA30 treatments (Table 1.1). 
Table 1.1. List of putative fimbrial genes that showed increased expression after adaptation at pH 5 for 60' and shock at pH 3 for 30'. Adapted from (63)

\begin{tabular}{|c|l|c|}
\hline Gene ID & \multicolumn{1}{|c}{ Putative Function } & Fold Expression \\
Z0639 & Adhesin/Invasin-Like Protein & 3.47 \\
\hline ECS1417 & $\begin{array}{l}\text { Putative 2-Component Regulator, 2 } \\
\operatorname{csg} D\end{array}$ & 3.02 \\
\hline ECS3723 & Type III Secretion Protein EpaR1 & 4.01 \\
\hline ECS0597 & Putative Fimbrial Protein, FimZ & 2.38 \\
\hline B0293 & Putative Fimbrial Protein, YagZ & 4.98 \\
\hline B0170 & Putative Membrane Protein - HofB & 5.45 \\
\hline B0136 & Putative Fimbrial Adhesin YadK & 4.94 \\
\hline
\end{tabular}

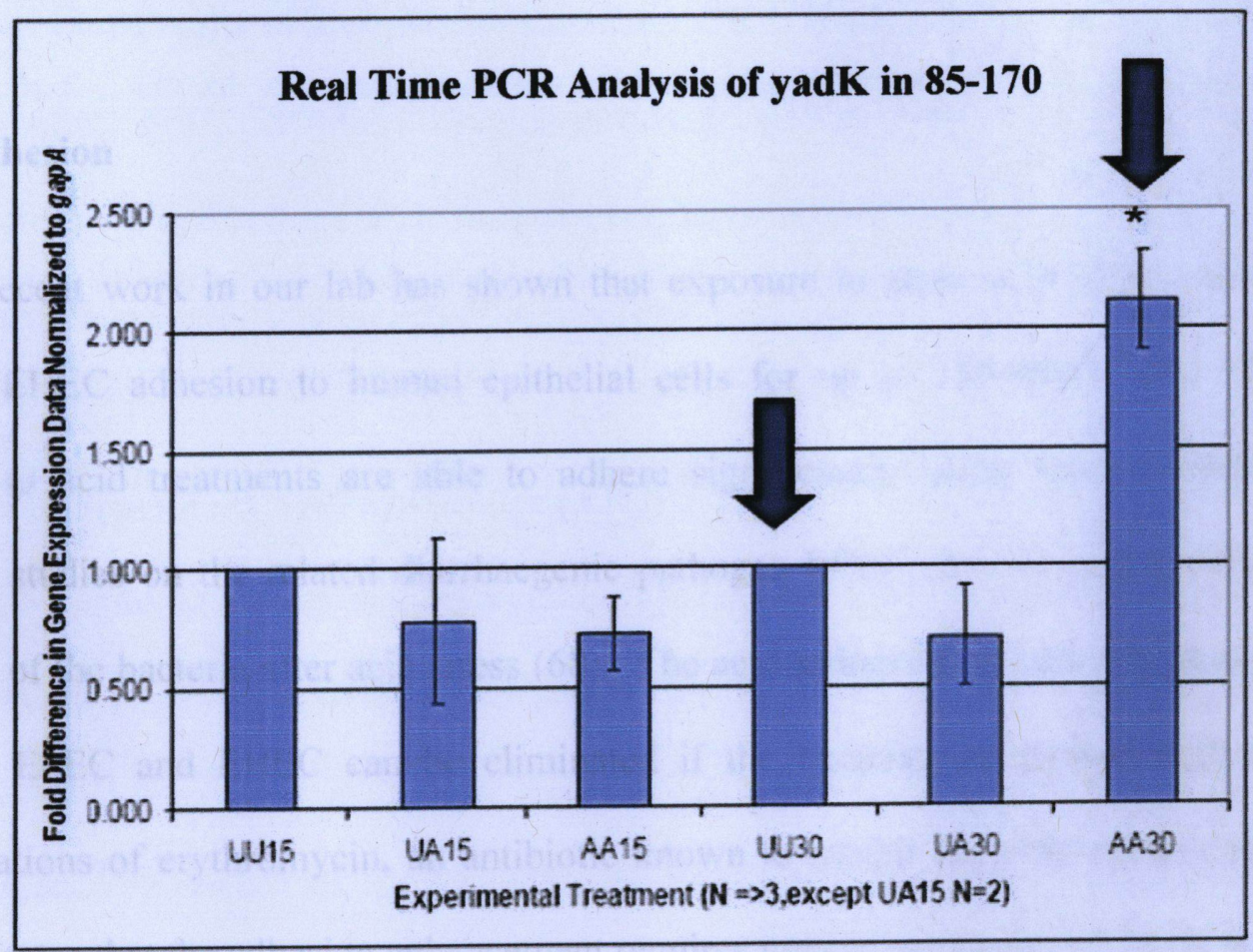

Figure 1.5 Real time PCR analysis of yadK. Data shows that the gene is increased by 2.5 fold in acid adapted, acid stressed bacteria. 


\subsection{Putative fimbrial protein YadK}

One of the genes that showed a 5-fold increase in gene expression after EHEC exposure to acid stress treatment was predicated to encode a putative fimbrial adhesion, YadK (Table 1.1). The same pattern of increased yadk expression after acid adaptation, acid stress was also confirmed by quantitative real-time reverse-transcriptase (RT) - PCR, strongly suggesting that this gene responded to acid stress treatment (Figure 1.5). The significant upregulation of $y a d K$ transcripts in acid-induced bacteria strongly correlates with the increased adhesion of acidstressed EHEC during bacteria-host cell adhesion experiments (90). This suggested that YadK may play a role in the adhesion of acid-stressed EHEC cells in vitro.

Bioinformatic analysis reveal that $y a d K$ is a 591 base pair long gene that is predicted to encode a minor subunit in a fimbrial adhesin complex expressed in the outer membranes of EHEC cells (Figure 1.6A). The $y a d K$ gene is identical in both EHEC serotypes EDL933 and Sakai. The $y a d K$ gene product is predicted to be fimbrial adhesin that is 196 amino acid in length with a molecular weight of $21.2 \mathrm{kDa}$ and a $\mathrm{pI}$ of 5.24. YadK bears a domain that belongs to the cl01416 superfamily. Members of the cl01416 family all carry a conserved fimbrial structure universally shared among several bacterial adhesins including the fim genes that are assembled into type 1 fimbriae.

$y a d K$ is predicted to be a minor subunit of the locus 2 putative fimbrial operon that has been identified among EHEC Sakai strains. Interestingly, the original MG1655 fimbrial locus that contains $y a d K(y a d C, y a d K, y a d L, y a d M$, htrE, ecpD and $y a d N)$ was discovered missing in the EHEC EDL933 and Sakai genome. The same locus was replaced by a different set of fimbrial genes (Z0146, Z0147, Z0148, Z0149,Z0150, Z0151 and Z0152 in EDL933; ECs0139, 
Ecs0140, Ecs0141, Ecs0142, Esc0143, Esc0144 and Esc0145 in Sakai) that share partial homology to the commensal strains (91). While these fimbrial genes follow the same nomenclature as the genes found in MG1655 (ie. Z0147 is also called "yadK") and is predicted to follow similar functions, investigators believe that they were once removed and re-inserted into the bacteria's chromosome and therefore are considered virulence factors (91). Like yadK, our lab's microarray data show that all the other genes in locus 2 appear to be upregulated by acid as well (74, Figure 1.6B).

Homologs of YadK are also found among other enteric pathogens including Salmonella and Shigella. The amino acid sequences of YadK in EHEC and in Salmonella bear a 63\% homology $\left(3 \mathrm{e}^{-42}\right)$, and a $61 \%$ homology to the Shigella YadK $\left(4 \mathrm{e}^{-34}\right)$. 
A.)

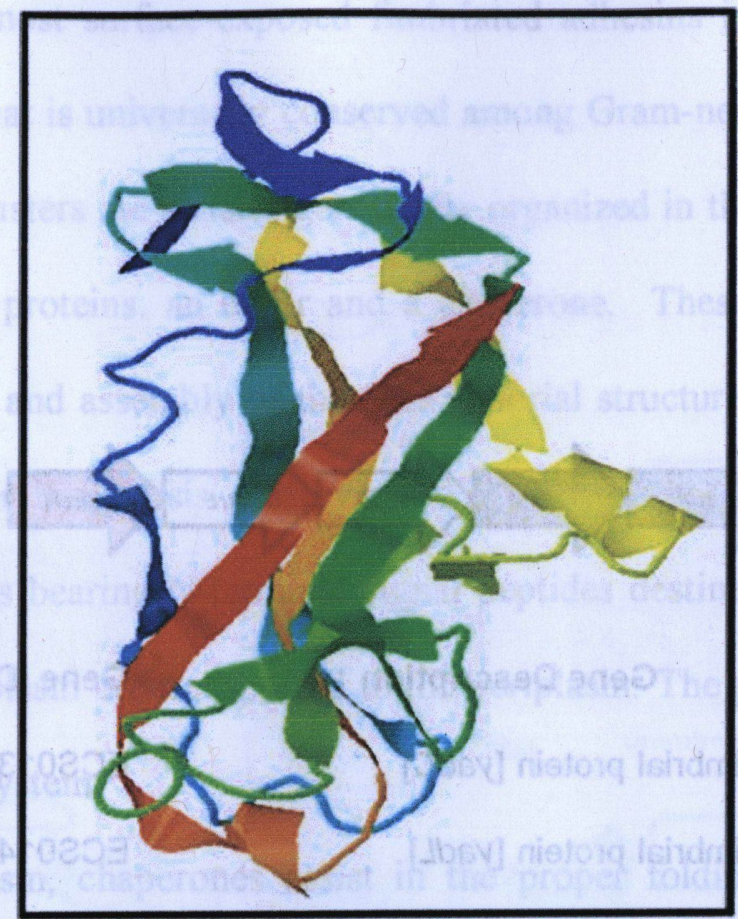

B.)

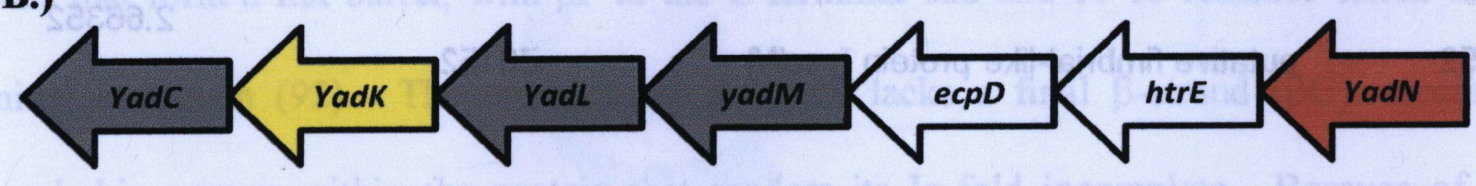

Major Subunit

Chaperone-Usher

Minor Subunit

Undefined

yadk

Figure 1.6 A. Predicted protein fold structure of YadK. PHYRE protein prediction folding software predicts the folding of YadK to be similar to fimbrial protein FimF. B. The yadK gene is located in locus 2 in both EHEC 0157:H7 strains EDL933 and Sakai. The predicted protein fold of the YadK adhesin shows strong homology to type1 fimbriae minor subunit FimF. Adapted from (41) 


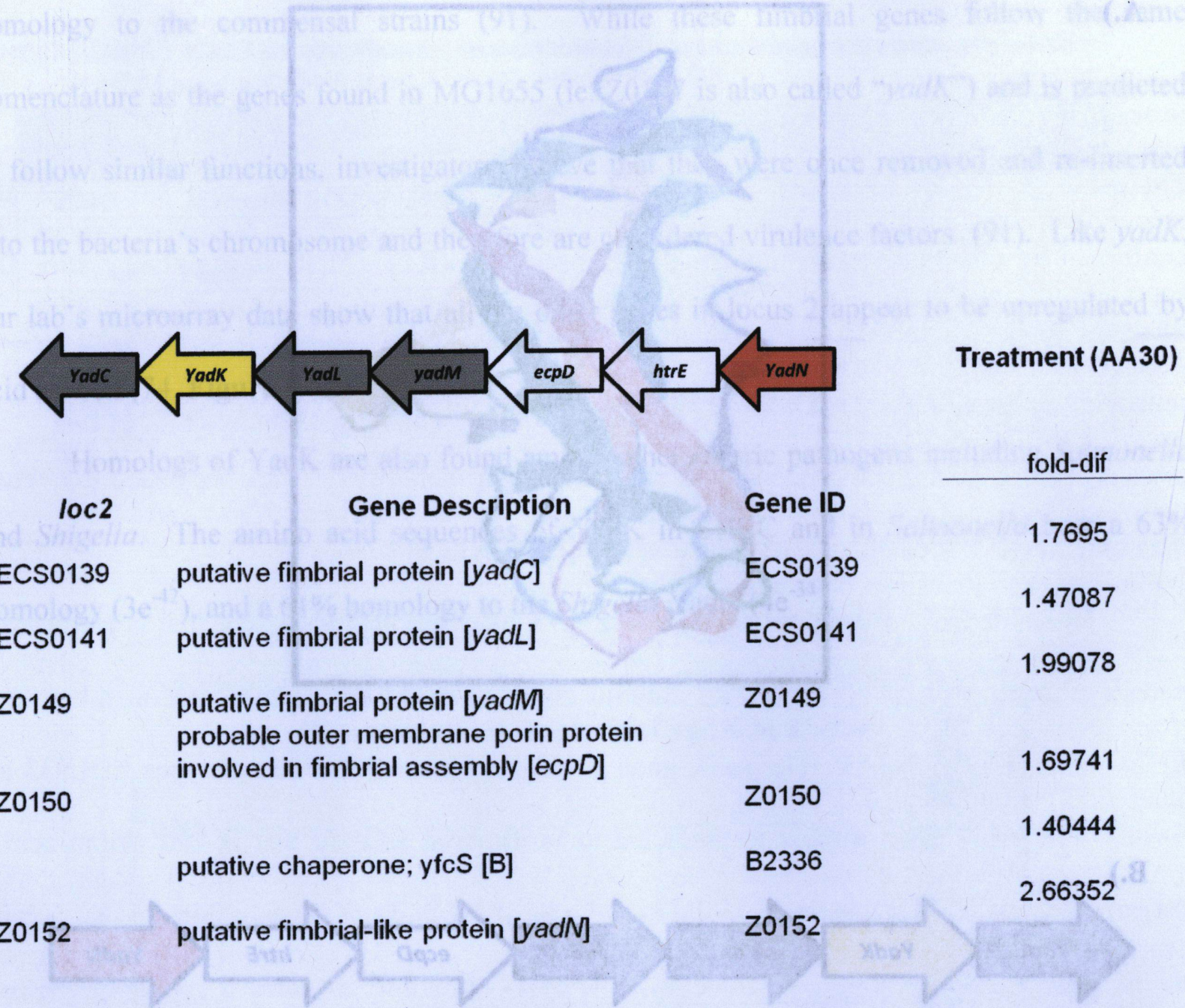

Figure 1.7 Transcriptional Expression of other Genes in locus 2 after Acid Adaptation and Acid Stress. Microarray analysis indicate that other genes in locus 2 are expressed positively after acid stress. (74) 


\section{Chaperone-Usher Mediated Biochemical Synthesis of the locus 2 Operon}

The biogenesis of most surface-exposed fimbriated adhesins is often mediated by the chaperone-usher pathway that is universally conserved among Gram-negative bacteria including EHEC (92). These gene clusters are usually genetically organized in the same arrangement and encode two key functional proteins: an usher and a chaperone. These proteins are especially important in the biogenesis and assembly of the final fimbrial structure (93). The mechanisms that follow chaperone-usher biogenesis are reviewed by Capitani, et al., (93) (Figure 1.8); briefly, pre-fimbrial proteins bearing N-terminal signal peptides destined for fimbrial assembly are synthesized in the cytoplasm are transported to the periplasm. The proteins are translocated through a type II secretion system.

Once in the periplasm, chaperones assist in the proper folding of these pre-fimbrial proteins. Crystal structures of type 1 and P-fimbrial pilins strongly indicate that pre-fimbrial subunit bear an immunoglobulin-like (Ig) structure composed of anti-parallel $\beta$-sheet ( $\beta$ A to $\beta F$ ) strands that form a flat barrel, with $\beta \mathrm{F}$ at the $\mathrm{C}$-terminal end and $10-18$ residues called the $\mathrm{N}$ terminal extension (92). The pre-fimbrial structure lacks a final $\beta$-strand $(\beta G)$, creating a hydrophobic groove within the protein that renders its Ig-fold incomplete. Because of this, thepre-fimbrial subunit remains unstable without the folding assistant of the boomerang-shaped chaperone. Chaperone N-terminal domains contain G1- $\beta$ donor strand that when in contact with pre-fimbrials, completes a stable Ig-fold. Chaperones also contain a conserved residues that anchor the C-terminal of pre-fimbrial subunits to guarantee the proper orientation of the fimbrial proteins in the fimbrial stalk $(92,93)$.

During polymerization of the fimbrial stalk, the pre-fimbrial protein is pushed to the cell surface from the membrane porin, usher, through donor-strand exchange. Polymerization occurs 


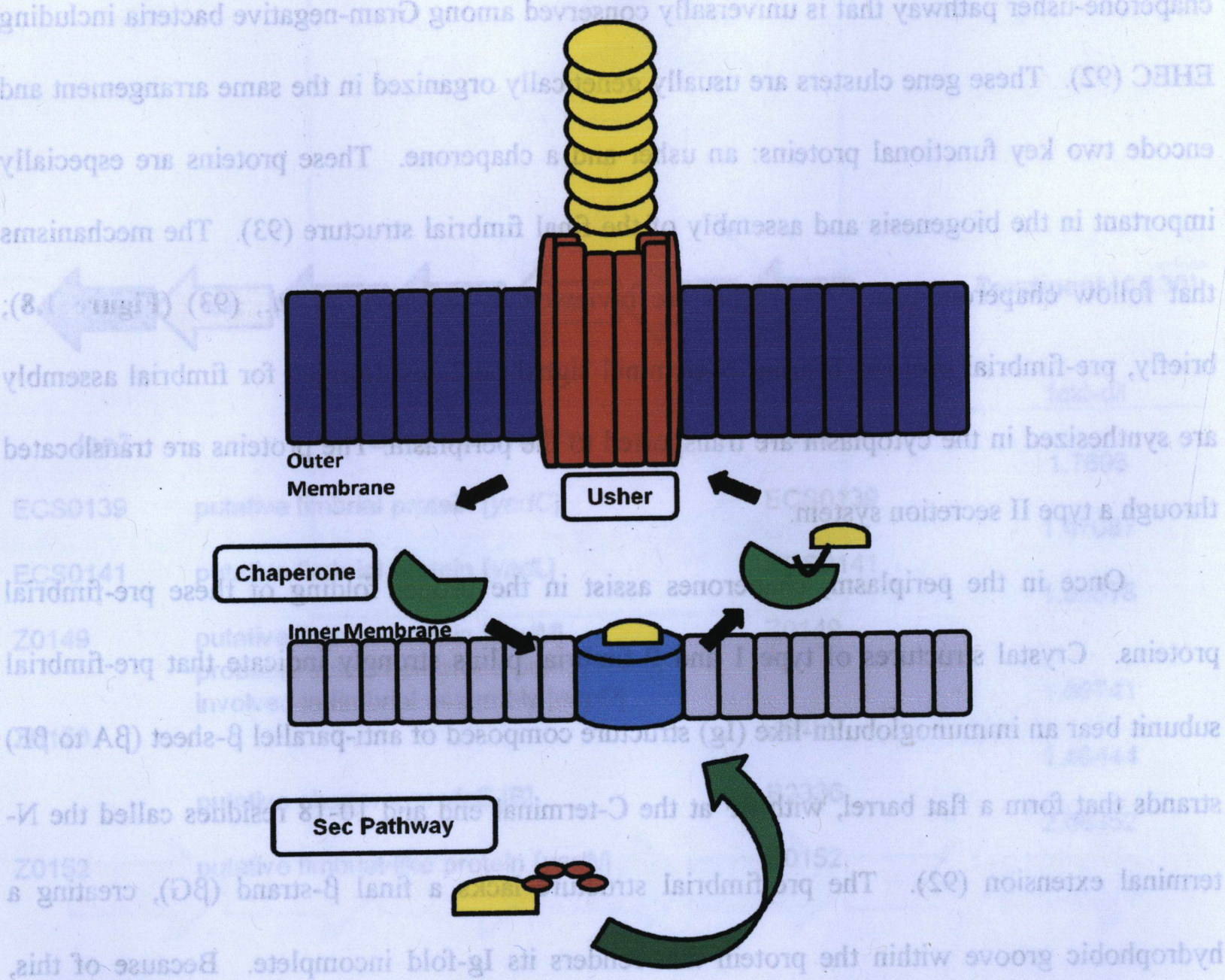

Figure 1.8 The chaperone-usher mechanism illustrates the biosynthesis of fimbrial adhesins like type-1 fimbriae. The key factors in this mechanism include a boomerang-shaped chaperone protein (green) that assist in the folding of pre-fimbrial subunits and a membrane porin usher (red) that guides the translocation and assembly of the prefumbrial subunits to the fimbrial stalk (yellow). Adapted from (88).

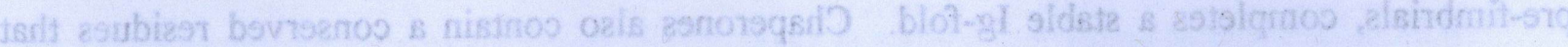

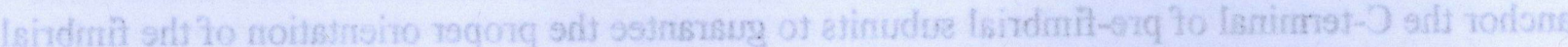

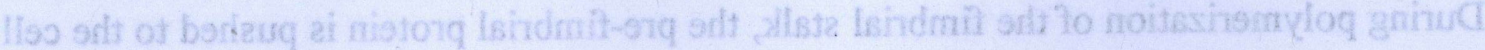


without the hydrolysis of ATP or electrochemical gradients (94). Instead, donor-strand exchange drives the assembly forward: once the pre-fimbrials are brought by the chaperone to the usher, the pre-pilins are released (95). The N-terminal extension of incoming pre-fimbrial fibers are inserted in the hydrophobic groove in an anti-parallel fashion to $\beta \mathrm{F}$. The $\mathrm{N}$-terminal extension replaces the G1-b donor and completes a stable Ig-fold. Donor strand exchange occurs at the outer membrane of the usher at a time-efficient manner an allows the continuous polymerization of the fimbrial stalk (96). The location of fimbrial subunit genes in their respective fimbrial clusters defines stoichiometric concentrations of the expressed fimbrial adhesins; Fimbrial genes closer to the promoter are expressed at higher concentrations that genes further downstream ( 97 , 98).

Protein fold recognition server (PHYRE) reveals a 100\% homology between the predicted tertiary structures of YadK to the NMR structure of E. coli type 1 fimbria subunit FimF (99). Though there is no empirical evidence of the YadK structure, protein prediction software strongly indicates that the protein is structurally composed of anti-parallel $\beta$-sheets. The predicted fold-structure of YadK also suggests that it bears a domain that likely interacts with the chaperone-usher proteins in a chaperone-usher mediated assembly pathway. BLASTP analysis also shows that YadK resembles known fimbrial proteins that follow the usher-chaperone pathway. The locus 2 gene cluster that $y a d K$ belongs to follows the same genetic organization as other chaperone-usher exported fimbriae (40) (Figure 1.9). ecpD and htre are predicted to be the chaperone and an usher of this operon respectively. If YadK follows a chaperone-usher biosynthesis, then it is likely exported to the periplasm by EcpD and translocated across the membrane by passing through HtrE. Once in the cell wall, YadK is assembled along the fimbrial 
shaft along with the other minor subunits, and either functions in cell adhesion or builds the fimbrial stalk. 
Type 1 Fimbriae
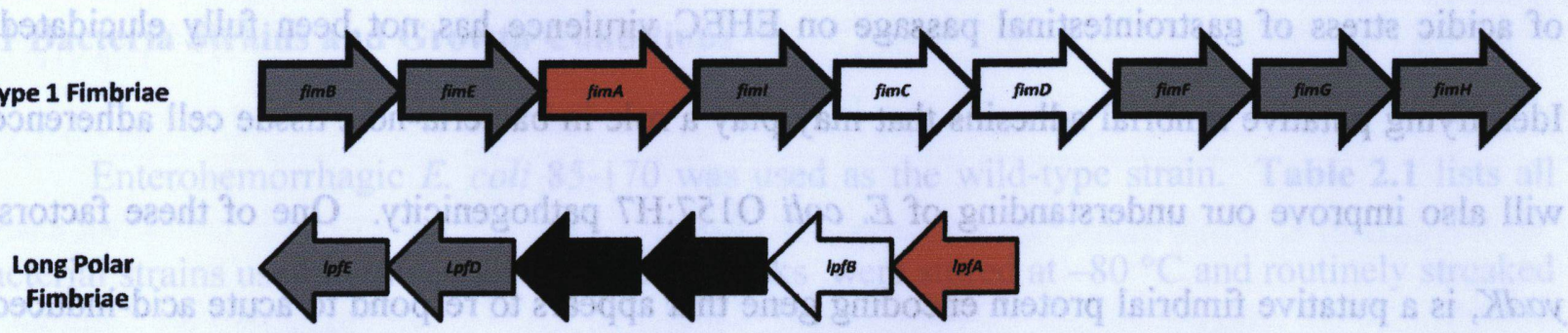

Curli

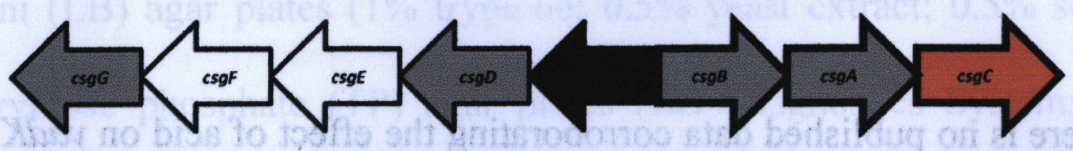

locus 2

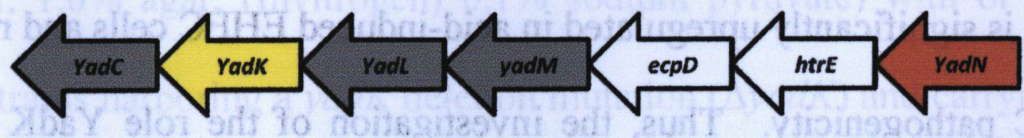

Figure 1.9 The genetic organization of $y a d K$ in locus 2 is similar to the genetic organization of other fimbrial loci that follow the chaperone-usher biosynthetic pathway. The protein EcpD resembles a chaperone protein whereas HtrE is predicted to be an usher. The YadK fimbrial protein (yellow) is predicted to be a minor fimbrial subunit in the entire locus. White filled arrows denote fimbrial usher-chaperone proteins; Red filled arrows denote major subunit. Arrows not drawn to scale. Adapted from (41). 


\subsection{Purpose of Investigation}

While the mechanisms of EHEC pathogenicity have been extremely studied, the impact of acidic stress of gastrointestinal passage on EHEC virulence has not been fully elucidated. Identifying putative fimbrial adhesins that may play a role in bacteria-host tissue cell adherence will also improve our understanding of $E$. coli $0157: \mathrm{H} 7$ pathogenicity. One of these factors, $y a d K$, is a putative fimbrial protein encoding gene that appears to respond to acute acid-induced EHEC.

While there is no published data corroborating the effect of acid on yadK expression, our lab has shown that it is significantly upregulated in acid-induced EHEC cells and raises questions of its role in EHEC pathogenicity. Thus, the investigation of the role YadK plays in acidinduced adhesion of EHEC 0157:H7 is important in improving our understanding of EHEC pathogenicity.

\subsection{Thesis Objectives}

I: To construction of a $\triangle y a d K$ mutant in EHEC 0157:H7.

In order to identify the role of the putative fimbrial protein gene yadK in EHEC pathogenesis, a yadK mutant in $85-170$ background must be constructed.

II: To characterize the adhesive properties of $\Delta y a d K$ mutant.

The adhesin properties of a $\Delta y a d K$ mutant will be assessed during both unadapted/unstressed and acid adapted/acid stressed treatments. 


\section{Materials and Methods}

\subsection{Bacteria Strains and Growth Conditions}

Enterohemorrhagic E. coli $85-170$ was used as the wild-type strain. Table 2.1 lists all bacterial strains used in this study. Glycerol stocks were stored at $-80^{\circ} \mathrm{C}$ and routinely streaked onto Luria-Bertani (LB) agar plates ( $1 \%$ tryptone; $0.5 \%$ yeast extract; $0.5 \%$ sodium chloride; $1.5 \%$ agar) or tryptose phosphate (TP) agar plates (BD Diagnostics System; $1.5 \%$ tryptose phosphate broth; $1.0 \%$ agar; (Invitrogen) $0.1 \%$ sodium pyruvate) with or without antibiotics. EHEC 85-170 strains harboring a $y a d K$ deletion mutation ( $\triangle y a d K$ ) and carrying the $\lambda$-red vector pKD46 (85-170(pKD46)) were grown with $100 \mu \mathrm{g} / \mathrm{mL}$ of kanamycin and $100 \mu \mathrm{g} / \mathrm{mL}$ ampicillan, respectively. Broth cultures for all the strains were prepared by inoculating one single isolated colony into $10 \mathrm{~mL}$ of $\mathrm{LB}$ broth or TP broth (with or without antibiotics) and incubated aerobically at $37{ }^{\circ} \mathrm{C}$ for $16-18 \mathrm{~h}$ with agitation. Plate cultures were maintained at $4{ }^{\circ} \mathrm{C}$ for $2-4$ weeks.

\subsection{Cell Culture}

Human colonic adenocarcinoma cells $(\mathrm{CaCo} 2)$ were obtained from the American Type Culture Collection (ATCC) and used in various adhesion assays. ATCC growth and cell maintenance guidelines were adapted for the preservation of the human cells. Frozen stocks of $\mathrm{CaCo} 2$ cells were grown in Minimal Essential Media 1x Eagle's (MEM) (Wisent; with Earle's salts and L-glutamine) supplemented with gentamycin $(20 \mu \mathrm{g} / \mathrm{mL})$ and $20 \%$ fetal bovine serum (FBS). $\mathrm{CaCo} 2$ cells were grown at $37{ }^{\circ} \mathrm{C}$ in air with $5 \%$ carbon dioxide $\left(\mathrm{CO}_{2}\right)$ and routinely fed with fresh media every 4 days. Passage of the cells was completed every 7 days. 
Table 2.1 List of strains used in this study.

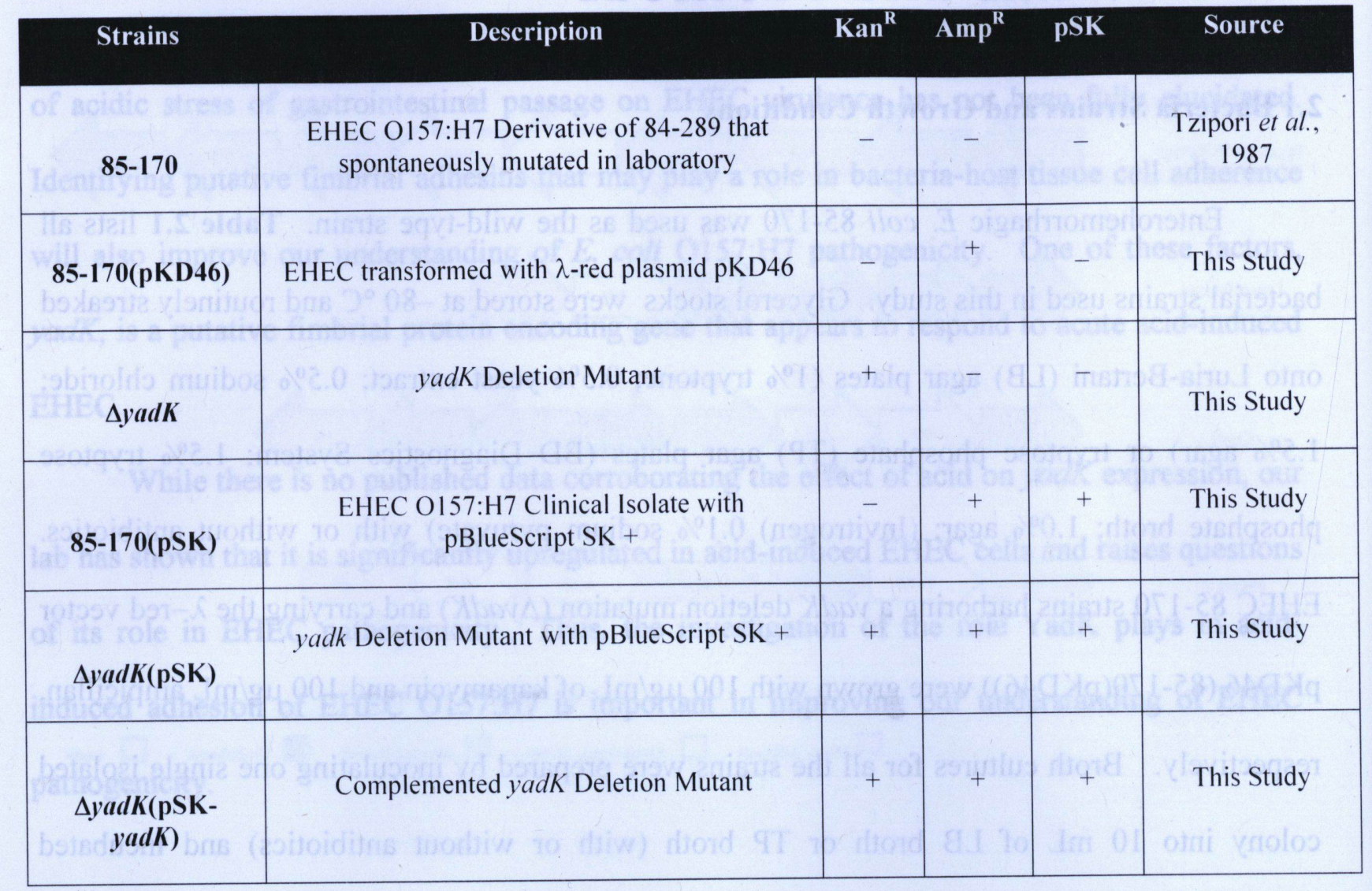




\subsection{Growth Assays}

A growth curve analysis was performed to assess the growth kinetics of each strain prior to the acid experiments. An overnight broth culture of each strain was prepared and grown at 37 ${ }^{\circ} \mathrm{C}$, with agitation. Twenty microliters of the overnight cultures were diluted into fresh $350 \mu \mathrm{L}$ media of either LB or Dulbelcco's Miminal Media (DMEM) (Wisent; 4.5g/L glucose, Lglutamine, sodium pyruvate, pH7.4). All of the diluted strains were loaded on a 96-well plate in triplicates and the growth kinetic experiment was performed in a microbiology workstation (Oy Growthcurves $\mathrm{Ab}$ Ltd.). The growth reading parameters included static incubation at $37^{\circ} \mathrm{C}$ with pre-shaking for $20 \mathrm{sec}$ before readings, and reading measurements for every $20 \mathrm{~min}$. The experiment was performed for a period of $16 \mathrm{~h}$ and statistically analyzed afterwards.

\subsection{PCR Analysis}

Polymerase chain reaction (PCR) was routinely used to amplify amplicons for Lambda Red Recombination and to screen for deletion mutants. Unless otherwise noted, all PCR reactions were performed using an HP Taq DNA Polymerase (UBI Bioinformatika), including the following reagents: $2.5 \mu \mathrm{L} 10 \mathrm{x}$ Taq reaction buffer, $5 \mu \mathrm{L}$ of $20 \mathrm{mM} \mathrm{MgSO} 4,0.25 \mu \mathrm{L}$ forward primer (final concentration of $10 \mathrm{mM}$ ), $0.25 \mu \mathrm{L}$ reverse primer (final concentration of 10 $\mathrm{mM}$ ), $2 \mu \mathrm{L} 10 \mathrm{mM}$ dNTP mix (Deoxynucleotide, UBI Bioinformatica Inc.) $0.5 \mu \mathrm{L}$ template, 0.5 $\mu \mathrm{L}$ of $5 \mathrm{u} / \mu \mathrm{L}$ Taq, and $16.5 \mu \mathrm{L}$ of sterile nuclease free water (Gibco). All PCR reactions were performed in a 96-well Biorad PCR machine. PCR products (10 uL) were resolved on 1\% agarose gels and visualized after ethidium bromide-staning under UV illumination. The primers used for this study are listed on Table 2.2. 
Table 2.2 Primers used for PCR in this study.

\begin{tabular}{|c|c|c|c|}
\hline $\begin{array}{l}\text { Primer } \\
\text { Name }\end{array}$ & Sequence $(5 '-3$ ') & ${ }^{\mathrm{T}} \mathrm{C}$ & $\begin{array}{l}\text { Target } \\
\text { Gene }\end{array}$ \\
\hline yadK_F I-Red Recombination & $\begin{array}{l}\text { 5'CTGTCAGGTTGAAGTCAGTAATAATGGCGTTG } \\
\text { TCGATCTCGTGTAGGCTGGAGCTGCTTC }{ }^{\prime}\end{array}$ & 77.1 & $\begin{array}{c}k^{k}{ }^{R} \text { cassette } \\
\mathrm{pKD} 4 / 85-170 \text { yadK }\end{array}$ \\
\hline vadK_R $\lambda$-Red Recombination & $\begin{array}{l}\text { 5'GGTGCTACCGAATAAATTGCTGTTGAGGAACC } \\
\text { ATCCGTTCATGGGAATTAGCCATGGTCC 3' }\end{array}$ & 76.4 & $\begin{array}{c}k a n^{R} \text { cassette } \\
\text { pKD4/85-170 yadK }\end{array}$ \\
\hline yadK-forward & 5'GGCATCATAAAATCGTAC 3 & 45.6 & 85-170 yadK \\
\hline yadK-reverse & 5'AACAATAACCTGGCTTCT 3 & 45.6 & $85-170$ yadK \\
\hline kan-forward & 5'TGTAGGCTGGAGCTGCTTC 3 & 55.3 & $\begin{array}{c}k_{a n}{ }^{R} \text { cassette } \\
\text { pKD4 }\end{array}$ \\
\hline kan-reverse & 5'ATGGGAATTAGCCATGGTCC 3 & 53.8 & $\begin{array}{l}\mathrm{kan}^{R} \text { cassette } \\
\text { pKD4 }\end{array}$ \\
\hline $\begin{array}{l}\text { yadK-forward } \\
\quad \text { Sacll }\end{array}$ & $\begin{array}{l}\text { 5'AACCGCGGAAGGATATTAGAATGCTATGC } \\
\text { AGGCATCTAA 3' }\end{array}$ & 66.9 & $\begin{array}{l}85-170 \text { yadK } \\
\text { SacII RE Site }\end{array}$ \\
\hline $\begin{array}{l}\text { yadK-reverse } \\
\text { BamHI }\end{array}$ & 5'TTGGATCCTATTATTCGTAAGATACGTAT 3' & 56.2 & $\begin{array}{l}\text { 85-170 yadK/ BamHI } \\
\text { RE Site }\end{array}$ \\
\hline yadC-F & 5'TTAGTCTGGCGTCACAAATG 3' & 58.0 & $\begin{array}{c}\text { RT-PCR } \\
85-170 \text { yadC }\end{array}$ \\
\hline $\operatorname{yad} C-\mathrm{R}$ & 5'TCTGGGTGCTTGGTATGAAG 3 & 60.0 & $\begin{array}{c}\text { RT-PCR } \\
85-170 \text { yadC }\end{array}$ \\
\hline yadK-F-RTPCR & 5'TGGTCTCTTGCGATAACATTC 3 & 60.0 & $\begin{array}{l}\text { RT-PCR } \\
85-170 \text { yadK }\end{array}$ \\
\hline yadK-R-RTPCR & 5'TGAGGGAACAGCATTGCCAG 3', & 62 & $\begin{array}{c}\text { RT-PCR } \\
85-170 \text { yadK }\end{array}$ \\
\hline gapA_F-jkl & 5'AAAGGCGCTAACTTCGACCA 3', & 51.8 & $\begin{array}{l}\text { RT PCR } \\
85-170 \text { gapA }\end{array}$ \\
\hline gapA_R-jk2 & 5'GCAGCTTTTTCCAGACGAAC 3' & 53.8 & $\begin{array}{l}\text { RT PCR } \\
85-170 \text { gapA }\end{array}$ \\
\hline
\end{tabular}




\subsection{Preparation of Chemically Competent Cells}

A single isolated colony of $85-170$ strain was inoculated in to fresh LB broth and grown overnight at $37^{\circ} \mathrm{C}$ with agitation. The overnight culture was diluted 100 fold into fresh LB and re-cultured at $37^{\circ} \mathrm{C}$ with agitation until optical density (OD600) reached approximately 0.4 . The cells were briefly chilled on ice for $10 \mathrm{~min}$ and harvested at $4,000 \mathrm{xg}$ for $5 \mathrm{~min}$ at $4{ }^{\circ} \mathrm{C}$. The cells were resuspended with 1:4 volume $100 \mathrm{mM}$ iced-cold $\mathrm{MgCl}_{2}$ and chilled on ice for $5 \mathrm{~min}$. The cells were harvested as above and resuspended in 1:4 volume of iced-cold $100 \mathrm{mM} \mathrm{CaCl}$. The cells were chilled on ice for $20 \mathrm{~min}$, harvested as above and finally resuspended in 1:40 volume iced-cold $100 \mathrm{mM} \mathrm{CaCl}_{2}+15 \%$ glycerol. The cells were divided into $50 \mu \mathrm{L}$ aliquots in pre-chilled $1.5 \mathrm{~mL}$ microcentrifuge tubes (Axygen) and freeze-snapped in liquid nitrogen before being stored at $-80{ }^{\circ} \mathrm{C}$.

\subsection{Transformation of Chemically Competent 85-170}

Transformation of chemically competent $85-170$ cells with the plasmid pKD46 encoding the Lambda-Red Recombination proteins was adapted from One Shot Top10 Cloning protocol (Invitrogen). A $5 \mu \mathrm{L}$ aqliquot of pKD46 was added to $50 \mu \mathrm{L}$ of chemically competent $85-170$ cells. The mixture was cold shocked on ice for $30 \mathrm{~min}$, heat shocked at $42{ }^{\circ} \mathrm{C}$ for $30 \mathrm{~s}$ and resuspended with $150 \mu \mathrm{L}$ fresh LB. The cells were incubated for $1.5 \mathrm{~h}$ at room temperate, with agitation, and plated on LB agar supplemented with $100 \mu \mathrm{g} / \mathrm{mL}$ ampicillin for overnight growth at $30{ }^{\circ} \mathrm{C}$. Successful transformants were screened through replica-patch plating on fresh LB plates supplemented with $100 \mu \mathrm{g} / \mathrm{mL}$ ampicillin. The presence of pKD46 from clones that grew 
from the ampicillin plates was confirmed by plasmid extraction using a HiYield Plasmid Mini Kit (UBI Bioinformatica, Inc.).

\subsection{Preparation of Electrocompetent Cells}

Lambda $(\lambda)$ red recombination system is a novel molecular tool that aid in the partial or full inactivation of DNA fragments from bacteria chromosome through homologous recombination. Previous work on E. coli K-12 and O157:H7 strains demonstrate the efficacy of using $\lambda$ Red as a genetic device to knock out gene elements $(100,101)$. The $\lambda$ Red Recombination system encodes its own recombination functions exo (red $\alpha)$, bet (red $\beta)$ and gam that can be conveniently housed in a plasmid, temperature sensitive plasmid pKD46 (102). $\lambda$ exo functions to degrade one end of double stranded DNA at a $5^{\prime}$ to $3^{\prime}$ direction. It chews off mononucleotides from the 5 ' strand leaving behind a 3 ' overhang. This overhang provides a plausible space for single stranded, foreign DNA to base pair with the nicked genomic DNA upon recombination. The $\lambda$ beta recombinase stabilizes single stranded, foreign DNA and prevents its degradation. Beta also promotes the base pairing of single stranded, foreign DNA to its complementary genomic overhang. Finally, $\lambda$ gam binds to host RecBCD and inhibits host control over the recombination event (102).

Preparation of electrocompetent EHEC 85-170/pDK46 was adapted from Datsenko et al., and from the Molecular Cloning: A Laboratory Manual (100, 103). A single isolated colony of the bacteria was inoculated in to fresh $10 \mathrm{~mL} \mathrm{LB}$ broth containing $100 \mu \mathrm{g} / \mathrm{mL}$ ampicillin and grown overnight at $30{ }^{\circ} \mathrm{C}$ with agitation. Following overnight growth, the culture was diluted 100 fold and re-grown into fresh $\mathrm{LB}$ broth with $100 \mu \mathrm{g} / \mathrm{mL}$ ampicillin at $30^{\circ} \mathrm{C}$ with agitation. $\lambda$ Red system expression was induced with $1 \mathrm{mM}$ final concentration of L-arabinose and the 
bacteria was grown until an OD600 of 0.400 was reached. The cells were briefly chilled on ice for $15 \mathrm{~min}$ and harvested at $4000 \times \mathrm{g}$ for $15 \mathrm{~min}$ at $4^{\circ} \mathrm{C}$. The cell pellet was carefully resuspended in $1 / 2$ volume iced-cold sterile water and once again harvested by centrifugation. The pelleted cells were washed with $1 / 50$ volume of ice-cold sterile water and harvested as above. The cells were finally resuspended in $1 / 100$ volume of ice-cold $10 \%$ glycerol and aliquoted into $50 \mu \mathrm{L}$-volume in pre-chilled, sterile microcentrifuge tubes and kept at $-80{ }^{\circ} \mathrm{C}$ until used.

\subsection{Construction of the $y a d K$ Deletion Mutant}

The basic strategy is to replace a chromosomal sequence (gene to be inactivated) with a selectable antibiotic resistance cassette that is generated by PCR (Figure 2.1). In this procedure, recombination requires the phage $\lambda$ red recombinase, which is synthesized under the control of an inducible promoter on the easily curable low copy plasmid pKD46 $(100,101)$. A kanamycin resistance cassette was PCR amplified using primers with extensions that are homologous to the gene to be inactivated $(\mathrm{H} 1, \mathrm{H} 2)$. The resulting amplicon was introduced into competent EHEC carrying the $\lambda$ Red system and homologous recombination is used to facilitate gene replacement.

For this study, a kanamycin resistance cassette flanked by $20 \mathrm{nt}$ of homologous sequence to $y a d K$ gene was constructed by PCR using forward primer $y a d K \_F \lambda$-Red Recombination and reverse primer $y a d K \_$R- $\lambda$ Red Recombination (Table 2.2, Figure 2.1). The PCR cycle consisted of 1 min denaturation at $95^{\circ} \mathrm{C}$, followed by 30 cycles of $30 \mathrm{~min}$ at $95{ }^{\circ} \mathrm{C}, 45 \mathrm{~s}$ at $76{ }^{\circ} \mathrm{C}$ and 2.5 min at $72{ }^{\circ} \mathrm{C}$ with a final 7 min extension step at $72{ }^{\circ} \mathrm{C}$. PCR products $(10 \mathrm{uL})$ were resolved on $1 \%$ agarose gels and visualized after ethidium bromide-staning under UV illumination. The products were also purified using an Agarose Gel Extraction Kit (UBI Bioinformatica, Inc.), 
following manufacturer's instructions. The purified product was further precipitated at $-80{ }^{\circ} \mathrm{C}$ overnight. After precipitation the product centrifuged at $13000 \mathrm{rpm}$ for $15 \mathrm{~min}$ at $4{ }^{\circ} \mathrm{C}$ and was washed twice with $1 \mathrm{~mL} 70 \% \mathrm{EtOH}$ before being resuspended in a final of $2 \mu \mathrm{L}$ sterile, nuclease free $\mathrm{ddH}_{2} \mathrm{O}$. Fifty microliters of electrocompetent EHEC 85-170 cells carrying pKD46 were transformed by electroporation $(25 \mu \mathrm{F}, 200 \Omega)$ with $1 \mu \mathrm{L}$ of purified PCR product.

One milliliter of SOC ( $2 \%$ tryptone; $0.5 \%$ yeast extract; $0.05 \%$ sodium chloride; $1.0 \%$ $250 \mathrm{mM} \mathrm{KCl} ; 0.5 \%(\mathrm{v} / \mathrm{v}) 2 \mathrm{M} \mathrm{MgCl} 2 ; 2 \%(\mathrm{v} / \mathrm{v}) 20 \mathrm{mM}$ glucose) was added to the cells following electroporation. The cells were recovered at $37{ }^{\circ} \mathrm{C}, 220$ with agitation for $3 \mathrm{~h}$ and plated on LB agar plates supplemented with $100 \mu \mathrm{g} / \mathrm{mL}$ kanamycin for overnight incubation. Colonies that grew from the kanamycin agar plates were screened by re-patching onto fresh 100 $\mu \mathrm{g} / \mathrm{mL}$ kanamycin plates and re-grown at $37^{\circ} \mathrm{C}$, overnight. Successful mutants were verified for the correct insertion of the kanamycin resistance cassette in the yadK locus through PCR using $y a d K$ primers. Bands showing the correct insertion of kanamycin within the $y a d K$ locus were gel purified (UBI Bioinformatica, Inc.) and confirmed through DNA sequencing (ACGT Company, Toronto, ON). 


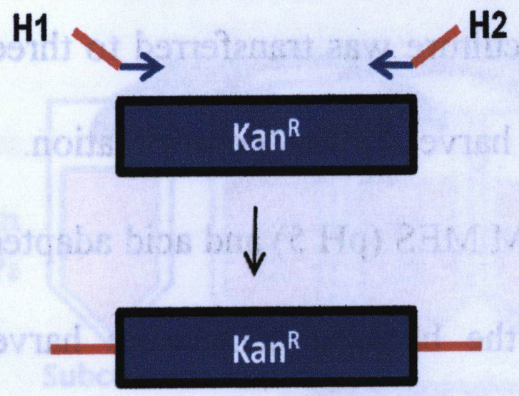

\section{Red Recombination}

$+$

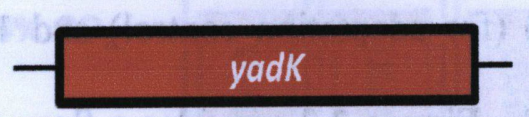

EHEC 0157:H7 strain 85-170

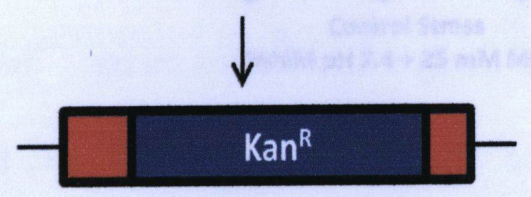

\section{Modified Chromosome}

Fig 2.1 Schematic of Lambda-Red promoted PCR-mediated recombination (96, 97). A kanamycin resistance cassette was PCR amplified with primers flanked by 20 nt homologous to regions within yadK (HI, H2). The resulting amplicon was introduced into 85-170 carrying pKD46. Red recombination was induced with L-arabinose and successful mutants were selected, screened and verified. 


\subsection{Acid Stress Treatment}

The acid treatment used for this study was adapted from DeJesus and coll. (68). A single isolated colony of 85-170 or 85-170 $4 y a d K$ was inoculated into $10 \mathrm{~mL} \mathrm{LB}$ broth (with or without $100 \mu \mathrm{g} / \mathrm{mL}$ kanamycin) at $37^{\circ} \mathrm{C}$ with agitation, and grown overnight. The culture was diluted 10 fold in DMEM (pH 7.4) and subcultured statically at $37^{\circ} \mathrm{C}$ with $5 \% \mathrm{CO}_{2}$, until OD600 of 0.4-0.6 was reached. Two milliliters of the subculture was transferred to three different sterile $15 \mathrm{~mL}$ flat cap centrifuge tubes (VWR) and harvested by centrifugation. The cell pellets were resuspended with $10 \mathrm{~mL}$ DMEM $+25 \mathrm{mM}$ MES (pH 5) and acid adapted statically at $37^{\circ} \mathrm{C}$ with $5 \% \mathrm{CO}_{2}$ for $1 \mathrm{~h}$. After adaptation, the bacteria cells were harvested by centrifugation, resuspended in $10 \mathrm{~mL}$ DMEM (pH 3) and acid shocked for 30 min at $37{ }^{\circ} \mathrm{C}$ with $5 \% \mathrm{CO}_{2}$. Unadapted, unshocked controls were also performed alongside acid stress treatment using $10 \mathrm{~mL}$ DMEM with $25 \mathrm{mM}$ MOPS (pH 7.4) (for adaptation control) and $10 \mathrm{~mL} \mathrm{DMEM}+25 \mathrm{mM}$ MOPs ( $\mathrm{pH} 7.4$ ), for acid shock control. Figure 2.2 provides a flow diagram of the acid stress treatment. 


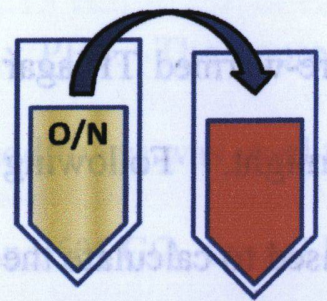

1.) Subculture $0 / \mathrm{n}$ in DMEM @ $37^{\circ} \mathrm{C}, 5 \% \mathrm{CO}_{2}$ $(0 D 600=0.4-0.6)$

\section{2.) Adapt for $1 \mathrm{~h}, 37^{\circ} \mathrm{C}, 5 \% \mathrm{CO}_{2}$}

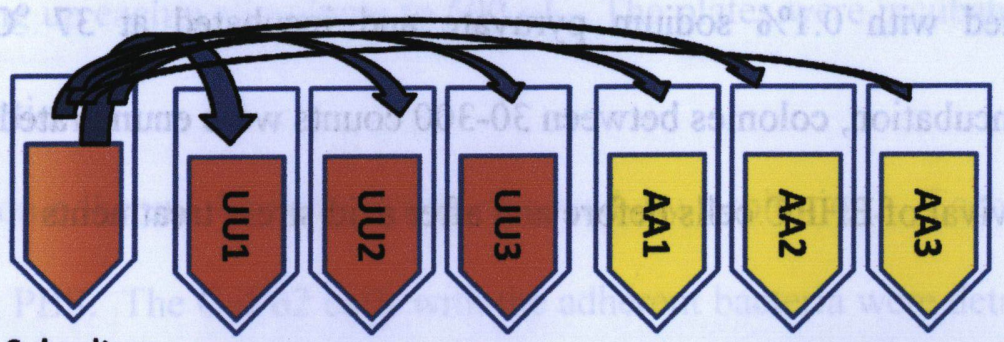

Subculture

Control Adaptation

Acid Adaptation DMEM pH $7.4+25$ mM MOPs DMEM pH $5.0+25$ mM MES

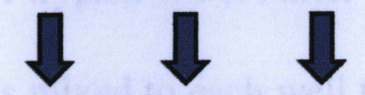

3.) Stress for $30^{\prime}, 37^{\circ} \mathrm{C}, 5 \% \mathrm{CO}_{2}$
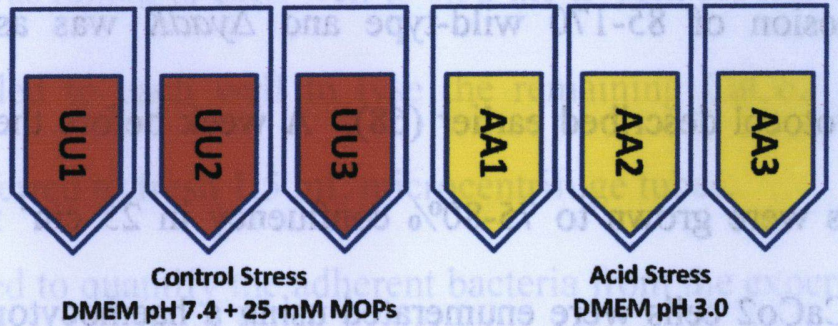

Fig 2.2 Scheme for acid treatment protocol. Overnight cultures of EHEC were prepared and re-cultured to mid-log phase. Both the acid stress treatment and control experiments were performed in triplicates. 


\subsection{Viability Assay Experiment}

The survival of 85-170 wild-type or $\Delta y a d K$ after acid stress treatment was assessed after each acid stress treatment experiment. Following acid treatment, $100 \mu \mathrm{L}$ of acid-induced bacteria was loaded into $900 \mu \mathrm{L} 1 \times$ PBS (PBS, Wisent without calcium and magnesium) and serially diluted. The dilutions $10^{-3}$ to $10^{-5}$ were plated in triplicates onto pre-warmed TP agar supplemented with $0.1 \%$ sodium pyruvate and incubated at $37{ }^{\circ} \mathrm{C}$ overnight. Following overnight incubation, colonies between $30-300$ counts were enumerated and used to calculate the percent survival of EHEC cells before and after acid stress treatments

\subsection{Bacteria-Cell Adhesion Assay}

Adhesion of $85-170$ wild-type and $\Delta y a d K$ was assessed using a bacteria-host-cell adhesion protocol described earlier (68). A week before the acid stress treatment experiment, $\mathrm{CaCo} 2$ cells were grown to $75-80 \%$ confluency in $25 \mathrm{~cm}^{2}$ flask. The day before acid stress treatment, $\mathrm{CaCo} 2$ cells were enumerated using a haemocytometer: briefly, $\mathrm{CaCo} 2$ cells were washed twice with 1x PBS and detached after the addition of $1 \mathrm{~mL}$ trypsin-EDTA (Wisent ; $0.25 \%$ trypsin; $1 \mathrm{mM}$ EDTA.4Na) and incubation at $37{ }^{\circ} \mathrm{C}$ with $5 \% \mathrm{CO}_{2}$ for $15 \mathrm{~min}$. The total cells in the flask were enumerated using a haemocytometer before being diluted into MEM (no additives) to reach a cell count of $2.5 \times 10^{5}$ cells (approximately $80 \%$ confluency). The cells were loaded into a 24-well flat bottom plates (BD Falcon) using $500 \mu \mathrm{L}$ aliquots per well. The cells are grown overnight at $37^{\circ} \mathrm{C}$ with $5 \% \mathrm{CO}_{2}$.

On the day of the acid stress experiment, $\mathrm{CaCo} 2$ cells were again enumerated and averaged to determine the total cell count. The averaged epithelial cell count was used in 
conjunction with the bacteria OD600 reading to determine the volume of bacteria to be loaded during infection. A multiplicity of infection (MOI) of 50-100 bacteria : $1 \mathrm{CaCo} 2$ cell was used for all experiments.

Media from each Caco2 cell well was carefully removed and cells were washed $3 \mathrm{x}$ with 1x PBS. The appropriate volume of bacteria cells was added to each well and MEM (without additives) was used to bring up each well volume to $500 \mu \mathrm{L}$. The plates were incubated at $37^{\circ} \mathrm{C}$ and $5 \% \mathrm{CO}_{2}$ for a $3 \mathrm{~h}$ infection.

After infection, non-adherent bacteria were removed by aspiration. Each well was washed five times with $1 \mathrm{x}$ PBS. The $\mathrm{CaCo} 2$ cells with the adherent bacteria were detached from the bottom of the well with $250 \mu \mathrm{L}$ of trypsin-EDTA after incubation at $37{ }^{\circ} \mathrm{C}$ with $5 \% \mathrm{CO}_{2}$ for 15 min. A $50-\mu \mathrm{L}$ volume of FBS was mixed to each well to stop the trypsin process and $700 \mu \mathrm{L}$ of iced-cold sterile water was added to each well to lyse the remaining $\mathrm{CaCo} 2$ cells. The remaining bacteria cells were transferred to fresh $1.5 \mathrm{~mL}$ microcentrifuge tubes.

Serial dilution was performed to quantify the adherent bacteria from the experiment. The dilutions were plated on TP agar containing $0.1 \%$ sodium pyruvate and incubated at $37{ }^{\circ} \mathrm{C}$ overnight. Following overnight growth, the plates were quantified and colonies between 30-300 counts were used for statistical analyses.

\subsection{2 byadK Mutant Complementation Experiment}

The full-length coding $y a d K$ gene was amplified by PCR with primers flanked by restriction enzymes BamHI and SacII (Table 2.1). The PRC reaction time included 1 mindenaturation at $95{ }^{\circ} \mathrm{C}, 30$ cycles of $45 \mathrm{~s}$ at $95{ }^{\circ} \mathrm{C}, 45 \mathrm{~s}$ at $60{ }^{\circ} \mathrm{C}, 1 \mathrm{~min}$ at $72{ }^{\circ} \mathrm{C}$, a final 
extension of $7 \mathrm{~min}$ at $72{ }^{\circ} \mathrm{C}$ with a hold time at $4{ }^{\circ} \mathrm{C}$. PCR products $(10 \mathrm{uL})$ were resolved on $1 \%$ agarose gel and visualized after ethidium bromide-staining under UV illumination.

The amplicon was then cloned into pCR2.1 and was used to transform chemically competent E. coli Topo10 cells using a TOPO TA Cloning Kit, following manufacturer's instructions (Invitrogen). Briefly, $4 \mu \mathrm{L}$ of fresh PCR product was mixed with $1 \mu \mathrm{L}$ salt solution, and $1 \mathrm{uL}$ of TOPO vector. The reaction mix was incubated at $22{ }^{\circ} \mathrm{C}$ for 5 minutes. Chemically competent TOP 10 cells were transformed with reaction mix following manufacturer's instruction (see above for protocol).

Following electroporation, the cells were plated on LB agar plates with $100 \mu \mathrm{g} / \mathrm{mL}$ ampicillin and $50 \mu \mathrm{L}$ of $20 \mathrm{mg} / \mathrm{mL}$ bromo-chloro-indolyl-galactopyranoside (X-Gal, Fermentas) for blue/white colony screening assay. White colonies were selected for patch plating and the plasmid carried by successful recombinant clones were purified using a HiYield Plasmid Mini Extraction Kit (UBI Bioinformatica, Inc.), following manufacturer's instructions.

A total of $26 \mu \mathrm{L}$ of plasmid pCR2.1 carrying the cloned yadK gene was digested with 1.5 $\mu \mathrm{L} 4000 \mathrm{u}$ of BamHI and $3 \mu \mathrm{L} \mathrm{1200u}$ of SacII (Fermentas) in a reaction mixture that included 3.4 $\mu \mathrm{L}$ buffer $\mathrm{G}$ and $0.6 \mu \mathrm{L}$ sterile, nuclease free $\mathrm{ddH}_{2} \mathrm{O}$ at $37^{\circ} \mathrm{C}$ for 1.5 hours. PCR products (10 uL) were resolved on $1 \%$ agarose gels and visualized after ethidium bromide-staning under UV illumination. A $30 \mu \mathrm{L}$ aliquot of the isopropyl $\beta$-D-1-thiogalactopyranoside (IPTG) inducible expression vector pBlueScript $\mathrm{SK}+(58)$ was also digested in this manner.

A Rapid DNA Ligation Kit (Fermentas) was used to complete the complementation experiment. A total of $10 \mu \mathrm{L}$ of the digested yadK insert was mixed with $1.35 \mu \mathrm{L}$ of digested pBlueScript SK+, $4 \mu \mathrm{L}$ of $5 \mathrm{x}$ rapid ligation buffer, $1 \mu \mathrm{L}$ of $5 \mathrm{u} / \mu \mathrm{L}$ T4 DNA ligase and $3.65 \mu \mathrm{L}$ sterile, nuclease-free $\mathrm{ddH}_{2} \mathrm{O}$ and the entire mixture was incubated at $22{ }^{\circ} \mathrm{C}$ for $5 \mathrm{~min}$. A total of 
$2 \mu \mathrm{L}$ of the ligation mix was used for chemical transformation (see above for protocol). Successful clones were screened using restriction enzyme digestion with BamHI and SacII and confirmed by DNA sequencing (ACGT Co., Toronto, ON).

\subsection{Induction of the complemented $y a d K$ in pBlueScript SK+}

The expression of any genes cloned into pBlueScript $\mathrm{SK}+$ is controlled by $\mathrm{T} 7$ promoter induced by IPTG (58). During the bacteria-cell host adhesion experiments, yadK expression in the complemented strain was induced with the addition of $1 \mathrm{mM}$ IPTG (Invitrogen) during the subculturing step.

For transcriptional analyses experiments (described below), the induction of $y a d K$ in the complemented strain was achieved by inoculating $1 \mathrm{~mL}$ of overnight culture into $8 \mathrm{~mL}$ of fresh DMEM with $1 \mathrm{mM}$ IPTG. The subculture was grown aerobically at $37{ }^{\circ} \mathrm{C}$ with agitation until an OD600 of 0.4-0.6 was reached.

\subsection{Total RNA Isolation}

Total RNA from $85-170(\mathrm{pSK}), \Delta y a d K(\mathrm{pSK})$ and $\Delta y a d K(\mathrm{pSK}-y a d K)$ strains were extracted to determine the expression of $y a d K$ and the downstream gene, yadC. Following IPTG induction (see above), bacterial strains were harvested by centrifugation and the pelleted cells were snap-frozen in liquid nitrogen and stored at $-80{ }^{\circ} \mathrm{C}$ until needed for the RNA extraction.

The frozen pellets were slowly thawed on ice and resuspended with $1 \mathrm{~mL}$ Trizol (Gibco, Life Technologies Inc.). The thawed bacteria-Trizol mixtures were quickly loaded onto cold lysis matrix B tubes (MP Biomedicals). The tubes were vigorously shaken in the Fast-Prep FP 120 cell disruptor for $45 \mathrm{~s}$ and chilled on ice for $5 \mathrm{~min}$. A $350-\mu \mathrm{L}$ volume of chloroform:isoamyl 
alcohol (24:1) was added to each tube to precipitate any proteins from the disrupted bacteria. The tubes were gently inverted for $15 \mathrm{~s}$, incubated at room temperature for $2 \mathrm{~min}$ and then centrifuged at $10,000 \times \mathrm{g}$ at $4^{\circ} \mathrm{C}$ for $15 \mathrm{~min}$. The upper aqueous layer of each tube was transferred to a new $1.5 \mathrm{~mL}$ microcentrifuge tube. Another volume of $350 \mu \mathrm{L}$ of chloroform:isoamyl alcohol $(24: 1)$ was added to the clear, aqueous layer. The tube was inverted gently and incubated at room temperature for $2 \mathrm{~min}$. Following centrifugation at $10,000 \mathrm{xg}$ at 4 ${ }^{\circ} \mathrm{C}$ for $15 \mathrm{~min}$, the upper aqueous layer of each tube was transferred to a new $1.5 \mathrm{~mL}$ microcentrifuge tube.

The remaining nucleic acid in each tube was precipitated with the addition of $350 \mu \mathrm{L}$ High Salt Solution (Molecular Research Centre) and $250 \mu \mathrm{L}$ of room temperature isopropanol $100 \%$ and incubated at $-20{ }^{\circ} \mathrm{C}$ from 15 min to overnight. After the precipitation step, all tubes were inverted several times and then centrifuged $10,000 \mathrm{xg}$ at $4{ }^{\circ} \mathrm{C}$ for $15 \mathrm{~min}$. The supernatant was aspirated and the pellets centrifuged for $5 \mathrm{~min}$, to remove any remaining liquid. The pellets were air dried for 10-15 min and mixed with $75 \mu \mathrm{L}$ of $1 \times$ RNA-secure (Ambion). The tubes were incubated at $65^{\circ} \mathrm{C}$ for $10 \mathrm{~min}$, with constant shaking to fully dissolve the RNA. The RNA concentration and integrity was measured spectrophotometrically and assessed with gel electrophoresis. The isolated RNA was either stored in $-80{ }^{\circ} \mathrm{C}$ or used immediately for further experiments.

\subsection{DNase Treatment}

DNase treatment of the purified RNA samples was performed using a TURBO DNA Free Kit (Ambion). A total of $44 \mu \mathrm{L}$ of purified RNA was incubated with $1 \mu \mathrm{L}$ of $2 u / \mu \mathrm{L}$ DNAse and 
$5 \mu \mathrm{L}$ of $10 \mathrm{x}$ Turbo DNAse buffer for 30 minutes at $37^{\circ} \mathrm{C}$. A $5 \mu \mathrm{L}$ volume of the DNAse Inactivation Reagent was added to the mixture to stop the reaction. The reaction mixture was centrifuged at $10,000 \times \mathrm{g}$ for $15 \mathrm{~min}$ and the treated RNA was transferred to a clean $1.5 \mathrm{~mL}$ microcentrifuge tube.

\subsection{6 cDNA Synthesis}

A qScript Flex Synthesis Kit (Ambion) was used to synthesize cDNA from purified RNA extracted from acid stress treated $85-170(\mathrm{pSK}), \Delta y a d K(\mathrm{pSK})$ and $\Delta y a d K(\mathrm{pSK}-y a d K)$ cells. Depending on the RNA concentration used, variable amount of DNAse treated RNA was mixed with a variable volume of nuclease free water and $2 \mu \mathrm{L}$ of $10 \mathrm{x}$ random primer to complete a 15 $\mu \mathrm{L}$ volume reaction. The reaction mixture was mixed by tapping, centrifuged for $5 \mathrm{~min}$ at $10,000 \mathrm{x} g$ at room temperature and incubated at $65{ }^{\circ} \mathrm{C}$ for 5 minutes. After incubation, the reaction was briefly chilled on ice.

Four microliters of $5 \mathrm{x}$ qScript Flex Reaction Mix and $1 \mu \mathrm{L}$ of qScript Flex Reverse Transcriptase were added to the chilled reaction mixture. The mixture was left to stand on ice for a few minutes before being vortexed and collected through centrifugation. cDNA synthesis was completed by incubating the mixture for $10 \mathrm{~min}$ at $25{ }^{\circ} \mathrm{C}, 45 \mathrm{~min}$ at $42{ }^{\circ} \mathrm{C}, 5 \mathrm{~min}$ at $85{ }^{\circ} \mathrm{C}$ and a final hold at $4{ }^{\circ} \mathrm{C}$.

\subsection{Semi-quantitative Reverse Transcriptase PCR (RT-PCR)}

The expression of $y a d K$ and $y a d C$ in the complemented $\Delta y a d K(\mathrm{pSK}-y a d K)$ background was confirmed through semi-quantitative reverse transcriptase PCR (RT-PCR). Forward yadK-F and reverse $y a d K$-R primers were used to amplify yadK while forward yadC-F and reverse $y a d C$ - 
R primers were used to amplify yadC. A $25 \mu \mathrm{L}$ PCR reaction mixture consisting of $2.5 \mu \mathrm{L} 10 \mathrm{x}$ PCR Buffer, $0.75 \mu \mathrm{L} 50 \mathrm{mM} \mathrm{MgCl} 2,0.5 \mu \mathrm{L} 10 \mathrm{mM}$ dNTPs, $0.15 \mu \mathrm{L} 100 \mu \mathrm{M}$ forward primer, $0.15 \mu \mathrm{L} 100 \mu \mathrm{M}$ reverse primer, $0.1 \mu \mathrm{L}$ AccuStart Taq polymerase (Quanta) and $20.85 \mu \mathrm{L}$ nuclease free $\mathrm{ddH}_{2} \mathrm{O}$. The reaction was incubated for 4 min at $94{ }^{\circ} \mathrm{C}$, followed by 30 cycles of $15 \mathrm{~s}$ at $94{ }^{\circ} \mathrm{C}, 30 \mathrm{~s}$ at $55{ }^{\circ} \mathrm{C}, 30 \mathrm{~s}$ at $72{ }^{\circ} \mathrm{C}$ and a final hold at $4{ }^{\circ} \mathrm{C}$. The housekeeping Dglyceraldehyde-3-phosphate dehydrogenase encoding GapA was used as a loading control for both reactions. 


\section{Results}

\subsection{Successful construction of the $y a d K$ insertional mutant using the $\lambda$-Red recombination system}

A yadK deletion mutant ( $($ yadK) was constructed using the Lambda Red Recombination system. Several hundred clones were screened for the insertion of a kanamycin resistance cassette into the yadK locus by colony PCR. Two sets of primers including one pair that targets the $y a d K$ gene and another against the kanamycin resistance gene were used to determine the correct integration of kanamycin in yadK locus. One successful recombinant was obtained (Figure 3.1). The $\Delta y a d K$ mutant (lanes 1, 11) produced an amplicon of $0.5 \mathrm{~kb}$ using the kanamycin resistance primers, indicating the successful insertion of kanamycin resistance cassette into the genome (lane 1). The same clone also produced an amplicon of $1.5 \mathrm{~kb}$ in size, confirming the integration of the antibiotic marker into the $y a d K$ locus (lane 11).

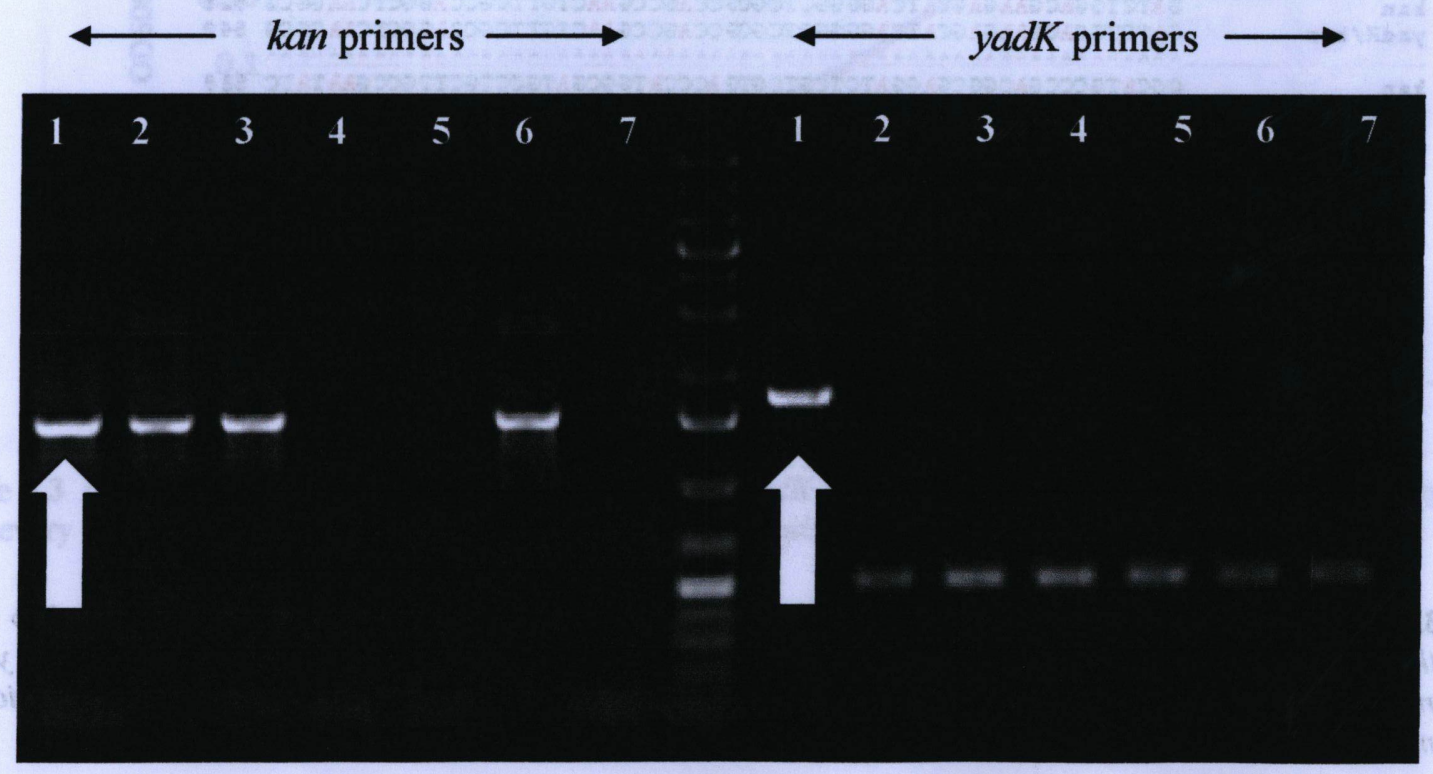

Figure 3.1 Screening of recombinant clones by PCR. PCR products amplified by kanamycin resistance cassette primers are $1.0 \mathrm{~kb}$ in size. PCR products amplified by $y a d K$ primers are $0.5 \mathrm{~kb}$ in size. The successful yadK mutant showed a PCR amplified product of $1.5 \mathrm{~kb}$. 


\subsection{Sequence confirmation of $\Delta y a d K$ mutant}

The successful insertion of the kanamycin-resistance cassette into the yadK locus of EHEC 85-170 was confirmed by DNA sequencing (Figure 3.2).

\begin{tabular}{|c|c|c|}
\hline adth/lan & 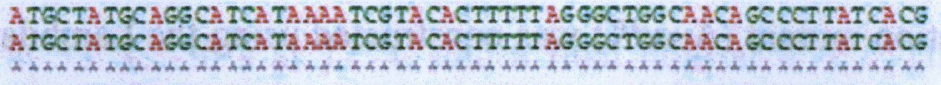 & 60 \\
\hline $\begin{array}{l}a d K \\
a d K / L a n\end{array}$ & 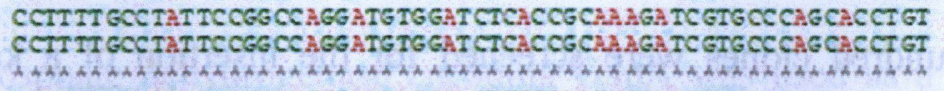 & $\begin{array}{l}120 \\
120\end{array}$ \\
\hline $\begin{array}{l}\text { ERT } \\
\text { YadR/kar }\end{array}$ & 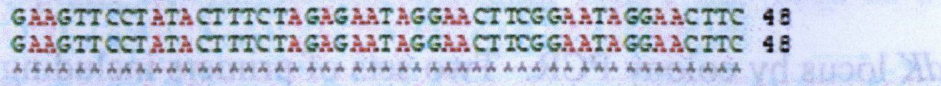 & \\
\hline $\begin{array}{l}\operatorname{lan} \\
\operatorname{ladR} / \operatorname{kan}\end{array}$ & 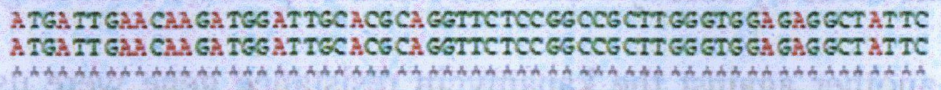 & $\begin{array}{l}60 \\
60\end{array}$ \\
\hline $\begin{array}{l}\text { kan } \\
\text { YadK/han }\end{array}$ & 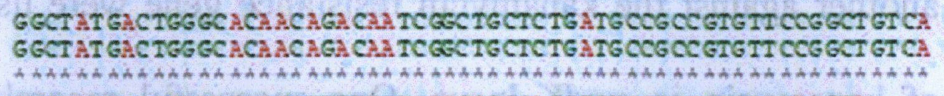 & $\begin{array}{l}120 \\
120\end{array}$ \\
\hline $\begin{array}{l}\text { ran } \\
\text { yadK/ran }\end{array}$ & 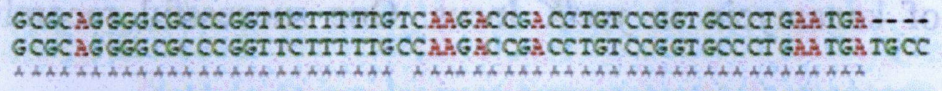 & $\begin{array}{l}176 \\
180\end{array}$ \\
\hline $\begin{array}{l}\text { kan } \\
\text { yadK/kan }\end{array}$ & 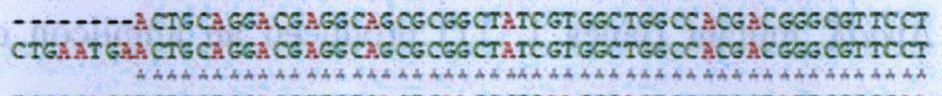 & $\begin{array}{l}228 \\
240\end{array}$ \\
\hline $\begin{array}{l}2 n \\
2 d x / \text { than }\end{array}$ & 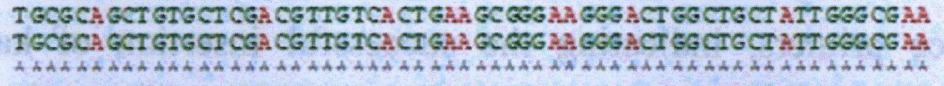 & $\begin{array}{l}2 \mathrm{~A} 8 \\
300\end{array}$ \\
\hline an & 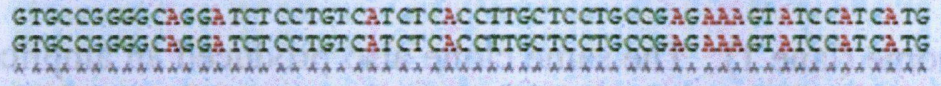 & $\begin{array}{l}348 \\
360\end{array}$ \\
\hline & 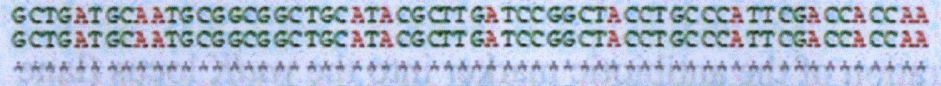 & \\
\hline $\begin{array}{l}\text { lan } \\
7^{2} d K / \operatorname{lan}\end{array}$ & 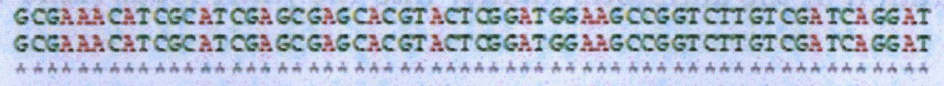 & $\begin{array}{l}468 \\
480\end{array}$ \\
\hline $\begin{array}{l}\text { kan } \\
\text { gadk/han }\end{array}$ & 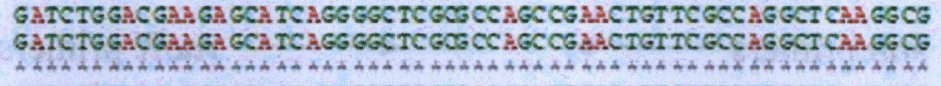 & $\begin{array}{l}528 \\
540\end{array}$ \\
\hline$k^{2 x} d x / k a n$ & 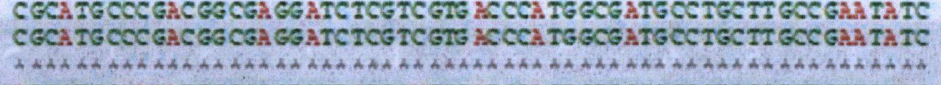 & 600 \\
\hline $\begin{array}{l}\text { kan } \\
\text { tadr/kan }\end{array}$ & 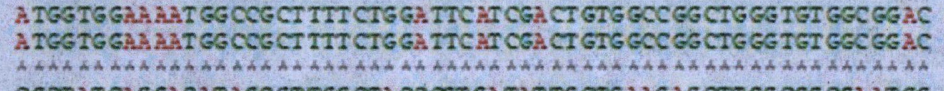 & $\begin{array}{l}648 \\
660\end{array}$ \\
\hline $\begin{array}{l}\text { lan } \\
\text { yadK/kan }\end{array}$ & 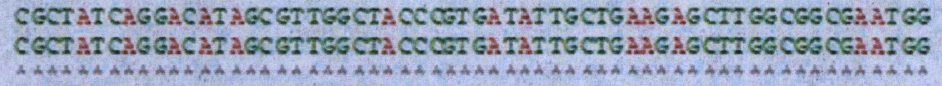 & $\begin{array}{l}708 \\
720\end{array}$ \\
\hline $\begin{array}{l}\text { kan } \\
y^{2} d x / k a n\end{array}$ & 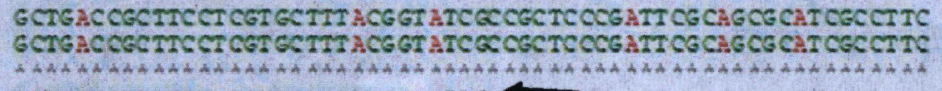 & $76 \mathrm{a}$ \\
\hline $\begin{array}{l}\text { kan } \\
\text { gadr/zan }\end{array}$ & 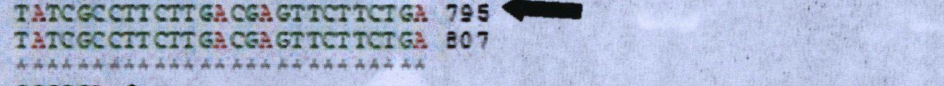 & \\
\hline 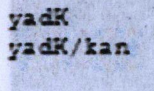 & $\begin{array}{l}\text { GCGGGS } 6 \\
\text { GCGGSA } 6 \\
+\operatorname{tath+}\end{array}$ & \\
\hline
\end{tabular}

Figure 3.2 The sequence confirmation of the $\Delta y a d K$ disrupted locus. Sequence has been modified to only include the disrupted yadK gene, the upstream FRT site and the inserted kan resistance cassette. yadK = yadK gene; kan = kan resistance cassette; yadk/kan = sequence from successful mutant. Arrows represent the insertion of the kanamycin resistance cassette. Sequence alignment by performed using ClustalLW (104). 
3.3 Growth kinetic analyses of 85-170 wild-type and $\Delta y a d K$ strains

A growth kinetics analysis was performed on the 85-170 wild-type and $\Delta y a d K$ mutant strains to establish that the insertion of the kanamycin resistance cassette did not affect the $\Delta y a d K$ mutant's growth rate. Both the $85-170$ and $\Delta y a d K$ doubled comparably for $180 \mathrm{~min}$ (Figure 3.2). Thus, any changes in adhesion levels observed from both strains are likely due to the mutation at the $y a d K$ locus and not because of incomparable growth ability due to the insertion of the kanamycin resistance casette.

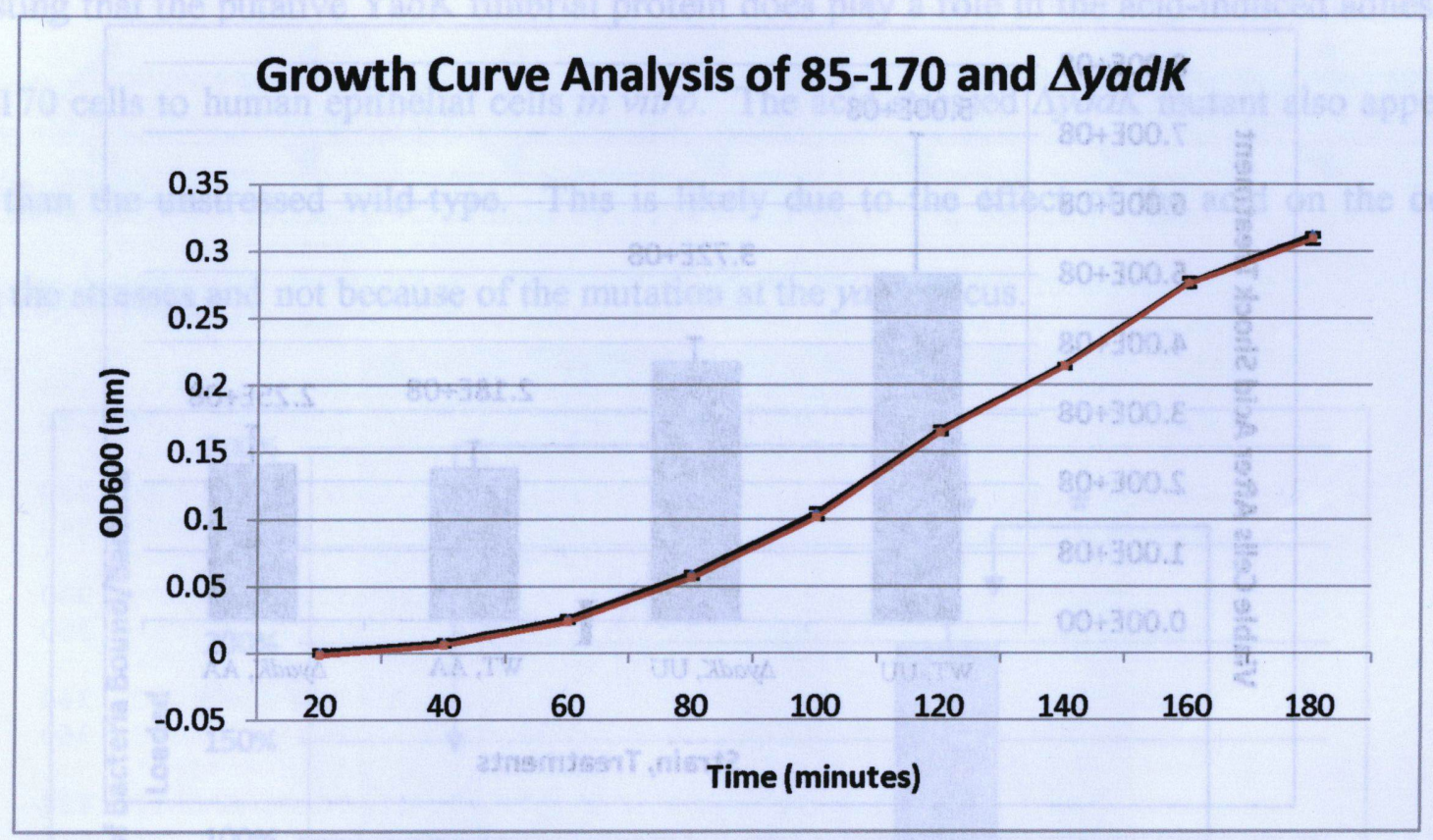

Figure 3.3 Growth kinetics of EHEC 85-170 (-) and $\triangle y a d K(-)$ in LB broth at $37^{\circ} \mathrm{C}$. OD600 readings were taken every $20 \mathrm{~min}$ to analyze growth rates of wild-type and yadK mutant strains. 


\subsection{Inactivation of yadK gene does not affect the survival of EHEC 85-170 under acid stress}

There was no significant difference between the viability of 85-170 wild-type strain and its $\Delta y a d K$ mutant during unadapted/unstressed (UU) acid stress conditions. Similarly, there was no significant difference between the viability of 85-170 wild-type strain and its $\Delta y a d K$ mutant after acid stress treatment (AA30). This strongly demonstrates that the disruption of yadK locus did not affect the ability of EHEC 85-170 strain to survive acid stress.

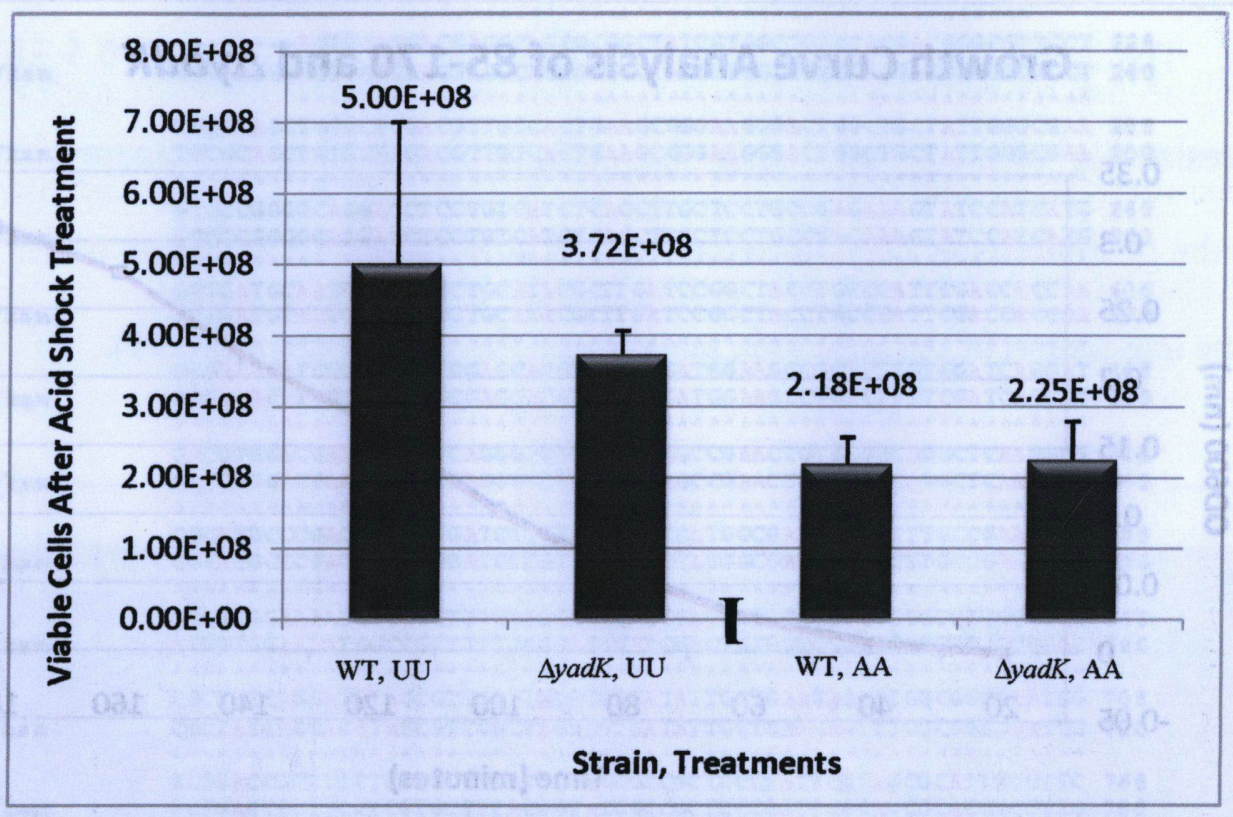

Figure 3.4 The viability of 85-170 wild-type and its $\Delta y$ adK mutant during unadapted, unstressed and during acid adapted, acid stressed conditions. The data represents the average of three independent trials $(n=3) . W T=$ wild-type, $\Delta y a d K-=\Delta y a d K$ mutant; $U U=$ unadapted/unstressed; $A A=$ acid adapted/acid stressed. 


\subsection{Putative fimbrial protein YadK is not involved in adhesion of unadapted/unstressed bacteria}

The adhesion of 85-170 wild-type and $\Delta y a d K$ mutant to $\mathrm{CaCo}$-cells were similar under unadapted/unstressed conditions. This suggested that the YadK protein does not appear to play a major role in bacterial-host cell adhesion in the absence of acid stress.

In contrast, the adhesion of the $\triangle y a d K$ mutant cells was significantly decreased compared to wild-type cells following acid stress treatment. There was a 10 -fold difference in adhesion levels between the acid treated 85-170 wild-type and the acid treated $\Delta y a d K$ mutant cells, suggesting that the putative YadK fimbrial protein does play a role in the acid-induced adhesion of 85-170 cells to human epithelial cells in vitro. The acid stressed $\Delta y a d K$ mutant also appears lower than the unstressed wild-type. This is likely due to the effect of the acid on the cells during the stresses and not because of the mutation at the $y$ adK locus.

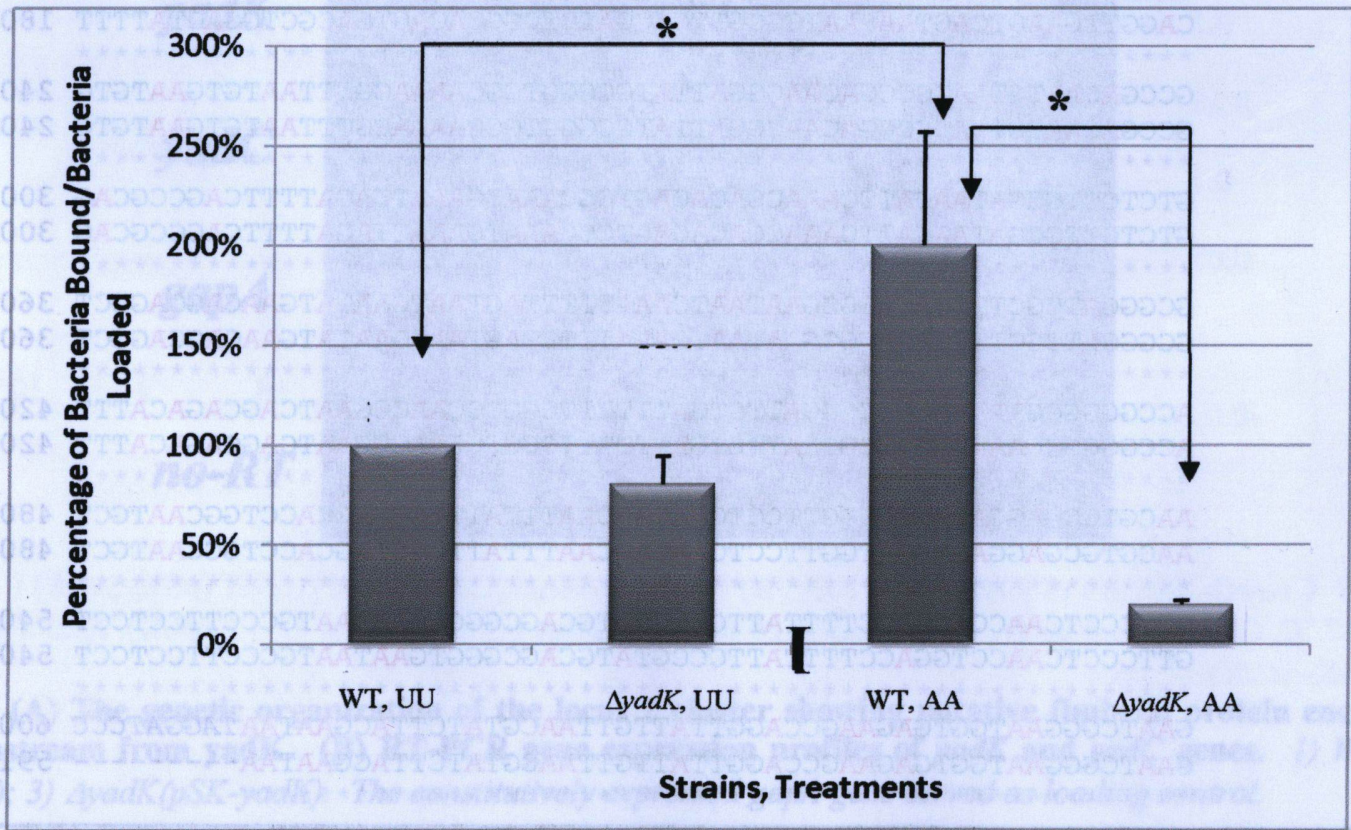

Figure 3.5 Adhesion was assessed and compared during a bacteria-host cell adhesion experiment. The data represents the mean of three independent trials \pm standard deviation $(n=3)$ with an MOI of 50-100. The adhesion to human epithelial cells has been normalized to the unadapted, unstressed treated wild-type. WT = wild-type; $\Delta y a d K$ $=\Delta y a d K$ mutant; $U U=$ unadapted/unstressed; $A A=$ acid adapted/acid stressed. $100 \%$ represents adhesion of 1.8 bacteria/Caco2 cell. ${ }^{*} P<0.05$. 


\subsection{Complementation experiment restores functional yadK gene in $\triangle y a d K$ mutant}

A complementation experiment was performed to restore the full-length coding yadK gene into the $\triangle y a d K$ deletion mutant. The full-length coding $y a d K$ gene was amplified by PCR and cloned into pBlueScript SK+ inducible expression vector. pBlue Script SK+ plasmid carrying the successfully cloned $y a d K$ in the complemented $\Delta y a d K$ strain ( $\Delta y a d K(p S K-y a d K))$ were purified and RE digested to confirm correct orientation. The full-length coding yadK gene cloned into pSK was confirmed through DNA sequencing. Its complete sequence was compared against the established $y a d K$ gene sequence found in EHEC EDL933 genome using ClustalW sequence alignment program (104).

$$
\begin{aligned}
& \text { comp } \\
& \text { yadK } \\
& \text { comp } \\
& \text { yadK } \\
& \text { comp } \\
& \text { yadK } \\
& \text { comp } \\
& \text { yadK } \\
& \text { comp } \\
& \text { yadK } \\
& \text { comp } \\
& \text { yadK } \\
& \text { comp } \\
& \text { yadK } \\
& \text { comp } \\
& \text { yadK } \\
& \text { comp } \\
& \text { yadK } \\
& \text { comp } \\
& \text { yadK }
\end{aligned}
$$

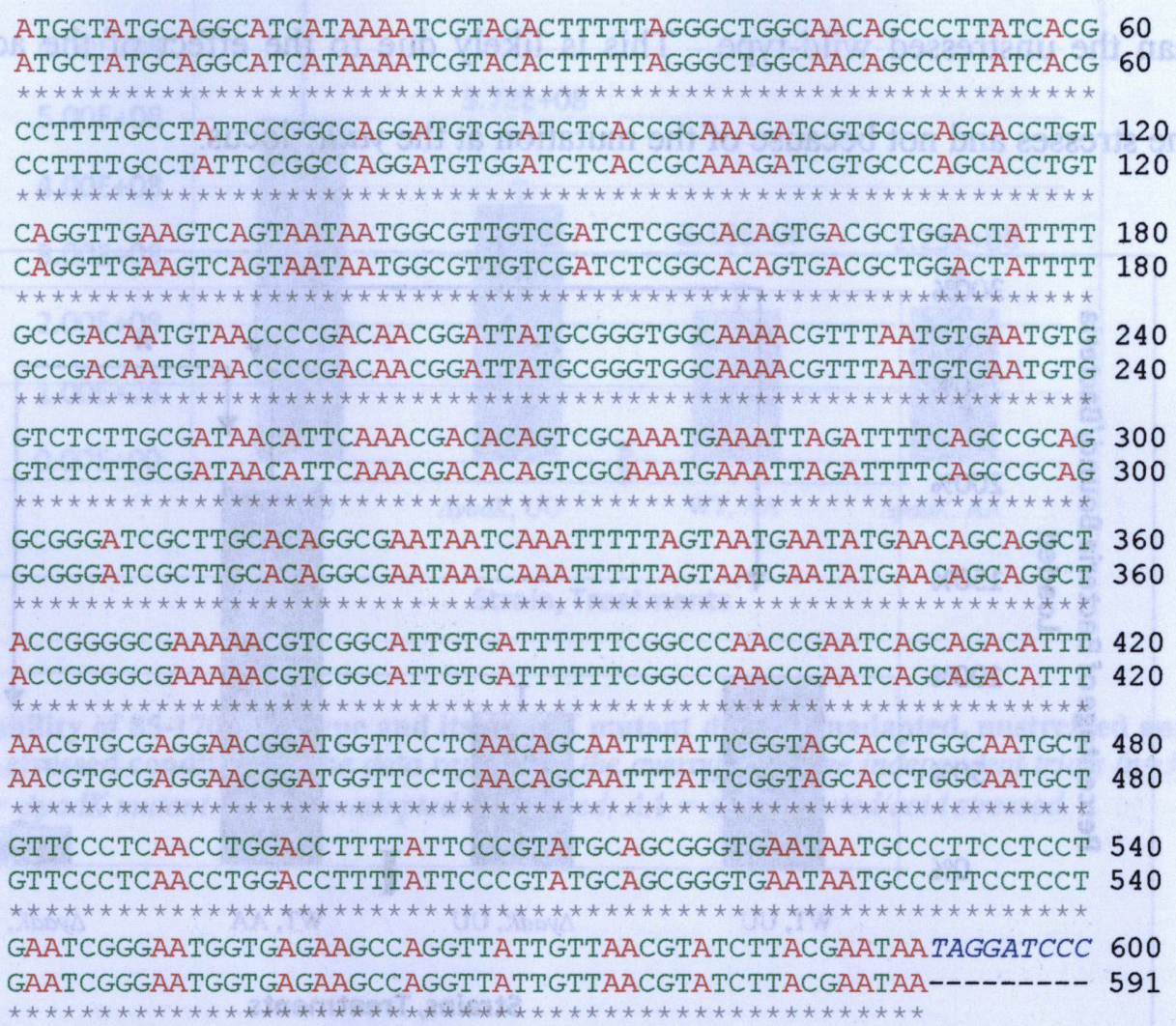

Figure 3.6 Sequence alignment between the wild-type yadK gene in EDL933 strain and the yadK gene cloned into the pBlueScript SK+ inducible expression vector. 


\section{7 $y a d K$ expression is confirmed in the $\Delta y a d K$ complemented strain, $\Delta y a d K(p S K-y a d K)$}

The expression of $y a d K$ in the complemented $\Delta y a d K(\mathrm{pSK}-y a d K)$ strain was confirmed by semi-quantitative RT-PCR analysis. A very faint band in the wild-type was also seen, confirming the expression of $y a d K$ in this strain. The $y a d K$ transcript was absent from the $\Delta y a d K$ mutant, confirming the disruption of the $y a d K$ locus.

The reading frame of the target gene and that of the kanamycin resistance gene (antibiotic selection marker) are aligned, preserving the original downstream reading frames in order to avoid polar effects.
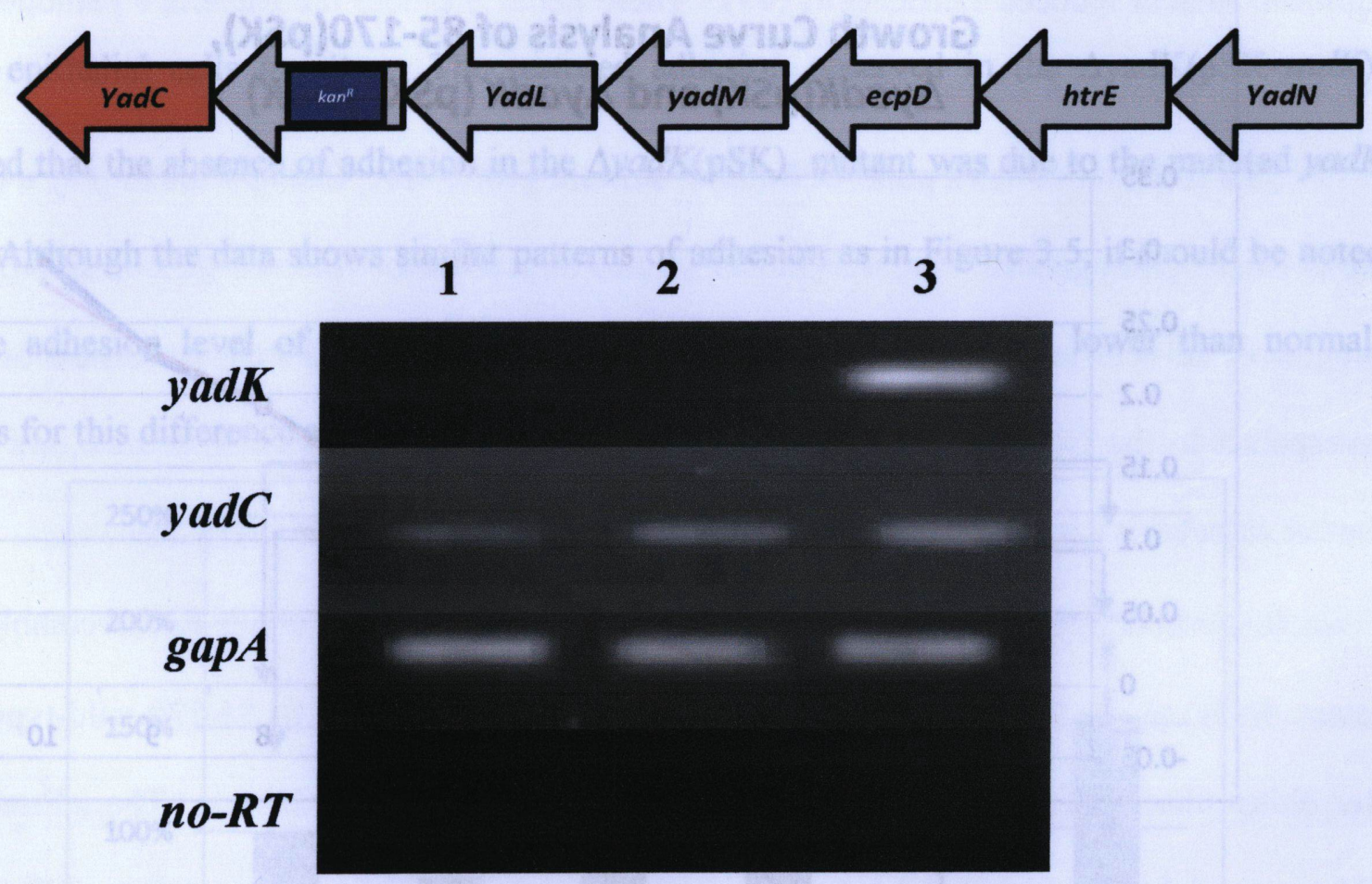

Figure 3.7 (A) The genetic organization of the locus 2 cluster showing putative fimbrial protein encoding gene yadC downstream from yadK. (B) RT-PCR gene expression profiles of yadK and yadC genes. 1) WT(pSK); 2) $\triangle y a d K(p S K) ; 3) \Delta y a d K(p S K-y a d K)$. The constitutively expressed gapA gene served as loading control. 


\subsection{Growth kinetic analyses $85-170(\mathrm{pSK})$ and $\triangle y a d K$ complemented strains}

The growth kinetics of $85-170(\mathrm{pSK})$ and $\Delta y a d K(\mathrm{pSK})$ and complemented $\Delta y a d K(\mathrm{pSK}$ yadK) strains were measured to confirm that all the strains grew comparably during the infection section of the study (180 min total). As before, all strains grew comparatively after $180 \mathrm{~min}$ of incubation, indicating that transformation with plasmid $\mathrm{pSK}+$ did not affect growth yield under the experimental conditions tested.

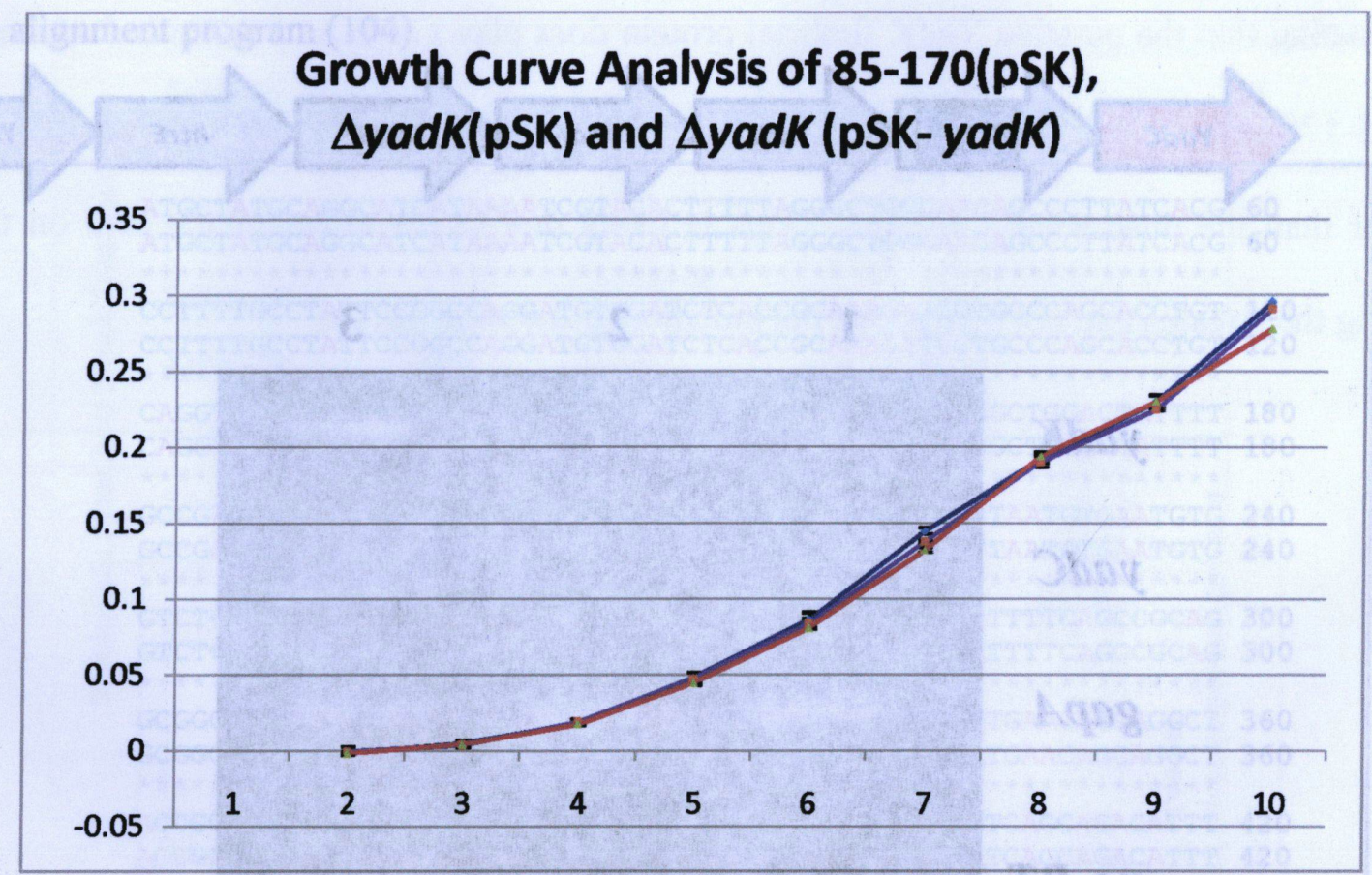

Figure 3.8 Growth kinetics of EHEC 85-170(pSK) (--), $\Delta y a d K(p S K)(---)$ and $\Delta y a d K$ (pSK-yadK) (--) in LB broth at $37^{\circ} \mathrm{C}$. OD600 readings were taken every $20 \mathrm{~min}$ to analyze growth rates of 85-170(pSK), $\Delta y a d K(\mathrm{pSK})$ and $\triangle y a d K(\mathrm{pSK}-$ yadK) strains. 


\subsection{Complemented strain behaves restores adhesion of acid-induced EHEC}

The adhesion of the $85-170(\mathrm{pSK})$ and $\Delta y a d K(\mathrm{pSK})$ and complemented $\Delta y a d K(\mathrm{pSK}-$ $y a d K)$ strains to $\mathrm{CaCo}-2$ human epithelial cells were similar under unadapted/unstressed conditions as in Figure 3.9. The adhesion of the unadapted/unstressed $85-170(\mathrm{pSK})$ and acid adapted/acid stressed $\Delta y a d K(\mathrm{pSK})$ to $\mathrm{CaCo}-2$ human epithelial cells were significantly different, as expected. An increase in acid-induced adhesion was observed among the acid stressed 85$170(\mathrm{pSK})$. This phenotype was absent in acid induced $\Delta y a d K(\mathrm{pSK})$ cells. Adhesion to CaCo-2 human epithelial cells was restored in the complemented $\Delta y a d K($ pSK-yadK). Once again, this reiterates that YadK plays a crucial role in the acid-induced adhesion of $85-170$ bacteria cells to human epithelial cells in vitro. The restored adhesion observed in the $\Delta y \operatorname{adK}(\mathrm{pSK}-\mathrm{yadK})$, indicated that the absence of adhesion in the $\Delta y a d K(\mathrm{pSK})$ mutant was due to the mutated $y a d K$ locus. Although the data shows similar patterns of adhesion as in Figure 3.5, it should be noted that the adhesion level of the strains transformed with pSK is slightly lower than normal.

Reasons for this difference are discussed in section 4.0. *

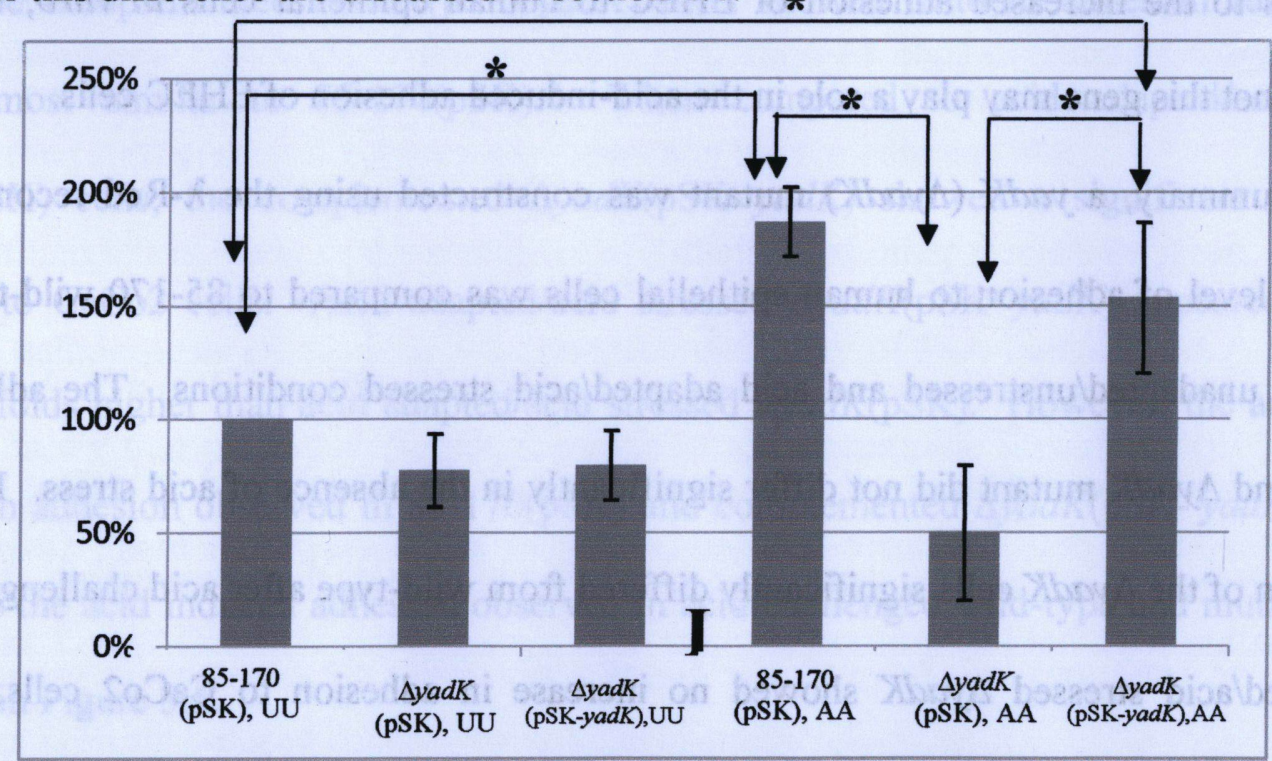

Figure 3.9 Adhesion was assessed and compared during a bacteria-host cell adhesion experiment. The data represents the mean of three independent trials \pm standard deviation $(n=3)$ with an MOI of 50-100. The adhesion to human epithelial cells has been normalized to the unadapted, unstressed treated wild-type. 85-170(pSK)=85-170 transformed with pSK; $\Delta y a d K(p S K)=\Delta y a d K$ mutant transformed with $p S K ; \Delta y a d K(p S K-y a d K)=$ complemented $\Delta y a d K$ mutant; $U U=$ unadapted/unstressed; $A A=$ acid adapted/acid stressed. $100 \%$ represents adhesion of 0.1 bacteria/Caco2 cell. ${ }^{*} P<0.05$. 


\section{Discussion}

Acidity is an important host barrier protection against disease-causing bacteria. Gastrointestinal pathogens must overcome the acute acid conditions of the stomach to be able to successfully colonize and cause illness in their victims. Several of these microorganisms including the major human pathogen enterohemorrhagic Escherichia coli $\mathrm{O157:H7}$, have developed ways to adapt and survive against acid stress. EHEC possesses several sophisticated acid-response systems that allows it to tolerate acid-challenged media in vitro and in vivo (72, $73,74)$. Whole genome transcriptional analyses also reveal that certain virulent genes are highly expressed in acid induced EHEC cells (69). These genes promote the bacteria's pathogenicity, including its adherence to host tissue cells.

This study identifies a putative fimbrial adhesin gene, $y a d K$, that appears to play a crucial role in EHEC pathogenesis. Transcriptional studies on yadK show that the gene is significantly upregulated in acid-induced EHEC strain 85-170 (69). The upregulated expression of yadK corresponds to the increased adhesion of EHEC to human epithelial cells in vitro, we asked whether or not this gene may play a role in the acid-induced adhesion of EHEC cells.

In summary, a yadK ( $(y \mathrm{yadK})$ mutant was constructed using the $\lambda$-Red recombination system. Its level of adhesion to human epithelial cells was compared to 85-170 wild-type cells after either unadapted/unstressed and acid adapted/acid stressed conditions. The adhesion of wild-type and $\triangle y a d K$ mutant did not differ significantly in the absence of acid stress. However, the adhesion of the $\Delta y a d K$ cells significantly differed from wild-type after acid challenge. While acid adapted/acid stressed $\Delta y a d K$ showed no increase in adhesion to $\mathrm{CaCo2}$ cells, its acid challenged wild-type cells counterpart adhered 2.5 -folds higher. 
To determine whether or not the decreased adhesion in the $\Delta y a d K$ was due to the disruption of the $y a d K$ locus, the $\Delta y a d K$ was complemented with the full-length, coding $y a d K$ gene. The adhesion phenotype of the $85-170(\mathrm{pSK}), \Delta y a d K(\mathrm{pSK})$ and $\triangle y a d K(\mathrm{pSK}-y a d K)$ show no significant difference under unadapted/unstressed conditions. As expected, an acid induced increased in adhesion on human epithelial cells was observed in $85-170(\mathrm{pSK})$ cells compared to $\Delta y a d K(\mathrm{pSK})$ after acid stress. Restoration of adhesion in $\Delta y a d K(\mathrm{pSK}-y a d K)$ cells were also observed during acid adapted/acid stressed experiments.

The complementation experiment revealed that the levels of adhesion exhibited by the $85-170(\mathrm{pSK}), \Delta y a d K(\mathrm{pSK})$ and $\Delta y a d K(\mathrm{pSK}-y a d K)$ strains differed from those of the 85-170 wild-type and $\triangle y a d K$ mutant after acid challenge (Figure 3.9). While 85-170(pSK) showed increased adhesion after acid adaptation/acid stress compared to acid adapted/acid stressed $\Delta y a d K(\mathrm{pSK})$ and even the unadapted/unstressed control, its levels of increased adhesion did not correspond to the original 2.5 -fold adhesion increase noted in wild-type $85-170$ cells.

The complemented $\Delta y a d K(\mathrm{pSK}-y a d K)$ cells showed restored adhesion function with levels almost similar to $85-170(\mathrm{pSK})$. When compared to acid adapted/acid stressed $\Delta y a d K(\mathrm{pSK})$ cells, the complemented $\Delta y a d K(\mathrm{pSK}-y a d K)$ showed a significant increase in adhesion to $\mathrm{CaCo} 2$ cells. Acid adapted/acid stressed $\Delta y a d K(\mathrm{pSK}-$ yadK) appeared to adhere

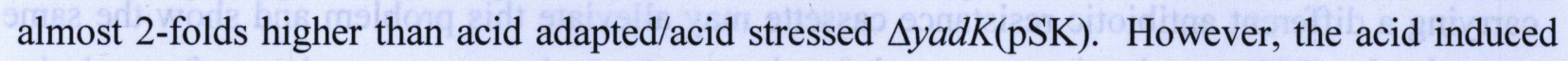
increase in adhesion observed in $85-170(\mathrm{pSK})$ and complemented $\Delta y a d K(\mathrm{pSK}-y a d K)$ were not as high as the acid induced adhesion observed in acid challenged wild-type and mutant cells, as observed in Figure 3.5 .

It is plausible that the inclusion of the cloning vector pBluescript $\mathrm{SK}+$ in the strains during the complementation experiments affected the bacteria at molecular level. Gallant et al., 
recently documented that common $\beta$-lactamases such as ampicillin affected proper cellular wall formation in Pseudomonas aeruginosa strains complemented with vectors containing $\beta$ lactamase resistance cassettes (105). B-lactamase works to prevent the degradation of the bacteria peptidoclycan wall from b-lactam class antibiotics such as ampicillin. One of its mode of action includes preventing the degradation of NAM and NAG linkage. In this study, investigators found that complementing Pseudomonas aeruginosa mutants with pUCP20, which encoded an ampicillin resistance marker TEM-1, disrupted the bacteria's ability to twitch, adhere to other bacteria and form biofilm communities. It is probable that the $\beta$-lactam resistant peptidoclyan may actually have an altered cellular organization therefore disrupt normal cell wall related activity including biofilm formation (105). The investigators propose that horizontal acquisition of $\beta$-lactam resistance including plasmid vectors may have some physical cost in the bacteria's survival including impaired cell wall function.

While the introduction of $\mathrm{pSK}+$ in the strains does not appear to affect the bacteria's growth rate or survival, it may influence the bacteria's adhesive properties. Since YadK is predicted to be part of a fimbrial operon that is presumably located in the cellular wall of EHEC, it is possible that the production of the $\beta$-lactamase from $\mathrm{pSK}+$ influences the adhesion of the cells in vitro. It is likely that cloning the full-coding $y a d K$ gene into a different expression vector carrying a different antibiotic resistance cassette may alleviate this problem and show the same level of increased acid induced adhesion as observed in acid challenged wild-type and mutant strains. While there is no molecular or empirical proof to support this presumption, the adhesion of all three 85-170(pSK), $\Delta y a d K(\mathrm{pSK})$ and $\Delta y a d K(\mathrm{pSK}-y a d K)$ did appear much lower compared to $85-170$ wild-type and $\triangle y a d K$ cells during the experiments during both unadapted/unstressed treatment (result not shown). 
YadK is predicted to be a fimbrial adhesin protein that is part of a fimbrial operon, locus 2 (40). The genetic organization of $y a d K$ in locus 2 resembles other chaperone-usher mediated fimbrial operons. The gene $y a d K$ has also been suggested as a virulent factor in pathogenic $E$. coli, as its insertion in EHEC genome differs from the location in commensal E. coli. However, in spite of the current knowledge on this gene, $y a d K$ or its adhesin product has never been identified before nor has it been implicated in bacteria-host cell adhesion. Regardless, the knowledge that a putative fimbrial protein in pathogenic $E$. coli can respond positively towards acid stimuli considerably broadens our understanding of both environmental and genetic factors that promote its virulence.

The pH 6 antigen encoding gene ( $p s a)$ in pneumonic causing plague, Yersinia pestis, has been strongly investigated as an acid-induced virulence factor that promotes adhesion of $Y$. pestis on human resipiratory tract epithelial cells in vitro (106). Investigators identified this chromosomally encoded fimbrial surface protein during transcriptional studies performed on several Yersinia serotypes (reviewed in 107). The gene encoding PsA is expressed maximally in acidic environments, particularly during the acidification of phagolysosomes. psA transcripts were observed strongest after cultures were grown in pH 6 medium (108).

Although it is likely that a multitude of proteins and other virulence factors are required to for the pathogenesis of $Y$. pestis infection, the discovery of PsA identifies an acid inducible virulence factor that promotes the pathogenesis of the pneumonic plague (108). In the same manner, while there are likely many other acid-induced virulence factor candidates that are involved in E. coli $\mathrm{O} 157: \mathrm{H} 7$ pathogenesis, this study is the first to identify a putative fimbrial protein that is likely induced because by acute acid stress. 
Previous work has shown that the increased expression of yadK correlates with increased adhesion of EHEC 85-170 cells on tissue epithelial cells in vitro (95). This study shows that disruption of the yadK locus eliminates the increased adhesion observed among acid-stressed EHEC cells. The results of this study demonstrate that a putative adhesin may likely play an important role in the adhesion of acid stressed pathogenic enterohemorrhagic E. coli O157:H7.

This study also shows that acid has a considerable effect on the pathogenesis of $E$. coli O157:H7 bacteria. Acid has often been used as a means to control bacteria growth in the food industry. Similarly, acid is also one of the defense barriers that humans employ against pathogenic microorganisms during colonization. Over the past decade, studies have established that EHEC is able to survive and adapt in acute acid conditions. EHEC challenged in moderate acid media are able to tolerate very acidic conditions than non-acid adapted cells (71). Food scientists have also shown that acid-adapted EHEC cells are able to tolerate heat conditions, freeze-thaw practices $(84,86)$. Recent studies have shown that acid also increases virulence factors in EHEC cells (88). Whole genome profiling reveals that acid-induced EHEC show significantly upregulated levels of flagella, adhesins, and other virulent effectors $(69,88)$.

Base on the current knowledge of how acid affects EHEC pathogenicity and findings on $y a d K$, as a novel gene that appears to plays a role in acid-induced EHEC cells, acid appears to induce virulence factors in EHEC O157:H7. These results strongly suggest that acid stress, which is a part of the host's natural assault to resist invasion by foreign organisms, may actually regulate factors responsible for enhanced bacteria-host attachment, resulting in increased EHEC virulence. From these experiments, one can easily speculate that acid promotes virulence expression in EHEC O157:H7 and increases its pathogenicity and ability to cause disease (Figure 4.1) 
Furthermore, the modulation of $y a d K$ adhesin expression by environmental stress such as acid that results in specific host-cell adhesion appears to be a direct response to the bacteria's localized microenvironment. This strongly indicates that pathogens like EHEC 0157:H7 may be primed by host environmental conditions it encounters. Food sanitation practices involving the use of acid against pathogenic microorganisms may actually promote expression of virulence factors in these pathogens and contribute to their pathogenicity. The acid in the human stomach may actually serve to induce expression of these virulence genes.

Finally, the investigation of a putative fimbrial protein, YadK that appears to play a role in acid-induced adhesion of EHEC 0157:H7 cells significantly contribute to our growing understanding of pathogenic E. coli virulence. Knowing that acid may actually encourage increased virulence in EHEC, including the upregulation of novel fimbrial adhesins like YadK, may influence our current food sanitation practices. Antimicrobial strategies that can neutralize the effects of acid on EHEC or use novel adhesins like YadK as therapy targets may reduce the colonization of this deadly pathogen. In general, the knowledge garnered from this study provides us with new insights on EHEC 0157:H7 that can be used as both preventive and therapeutic measures in the future. 


\section{Exposure to Acute Acid Condition}

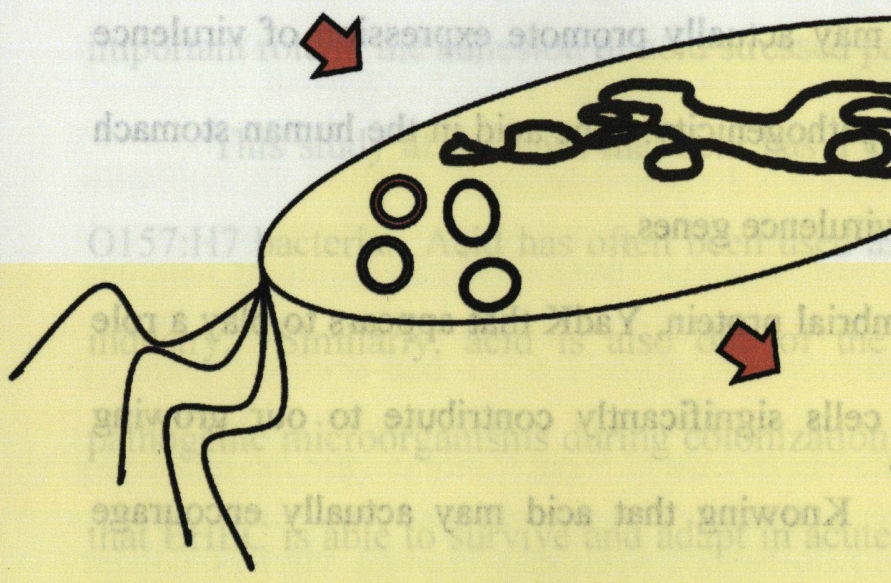

\section{Increase Expression of \\ Acid Responsive Genes \\ (i.e. yadK)}

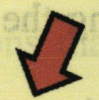

\section{Increased Bacteria-Host Cell Adhesion}

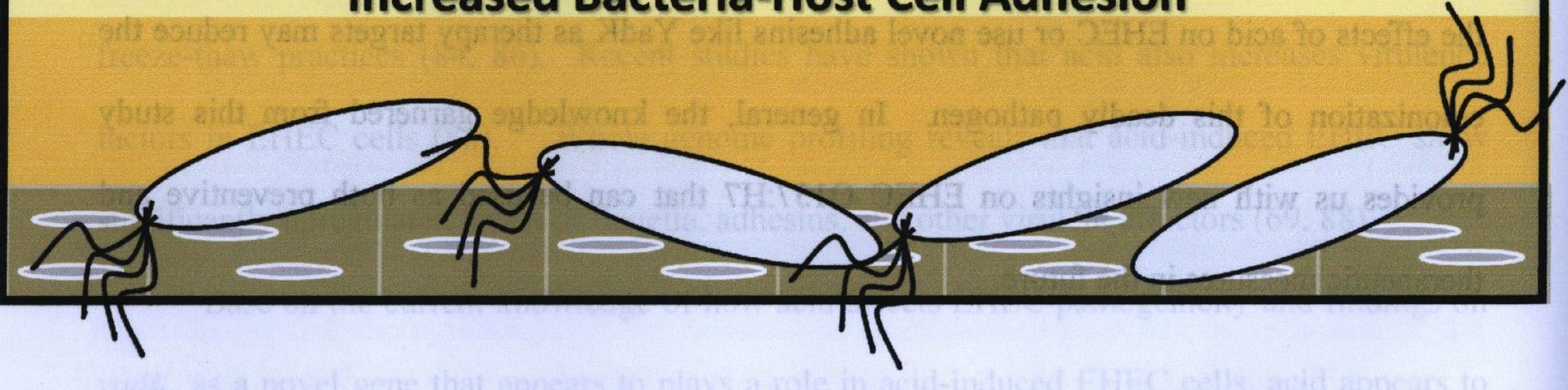

Figure 4.1 The effect of acid on the virulence of EHEC 0157:H7. Acid, which is once thought of as a substantial means of controlling pathogen growth, appears to increase the virulence of pathogenic E. coli O157:H7. Exposure of EHEC cells to acid appears to promote the induction and regulation of virulent genes including the increased expression of a putative fimbrial adhesin gene, yadK. As a result, acid stressed EHEC adheres to human epithelial cells much better than their no acid stressed counterparts. 


\section{Future Directions}

There is more work to be done in both understanding EHEC O157:H7 virulence and characterizing the adhesin gene, yadK. While this study provides meaningful insights on the yadK gene, including the possible environmental factors that regulate it, nothing is known about the adhesin protein. Further work must be done to examine YadK and determine how much of the protein product is translated, processed and assembled after acid stress, where it localizes in the cell and whether it binds directly on human epithelial cells.

While this study suggests that $y a d K$ is significantly upregulated in the presence of acid, the molecular factors that promote and disable its expression are still unknown. It would be noteworthy to investigate the molecular regulation of yadK in vivo and shed light to how the locus 2 operon functions. What other environmental conditions promote the expression of the genes in this operon? What prevents locus 2 expression?

The role of YadK as a putative virulence factor also needs to be further examined. Our data suggests that YadK does play a role in adhesion of acid-stressed bacteria; however, it is not enough to establish that it is a novel putative fimbrial protein that promotes virulence in EHEC.

Recent characterization of $y a d K$ suggests that it responds to quorum sensing signal, autoinducer $2(\mathrm{AI}-2)(109,110,111)$. Recent developments in quorum sensing among commonsal $E$. coli demonstrate that $y a d K$ is induced by AI-2 stimulation during in vitro studies. The process of quorum sensing allows bacteria to regulate important physiologically processes such as bioluminescence, antibiotic production, virulence, and plasmid conjugal transfer in a diverse community (109). Bacteria express low molecular molecular weight signalling pheromones, referred to as autoinducers, as means of cell-to-cell communication. Several classes of 
autoinducers have been identified including AI-1, AI-2, AI-3 and AI-peptides (110). Of these, $\mathrm{AI}-2$ expression has been observed specifically among commensal and pathogenic $E$. coli, and is believed to released when bacteria reaches stationary phase.

Two gene array studies have shown that the gene $y a d K$ is strongly induced by AI-2 concentration in media. DeLisa, et al., identify $y a d K$ as one of the genes that responded to differential AI-2 concentration (109). Both $y a d K$ and locus 2 major subunit yadN show a significant 3.8 and 3.5-fold increase among E. coli strains resuspended in media with high AI-2 concentration. Mutation of LsrK, a cytoplasmic kinase that inhibits the repressor of AI-2 receptor LuxS, reveals a significant 2.4-fold decrease of yadK expression. As a result, investigators suggest that the presence of $\mathrm{AI}-2$ in the environment strongly regulates the expression of this gene (111). Finally, Soni et al., reports that the presence of AI-2 in culture media influences the expression of $y a d K$ in EHEC O157:H7 strains (110).

Investigation on $y a d K$ reveals that it responds to quorum sensing signals and may be implicated in E. coli biofilm formation. Biofilm formation is a pathogenic mechanism that hinders the eradication of organisms. Work will be performed to test the ability of EHEC O157:H7 and its YadK deficient mutant to form biofilms under acid stress conditions. 


\section{References}

(1) Mead, P.S. and P. M. Griffin. 1998. Escherichia coli O157:H7. The Lancet. 352:1207-1212.

(2) LeBlanc, J.L. 2003. Implication of virulence factors in Escherichia coli O157:H7 Pathogenesis. Crit. Rev. Microbiol. 29(4): 277-296.

(3) Beachey, E. H. (1981). Bacterial adherence: adhesin-receptor interactions mediating the attachment of bacteria to mucosal surface. J. Infec. Dis. 143(3), 325-345.

(4) Bielaszewska, M., Kock, R., Friedrich, A. W., Von Eiff, C., Zimmerhackl, L. B., Karch, H. and A. Mellmann. 2007. Shiga-toxin mediated hemolytic uremic syndrome: time to change the diagnostic paradigm? PLoS One. 71(12) 7129-7139.

(5) Yoon, J. W. and C. J. Hovde. 2009. All blood, no stool: enterohemorrhagic Escherichia coli O157:H7 infection. J. Vet. Sci. 9(3): 219-231.

(6) Lavigne, J.P. and A.B. Blanc-Potard. 2008. Molecular evolution of Salmonella enterica serovar Typhimurium and pathogenic Escherichia coli: from pathogenesis to therapeutics. 2008. Infect. Genet. Evol. 8: 217-226.

(7) Welinder-Olsson, C. And B. Kaijser. 2005. Enterohemorrhagic Escherichia coli (EHEC). Scand. J. Infect. Dis. 37: 405-416.

(8) Mead, P. S., Slutsker, L., Dietz, V., Mc Caig, L. F. Bresee, J. S., Shapiro, C., Griffin, P. M. and R. V. Tauxe. 1999. Food-related illness and death in the United States. Emerg. Infect. Dis. 5: 607-625.

(9) Kaper, J. B. and A. O' Brien. 1998. Shiga-toxin producing E. coli: yesterday, today and tomorrow. Escherichia coli O157: H7 and other Shiga-Toxin producing Escherichia coli strains. ASM Press. Washington, DC.

(10) Callaway, T. R., Carr, M. A., Edrington, T. S., Anderson, R. C. And D. Nisbet. 2009. Diet, Escherichia coli O157:H7, and cattle: a review after 10 years. Curr. Issues. Mol. Biol. 11: $67-80$.

(11) Belongia, E. A., Osterholm, M. T., Soler, J. T., Ammend, D. A., Braun, J. E. and K. K. MacDonald. 1993. Transmission of Escherichia coli O157:H7 infection in Minnesota child day-care facilities. JAMA. 269: 883-888.

(12) Schmidt, H., Henekl, B. and H. Karch. 1997. A gene cluster closely related to type II secretion pathway operons of Gram-negative O157:H7 pathogenic Shiga-Toxin Producing 
Escherichia coli: phenotypic and genetic profiling of virulence traits and evidence for clonality. J. Infect. Dis. 179: 115-123.

(13) Torres, A., Zhou, X., and J. B. Kaper. 2005. Adherence of diarrheagenic Escherichia coli strains to epithelial cells. Infect. Immun. 73: 18-29.

(14) Frohlicher, E., Krause, G., Zweifel, C., Beutin, L. And R. Stephan. 2008. Characterization of attaching and effacing Escherichia coli (AEEC) isolated from pigs and sheep. BMC Microbiol. 8(144)

(15) Phillips, A., Navabpour, S., Hicks, S., Dougan, G., Wallis, T. and G. Frankel. 2000. Enterohemorrhagic Escherichia coli O157:H7 target Peyer's patches in humans and cause Attaching/Effacing lesions in both human and bovine intestine. Gut. 47: 377-381.

(16) Burland, V., Shao, Y., Perna, N. T., Plunkett, G., Sofia, H. J. and F. R. Blattner. 1998. The complete DNA sequence and analysis of the large virulent plasmid of Escherichia coli O157:H7. Nucleic Acids. Res. 26: 4196-4204.

(17) Perna, N. T., Mayhew, G. F., Posfai, G., Elliott, S., Donnenberg, M. S., Kaper, J. B. and F. R. Blattner. 1998. Molecular evolution of a pathogenicity island from Enterohemorrhagic Escherichia coli O157:H7. 66: 9810-9817.

(18) Dobrindt, U., Agerer, F., Michaelis, K., Janka, A., Buchrieser, C., Samuelson, M., Svanborg, C., Gottschalk, G., Karch, H. and J. Hacker. 2003. Analysis of genome plasticity in pathogenic and commensal Escherichia coli isolates by use of DNA arrays. J. Bacteriol. 185: 1831: 1840 .

(19) Iizumi, Y., Sagara, H., Kabe, Y. Azuma, M., Kume, K. Ogawa, M. Nagai, T., Gillespie, P. G., Sasakawa, C. and H. Handa. 2007. The enteropathogenic Escherichia coli effectors EspB facilitates microvillus effacing and antiphagocytosis by inhibiting myosin function. Cell Host Microbe. 2: 383-392.

(20) Konowalchuk, J., Speirs, J. L. and S. Stavrie. 1977. Vero response to cytotoxin of Escherichia coli. Infec. Immun. 18: 775-779.

(21) Besser, R. E. 1999. Escherichia coli O157:H7 Gastroenteritis and the hemolytic uremic syndrome: an emerging infectious disease. Annu. Rev. Med. 50:355-367.

(22) Fraser, M. E., Chernaia, M. M., Koxlov, Y. V. and M. N. G. Jones. 1994. Crystal structure of the holotoxin from Shigella disenteria at $2.5 \AA$ resolution. Nat. Struct. Biol. 1: 59-640. 
(23) Boerlin, P. 1999. Evolution of virulence factors in Shigella-Toxin producing Escherichia coli. Cell. Mol. Biol. Life. Sci. 56: 735-741.

(24) Calderwood, S. B., Auclair, F., Donohue-Rolfe, A., Keusch, G. T. and J. J. Mekalonos. 1987. Nucleotide sequence of Shiga-Like Toxin genes of Escherichia coli. Proc. Natl. Acad. Sci. USA. 84: 4364-4368.

(25) Nataro, J. P. and J. B. Kaper. 1998. Diarrheagenic Escherichia coli. Clin. Microbiol. Rev. 11: 142-201.

(26) Melton-Celsa, A. R. and A. D. O’Brien. 1998. Structure, biology and relative toxicity of Shiga-Toxin family members for cells and animals. Escherichia coli O157: H7 and other Shiga Toxin Producing Escherichia coli Strains. ASM Press. Washington, DC.

(27) Lingwood, C. A. 1996. Role of verotoxin receptors in pathogenesis. Trends Microbiol. 4: 147-153.

(28) Waddell, T. E., Lingwood, C. A. and C. L. Gyles. 1996. Interaction of verotoxin 2e with pig intestine. Infect. Immun. 64: 1714-1719.

(29) Chart, H. 2000. VTEC enteropathogenicity. J. Appl. Microbiol. Sym. Suppl. 88: 12S$23 \mathrm{~S}$.

(30) Ching, J. C., Jones, N. L. Ceponis, P. J., Karmali, M. A. and P. M. Sherman. 2002. Escherichia coli Shiga-Like Toxins induced apoptosis and cleavage of poly(ADP-Ribose) polymerase via in vivo activation. Infect. Immun. 70: 4669-4677.

(31) Donnenberg, M. S., Kaper, J. B. and B. B. Finlay. 1997. Interactions between enteropathogenic Escherichia coli and host epithelial cells. Trends Microbiol. 5: 109-114.

(32) Mellies, J. L, Barron, A. M. And A. M. Carmona. 2007. Enteropathogenic and enterohemorrhagic Escherichia coli virulence gene regulation. Infect. Immun. 75: 41994210 .

(33) Li, Z., Bell, C., Burret, A., Robias-Browne, R. M., Stiel, D., and E. O'Loughlin. 1993. The effects of Escherichia coli $\mathrm{O} 157: \mathrm{H} 7$ on intestinal structure and solute transport in rabbits. Gastroenterology. 104: 467-474.

(34) Sellwood, R. 1979. Escherichia coli diarrhea in pigs with or without the K88 receptor. Vet. Rec. 105: 228-230. 
(35) Krogfelt, K. A. 1991. Bacterial adhesion: Genetics, biogenesis, and role in pathogenesis of fimbrial adhesins of Escherichia coli. Rev. Infec. Dis. 13: 721-735.

(36) Gaastra, W and De Graaf, F. K. 1982. Host-specific fimbrial adhesins of noninvasive enterotoxigenic Escherichia coli strains. Microbiol. Rev. 46: 129-161.

(37) Klemm, P. 1982. Fimbrial adherence factors from pathogenic Escherichia coli strains. Tokai J. Exp. Clin. Med. 7: s185-s192.

(38) Hornick, D. B., Allen, B. L., Horn, M. A. and S. Clegg. 1991. Fimbrial types among respiratory iIsolates belonging to the family enterobacteriaceae. J. Clin. Microbiol. 29: 17951800.

(39) Beachey, E. H. 1981. Bacterial adherence: adhesin-receptor interactions mediating the attachment of bacteria to mucosal surface. J. Infec. Dis. 143: 325-345.

(40) Low, A., Holden, A., Rosser, T., and D. Gally. 2006. Analysis of fimbrial gene cluster and their expression in enterohemorrhagic Escherichia coli O157:H7. Environ Microbiol. 8: 1033-1047.

(41) Schilling, J.D. and M. A. Mulvey. 2001. Structure and function of Escherichia coli Type 1 pili: new insight into pathogenesis of urinary tract infections. J. Infec. Dis. 183: S36-40.

(42) Forero, M., Yakovenko, O., Sokurenko, E. V., Thomas, W. E. and V. Vogel. 2006. Uncoiling mechanics of Escherichia coli type I fimbriae are optimized for catch bonds. PLoS Biol. 4(9): e298

(43) Nichols, W. A., Clegg, S., and M. R. Brown. 1990. Characterization of type 1 fimbrial subunit gene (fimA) of Serratia marcescens. Mol. Microbiol. 4: 2119-2126.

(44) Bouckaert, J., Mackenzie, J., de Paz, J. L., Chipwaza, B., Choudhury, D. and Zavialov. 2006. The affinity of the FimH fimbrial adhesin is receptor-driven and quasi-independent of Escherichia coli pathotypes. Mol. Microbiol. 61: 1556-1568.

(45) Beloin, C., Houry, A., Froment, M., Ghigo, J. M. and N. Henry. 2008. A short-time scale colloidal system reveals early bacterial adhesion dynamics. PLoS Biol.. 6: 1549-1558.

(46) Gophna, U., Barlev, M., Seijfers, R., Oelschlager, T.A., Hacker, J. and Ron, E. Z., 2001. Curli fibers mediate internalization of Escherichia coli by eukaryotic Cells. Infec. Immun. 69: 2659-2665. 
(47) Brombacher, E., Baratto, A., Dorel, C. and P. Landini. 2006. Gene expression regulation by curli activator $\mathrm{CsgD}$ protein: modulation of cellulose biosynthesis and control of negative determinants for microbial adhesion. J. Bacteriol. 188, 2027-2037.

(48) Pesavento, C., Becker, G., Sommerfeldt, N., Possling, A., Tschowri, N., Mehlis, A. and R. Hengge. 2008. Inverse regulatory coordination of motility and curli-mediated adhesion in Escherichia coli. Genes Dev. 22, 2434-2446.

(49) Torres, A. G., Giron, J. A., Perna, N. T., Burland, V., Blattner, F. R., Avelino-Flores, F. and J. B. Kaper. 2002. Identification and Characterization of IpfABCC'DEE, a Fimbrial Operon of Enterohemorrhagic Escherichia coli O157:H7. Infec. Immun. 70: 5416-5427.

(50) Torres, A. G., Kanack, K. J., Tutt, C. B., Popov, V., and J. B. Kaper. 2004. Characterization of the second long polar (LP) fimbriae of Escherichia coli O157:H7 and distribtution of LP fimbriae in other pathogenic E. coli strains. FEMS Microbiol. Lett. 283: 333-344.

(51) Low, A. S., Dziva, F., Torres, A. G., Martinez, J. L., Rosser, T., Naylor, S., Spears, K., Holden, N., Mahajan, A., Findlay, J., Sales, J., Smith, D. G. E., Low, J. C., Stevens, M. P., and D. L. Gally. 2006. Cloning, expression and characterization of fimbrial operon F9 from enterohemorrhagic Escherichia coli O157:H7. Infec. Immun. 74: 2233-2244.

(52) Low, J. C., McKendrick, J. K., McKenchi, C., Fenlon, D., Naylor, S. W., Curri, C., Smith, D. G., Allison, L., and D. G. Gally. 2005. Rectal carriage of enterohemorrhagic Escherichia coli $\mathrm{O} 157$ in slaughtered cattle. Appl. Environ. Microbiol. 71: 93-97.

(53) Naylor, S. W., Low, J. C., Besser, T. E., Mahajan, E., Gunn, G. J., Pearce, M. C., McKendrick, L. J., Smith, D. G., and D. L. Gally. 2003. Lymphoid follicle-dense mucosa at the terminal rectum is the principal site of colonization of enterohemorrhagic Escherichia coli $\mathrm{O} 157: \mathrm{H} 7$ in the bovine host. Infect. Immun. 71: 1505-1512.

(54) Rendon, M. A., Aldana, Z., Erdem, A. L., Monterio-Neto, V., Vazquez, A., Kaper, J. B., Puenter, J., and J. A. Giron. 2007. Commensal and pathogenic Escherichia coli use a common pilus adherence factor for epithelial cell colonization. PNAS. 104: 10637-10642.

(55) Hayashi T., Makino K., Ohnishi M., Kurokawa K., Ishii K., Yokoyama K., Han C.G., Ohtsubo E., Nakayama K., Murata T., Tanaka M., Tobe T., Iida T., Takami H., Honda T., Sasakawa C., Ogasawara N., Yasunaga T., Kuhara S., Shiba T., Hattori M., and H., Shinagawa. 2001. Complete genome sequence of enterohemorrhagic Escherichia coli O157:H7 and genomic comparison with a laboratory strain K-12. DNA Res. 8: 11-22. 
(56) Pouttu, R., Westerlund-Wikstrom, B., Lang, H., Alsti, K., Virkola, R., Saarela, U., Sittonen, A., Kalkkinen, N., and T. K. Korhonen. 2001. matB, a common fimbrillin gene of Escherichia coli, expressed in a genetically conserved, virulent clonal group. J. Bacteriol. 183: 4727-4736.

(57) Frankel, G., Phillips, A. D., Trabulsi, L. R1., Knutton, S., Dougan, G. and S. Matthews. 2001. Intimin and the host-cell - is it bound to end in Tir(s)? Trends Microbiol. 9: 214-218.

(58) Niemann, H. H., Schubert, W. D. and D. W. Heinz. 2004. Adhesins and invasins of pathogenic bacteria: a structural view. Microbes. Infec. 6: 101-112.

(59) Ross, N. T. And B. L. Miller. 2007. Characterization of the binding surface of the transclocated intimin receptor, an essential protein for EPEC and EHEC cell adhesion. Protein Sci. 16: 2677-2683.

(60) Stevens, M. P., Van Diemen, P. M., Frankel, G., Phillips, A. D. and T. S. Wallis. 2002. Efa1 influences colonization of the bovine intestine by Shiga-toxin producing Escherichia coli serotypes O5 and O111. Infec. Immun. 70: 5158-51566.

(61) Van Dieman, P. M., Dziva, F., A.bu-Median, A., Wallis, T. S., Van Den Bosch, H., Dougan, G., Chanter, N., Frankel, G. and M. P. Stevens. 2007. Subunit vaccines base on intimin and Efa-1 polypeptides induce humoral immunity in cattle but do not protect against intestinal colonization by enterohemorrhagic Escherichia coli $\mathrm{O} 157: \mathrm{H} 7$ or $\mathrm{O} 26-\mathrm{H}^{-}$. Vet. Immunol. Immunopathol. 116: 47-58.

(62) Stevens, M. P., Roe, A. J., Vlisidou, I., Van Diemen, P. M., Ragione, R. M., Best, A., Woodward, M. J., Gally, D. L. and T. S. Walls. 2004. Mutation of toxB and a truncated version of the efa-1 gene in Escherichia coli O157:H7 influences the expression and secretion of the locus of enterocyte effacement-encoded proteins but not intestinal colonization in calves or sheep. Infec. Immun. 72: 5402-5411.

(63) Rashid, R. A., Tabata, T. A., Oatley, M. J., Besser, T. E., Tarr, P. I. and S. L. Moseley. 2006. Expression of putative virulence factors of Escherichia coli O157:H7 differs in bovine and human infections. Infec. Immun. 74: 4142-4148.

(64) Tarr, P. I., Bilge, S. S., Vary, J. C., Jelacic, S., Habeeb, R. L., Ward, T. R., Baylor, M. R. and T. Besser. 2000. Iha: a novel Escherichia coli O157:H7 adherence-conferring molecule encoded on a recently acquired chromosomal island conserved structure. Infec. Immun. 68 : 1400-1407.

(65) Einstein, B. I. 1981. Phase variation of type 1 fimbriae in Escherichia coli is under transcriptional control. Science. 214: 337-339. 
(66) Lindberg, S., Xia, Y., Sonden, B., Goransson, M., Hacker, J., \& Uhlin, B. E. 2008. Regulatory interactions among adhesin gene systems of uropathogenic Escherichia coli. Infec. Immun. 76: 771-780.

(67) Torres, A. G., Milflores-Flores, L., Garcia-Gallegos, J. G., Patel, S. D., Best, A., La Ragione, R. M., Martinez-Laguna, Y., and M. J. Woodward. 2007. Environmental regulation and colonization attributes of the long polar fimbriae (LPF) of Escherichia coli O157:H7. Int. J. Med. Microbiol. 297: 177-185.

(68) DeJesus, M., Agnieska A. Urban, M., Maragisan E., and D. Foster. 2005. Acid and bilesalt stress of enteropathogenic Escherichia coli enhances adhesion to epithelial cells and alters glycolipid receptor binding specificity. J. Infect. Dis. 192: 1430-1440.

(69) House B., Kus J.V., Prayitno N., Mair R., Que L., Chingcuanco F., Gannon V., Cvitkovitch D. and D. Barnett-Foster. 2009. Acid stress induced changes in enterohemorrhagic Escherichia coli O157:H7 virulence. Microbiology. Epub.

(70) Koutsoumanis, K. P. And J. N. Sofos. 2004. Comparative acid stress response of Listeria monocyotgenes, Escherichia coli $\mathrm{O} 157: \mathrm{H} 7$ and Salmonella Typhimirium after habituation at different $\mathrm{pH}$ conditions. Lett. Appl. Microbiol. 38: 321-326.

(71) Berry, E. D. and C. N. Cutter. 2000. Effects of acid adaptation of Escherichia coli O157:H7 on efficacy of acetic acid spray washes to decontaminate beef carcass tissue. Appl. Environ. Microbiol. 66: 1493-1498.

(72) Audia, J. P., Webb, C. C. And J. W. Foster. 2001. Breaking through the acid barrier: an orchestrated response to proton stress by enteric bacteria. Int. J. Med. Microbiol. 291: 97106.

(73) Bhagwat, A. A., Chan, L., Han, R., Tan, J., Kothary, M., Jean-Gilles, J. And B. D. Tall. 2005. Characterization of enterohemorrhagic Escherichia coli strains base on acid resistance phenotypes. Infec. Immun. 73: 4993-5003.

(74) Castanie-Cornet, M. P., Penfound, T. A., Smith, D., Elliott, J. F. and J. W. Foster. 1999. Control of acid resistance in Escherichia coli. J. Bacteriol. 181: 3525-3535.

(75) Sayed, A. K., Odom, C., and J. W. Foster. 2007. The Escherichia coli AraC-family regulators GadX and GadW activate gadE, the central activator of glutamate-dependent acid resistance. Microbiology. 153: 2584-2592.

(76) Foster, J. W. 2001. Acid stress responses of Salmonella and E. coli: survival mechanisms, tegulation and implications for pathogenesis. J. Microbiol. 39: 89-94. 
(77) Waterman, S. R., and P. L. C. Small. 1996. Identification of RpoS dependent genes assocaited with the stationary acid-Resistance phenotype of Shigella flexneri. Mol. Microbiol. 21: 925-940.

(78) Iyer, R., Williams, C. and C. Miller. 2003. Arginine-agmantine antiporter in extreme acid resistance in Escherichia coli. J. Bacteriol. 185: 6556-6661.

(79) Iyer, R., Iverson, T. M., Accardi, A. and C. Miller. 2002. A biological role for prokaryotic $\mathrm{ClC}$ chloride channels. Nature. 419: 715-718.

(80) Diez-Gonzales, F. and Y. Karaibrahimoglu. 2004. Comparison of the glutamate-, arginine-, and lysine- dependent acid resistance systems in Escherichia coli O157:H7. J. Appl. Microbiol. 96: 1237-1244.

(81) Leyer, G. J., Wang, L. L. and E. A. Johnson. 1995. Acid adaptation of Escherichia coli O157:H7 increases survival in acidic foods. Appl. Environ. Microbiol. 61: 3752-3755.

(82) Tosun, H., and S. A. Gonul. 2005. The effect of acid adaptation conditions on acid tolerence response of Escherichia coli O157:H7. Turk J. Biol. 29: 197-202.

(83) Lin, J., Smith, M. P., Chapin, K. C., Baik, H. S., Bennett, G. N. and J. W. Foster. 1996. Mechanisms of acid resistance in 'enterohemorrhagic Escherichia coli. Appl. Environ. Microbiol. 62: 3094-3100.

(84) Abdul-Raouf, U. M., Beuchat, R., and M. S. Ammar. 1993. Survival and growth of Escherichia coli $\mathrm{O} 157: \mathrm{H} 7$ in ground, roasted neef as affected by $\mathrm{pH}$, acidulants and temperature. Appl. Environ. Microbiol. 59: 2364-2368.

(85) Cheng, H., Yang, H. and C. Chou. 2002. Influence of acid adaptation on the tolerance of Escherichia coli O157:H7 to some subsequent stresses. J. Food Prot. 65: 260-265.

(86) Leenanon, B. and M. A. Drake. 2001. Acid stress, starvation, and cold stress effect poststress nehavior of Escherichia coli $\mathrm{O} 157: \mathrm{H} 7$ and nonpathogenic Escherichia coli. J. Food Prot. 64: 970-974.

(87) Allen, K. J., Lepp, D., McKellar, R. C. and M. W. Griffiths. 2008. Examination of stress and virulence gene expression in Escherichia coli O157:H7 using targeted microarray analysis. Foodborne Pathog. Dis. 5: 437-447.

(88) Alekshum, M. N. and S. B. Levy. 1999. The mar regulon: multiple resistance to antibiotics and other toxic chemicals. Trends Microbiol. 10: 410-413. 
(89) House, B., Mair, R., Cvitokovitch D. and D. Foster. 2006. Stress-induced changes in enterohaemorrhagic Escherichia coli O157:H7 Virulence. Sixth International Symposium on Shiga Toxin (Verocytotoxin) producing Escherichia coli infections (VTEC 2006). Melbourne AU.

(90) Chingcuanco, F., Levesque, C. M. and D. Foster. 2009. Role of a novel fimbrial adhesin in acid-Induced host adhesion of Escherichia coli O157:H7. 109 ${ }^{\text {th }}$ American Society for Microbiology (ASM 2009). Philadelphia, USA.

(91) Wu, G., Carter, B., Mafura, M., Liebana, E., Woodward, M. J. and M. F. Anjum. 2008. Genetic diversity among Escherichia coli O157:H7 isolates and identification of genes linked to human infections. Infec. Immun. 76: 845-856.

(92) Piatek, R., Zalewska, B., Bur, K. and J. Kur. 2004. The chaperone-usher pathway of bacerial adhesin biogenesis - from molecular mechanism to strategies of anti-bacteria prevention and modern vaccine design. Acta. Biochim. Pol. 52: 639-646.

(93) Capitani, G., Oliv, E., Glockshuber, R. and M. Grutter. 2006. Evidence for a novel domain of bacterial outer membrane ushers. Microbes and Infection. 8: 2284-2290.

(94) De Greve, H., Wyns, L. and J. Bouckaert. 2007. Combining sites of bacterial fimbriae. Curr. Opin. Struc. Biol. 17: 506-512.

(95) Sauer, F. G., Remaut, H., Hultgren, S. J. and G., Waksman. 2004. Fiber assembly by the chaperone-usher pathway. Biochim. Biophys. Acta. 1694: 259-267.

(96) Remaut, H., Rose, R. J., Hannan, T. J., Hultgren, S., Radford, S. E., Ashcroft, A. E. and G. Waksman. 2006. Donor-strand exchange in chaperone-assisted pilus assembly proceeds through a concerted beta strand displacement mechanism. Mol. Cell. 22: 831-842.

(97) Saulino, E. T., Bullit, E. and S. J. Hultgren. 2000. Snapshots of usher-mediated protein secretion and ordered pilus assembly. Proc. Natl. Acad. Sci. USA. 97: 9240-9245.

(98) Van Duijin, E., Bakkes, P. J., Heeren, R. M., Van den Heuvel, R. H., Van Heerikhuizen, H., Van der Vies, S. M. and A. J. Heck. 2005. Monitoring Macromolecular Complexes Involed in Chaperonin-Assited Protein Folding Cycle by Mass Spectrometry. Nat. Methods. 2: $371-376$.

(99) Kelley, L. A. and M. J. E. Sternberg. 2009. Protein structure prediction on the web: a case study using the pHYRE server. Nature Protocols. 4: 363-371.

(100) Murphy, K. C., and K. G. Campellone. 2003. Lambda Red-mediated recombineering engineering of enterohemorrhagic and enteropathogenic Escherichia coli. BMC Mol. Biol. 13: 4-11. 
(101) Datsenko, K. A., and B. Wanner. 2000. One-step inactivation of chromosomal genes in Escherichia coli K-12 using PCR products. Proc. Natl. Acad. Sci. USA 97: 6640-6645.

(102) Court, D. L., Sawitzke, J. A., and L. C. Thompson. 2002. Genetic engineering using homologous recombination. Annu. Rev. Genet. 36: 361-388.

(103) Sambrook, J., MacCallum, P. and D. Russell. Molecular cloning: a laboratory manual $3^{\text {rd }}$ Edition. Cold Spring Harbor Laboratory Press. New York.

(104) Thompson, J. D., Gibson, T. J. and D. G. Higgings. 2002. Multiple sequence alignment using ClustalW and ClustalX. Curr. Proto. Bioinformatics. 2: 2-3.

(105) Gallant, C. V., Daniels, C., Leung, J. M., Ghosh, A. S., Young, K. D., Kotra, L. P. and L. L. Burrows. 2005. Common beta-lactamase inhibit bacterial biofilm formation. Mol. Microbiol. 58: 1012-1024.

(106) Liu, F., Chen, H., Galvan, E. M., Lasaro, M. A., and D. M. Schifferli. 2006. Effects of Psa and F1 on the adhesive and invasive interactions of Yersinia pestis with human respiratory tract epithelial cells. Infec Immun. 74: 5636-5644.

(107) Straley, S. C. And R. D. Perry. 1995. Environmental modulation of gene expression and pathogenesis in Yersinia. Trends Microbiol. 3: 310-317.

(108) Price, S. B., Freeman, M. D., and K. S. Yeh. 1995. Transcriptional analysis of the Yersinia pestis $\mathrm{pH} 6$ antigen gene. J. Bacteriol. 177: 5997-6000.

(109) DeLisa, M. P., Wu, C. F., Wang, L., Valdes, J. J. and W. E. Bentley. 2001. DNA microarray-based identification of genes controlled by autoinducer 2-stimulated quorum sensing in Escherichia coli. J. Bacteriol. 183: 5239-5247.

(110) Soni, K. A., Lu, L., Jesudhasan, P. R., Hume, M. E. and S. D. Pillai. 2008. Influence of autoinducer-2 (AI-2) and beef sample extracts on E. coli O157:H7 survival and gene expression on virulence genes $y a d K$ and $h h A$. Food Microbiol. 73: M135-M1339.

(111) Li, J., Attila, C., Wang, L., Wood, T. K., Valdes, J. J. and W. E. Bentley. 2007. Quorum sensing in Escherichia coli is signaled by AI-2/LsrR: effects on small RNA and biofilm architecture. J. Bacteriol. 189: 6011-6020. 
